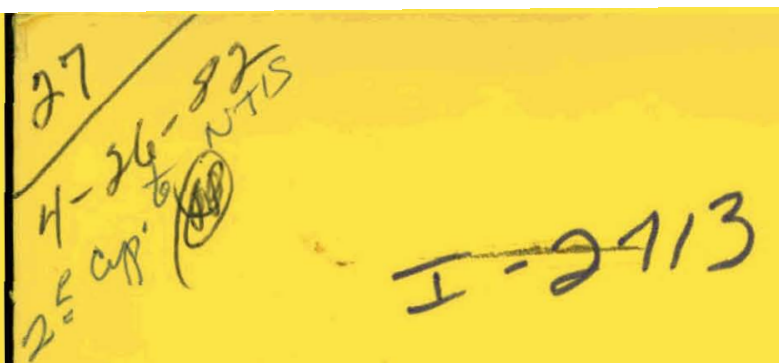

* ANL/CNSV-26

\title{
MASTER
}

\section{Development of Computer Simulations for Landfill Methane Recovery}

J. W. Massman, C. A. Moore, and R. M. Sykes

\section{DO NOT MICROFILM COVER}

\section{U. S. DEPARTMENT OF ENERGY}




\section{DISCLAIMER}

This report was prepared as an account of work sponsored by an agency of the United States Government. Neither the United States Government nor any agency Thereof, nor any of their employees, makes any warranty, express or implied, or assumes any legal liability or responsibility for the accuracy, completeness, or usefulness of any information, apparatus, product, or process disclosed, or represents that its use would not infringe privately owned rights. Reference herein to any specific commercial product, process, or service by trade name, trademark, manufacturer, or otherwise does not necessarily constitute or imply its endorsement, recommendation, or favoring by the United States Government or any agency thereof. The views and opinions of authors expressed herein do not necessarily state or reflect those of the United States Government or any agency thereof. 


\section{DISCLAIMER}

Portions of this document may be illegible in electronic image products. Images are produced from the best available original document. 
The facilities of Argonne National Laboratory are owned by the United States Government. Under the terms of a contract (W-31-109-Eng-38) among the U. S. Department of Energy, Argonne Universities Association and The University of Chicago, the University employs the staff and operates the Laboratory in accordance with policies and programs formulated, approved and reviewed by the Association.

\section{MEMBERS OF ARGONNE UNIVERSITIES ASSOCIATION}

The University of Arizona

Carnegie-Mellon University

Case Western Reserve University

The University of Chicago

University of Cincinnati

Illinois Institute of Technology

University of Illinois

Indiana University

The University of Iowa

Iowa State University
The University of Kansas

Kansas State University

Loyola University of Chicago

Marquette University

The University of Michigan

Michigan State University

University of Minnesota

University of Missouri

Northwestern University

University of Notre Dame
The Ohio State University

Ohio University

The Pennsylvania State University

Purdue University

Saint Louis University

Southern Illinois University

The University of Texas at Austin

Washington University

Wayne State University

The University of Wisconsin-Madison

NOTICE

This report was prepared as an account of work sponsored by an agency of the United States Government. Neither the United States Government nor any agency thereof, nor any of their employees, makes any warranty, express or implied, or assumes any legal liability or responsibility for the accuracy, completeness, or usefulness of any information, apparatus, product, or process disclosed, or represents that its use would not infringe privately owned rights. Reference herein to any specific commercial product, process, or service by trade name, trademark, manufacturer, or otherwise, does not necessarily constitute or imply its endorsement, recommendation, or favoring by the United States Government or any agency thereof. The views and opinions of authors expressed herein do not necessarily state or reflect those of the United States Government or any agency thereof.

Printed in the United States of America

Available from

National Technical Information Service

U. S. Department of Commerce

5285 Port Royal Road

Springfield, VA 22161

NTIS price codes

Printed copy: A06

Microfiche copy: A01 
Distribution Category:

Energy Conservation - Waste

Systems and Utilization (UC-95e)

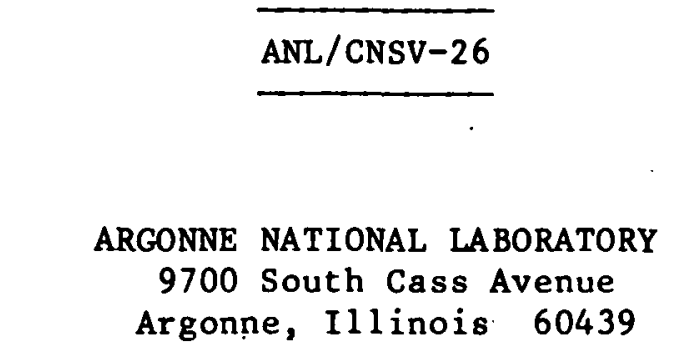

ANL/CNSV -26

DE82 013223
9700 South Cass Avenue Argonne, Illinois 60439

\title{
DEVELOPMENT OF COMPUTER SIMULATIONS \\ FOR LANDFILL METHANE RECOVERY
}

\author{
prepared by \\ Joel W. Massman, Charles A. Moore, \\ and Robert M. Sykes \\ Department of Civil Engineering \\ The Ohio State University \\ for \\ Argonne National Laboratory \\ Energy and Environmental Systems Division \\ Energy from Municipal Waste Program \\ under Argonne Contract 31-109-38-5261
}

December 1981

work sponsored by

U.S. DEPARTMENT OF ENERGY

Assiotant Secretary for Conservation and Renewable Energy

Office of Renewable Technology 
THIS PAGE

\section{WAS INTENTIONALLY LEFT BLANK}


ACKNOWLEDGMENTS . . . . . . . . . . . . . . . . . . . . . . v

ABSTRACT. . . . . . . . . . . . . . . . . . . . .... 1

1 INTRODUCTION . . . . . . . . . . . . . . . . . . . . . . 1

2 GAS FlOW IN a POROUS MEDIUM. . . . . . . . . . . . . . . . . . . 3

2.1 Mechanics of Flow in a Single Capillary Tube. . . . . . . . . . 3

2.2 Equations of Flow in a Single Capillary Tube. . . . . . . . . . 5

2.3 Mechanics of Flow in a Porous Medium. . . . . . . . . . . 10

2.4 Equations of Flow in a Porous Medium. . . . . . . . . . . . . 14

3 FINITE DIFFERENCE FORMULATION. . . . . . . . . . . . . . . . . 16

3.1 Equations of Flow in Matrix Form. . . . . . . ...... 16

3.2 Landfill Geometry and Boundary Conditions . . . . . . . . . . . 18

3.3 Finite Difference Algorithms. . . . . . . . . . . . . . . . . 22

4 FINITE DIFFERENCE COMPUTER CODES . . . . . . . . . . . . . . . . . 28

4.1 Code IV : . . . . . . . . . . . . . . . . . . . . . . 28

4.2 Code V. . . . . . . . . . . . . . . . . . . . . 31

5: COMPUTER SIMULATIONS . . . . . . . . . . . . . . . . . . . . 4 42

5.1 Computer Simulation of Methane Recovery for a Hypothetical

Landfil1........................... . . . 4 42

5.2 Computer Simulation. of Methane Recovery for the

Puente Hills Landfill....................... 48

6 METHANE GENERATION IN LANDFILLS. . . . . . . . . . . . . . . 58

6.1 Kinetic Controls for Landfill Methane Generation. . . . . . . . 58

6.2 Uninhibited Kinetics. . . . . . . . . . . . . . . . . . 59

6.3 Environmental Effects ...................... 60

6.4 Analytical Representation of Gas Generation Rate . . • . • • . 63

7 CONCLUSIONS AND RECOMMENDATIONS FOR FURTHER WORK . . . . . . . . . . . 64

7.1 Development of Interactive Graphics Capabilities. . . . . . . . . 64

7.2 Development of Hybrid Numerical Methods to Treat

Extraction Wells. . . . . . . . . . . . . . . 65

REFERENCES. . . . . . . . . . . . . . . . . . . . . . 66

APPENDIX A Code IV Listing . . . . . . . . . . . . . . . . . . 69

APPENDIX B Gode V listing. . . . . . . . . . . . . . . . . . . 87 
FIGURES

2.1 Diffusional Flow Mechanisms . . . . . . . . . . . . . . 4

2.2 Flow under Partial Pressure and Total Pressure Gradients. . . . . . 6

2.3 Flow of Gas. Particles through a Porous Medium . . . . . . . . . . 11

2.4 Model Used to Represent the Porous Medium . . . . . . . . . . 13.

3.1 Landfill Geometry and Boundary Condition Types. . . . . . . . . . . 20

4.1 Code IV, Subrout ine SolV. . . . . . . . . . . . . . . . . 32

4.2 Code IV, Subroutine CFIĹl. . . . . . . . . . . . . . . 34

4.3 Code IV, Subrout ine PREDIC/PRBDIC . . . . . . . . . . . . . . 34

4.4 Code IV, Subrout ine CORECT/CORBET . . . . . . . . . . . . . . 35

4.5 Code IV, Subrout ine PUMP. . . . . . . . . . . . . . 35

4.6 Code IV, Subroutine INVERT. . . . . . . . . . . . . 36

4.7 Code IV, Subroutine TRIDAG. . . . . . . . . . . . . . 36

5.1 Code IV Landfill Simulation, Well 1 . . . . . . . . . . . . 43

5.2 Code IV Landfill Simulation, Well 2 . . . . . . . . . . . . . 44

5.3 Code IV Landfill Simulation, Well 3 . . . . . . . . . . . . 45

5.4. Code IV Landfill Simulation, Well 4 . . . . . . . . . . . 46

5.5 Plan View of Puente Hills Landfill. . . . . . . . . . . . . 49

5.6 Extraction Wells in Puente Hills Landfill . . . . . . . . . 50

5.7 Cross Sections through Landfill . . . . . . . . . . . . . 51

5.8 Percentage Methane Contours through Cross Sections. . . . . . . : 53

$5.9^{\circ}$ Vacuum Contours at Well 2................... 54

5.10 Relative Percentages of Methane and Oxygen at Well 2, Cross

7.1 Sample Output from Computer Graphics Terminal . . . . . . . . . . 64

TABLES

4.1 Instructions for Data Preparation, Code IV . . . . . . . . . : 37

4.2 Instructions for Data Preparation, Code V. . . . . . . . . . . 39

5.1 Wells Examined in Code IV Landfill Simulation. . . . . . . . . . 42

5.2 Code IV Data Deck. . . . . . . . . . . . . . . . . . . . 47

5.3 Code V Data Deck . . . . . . . . . . . . . . . . . . . 52

6.1 Parameter Values for Methanogen Growth on Hydrogen and
Carbon Dioxide and on Acetic Acid. . . . . . . . . . . . . 61 


\section{ACKNOWLEDGMENTS}

The authors gratefully acknowledge the contributions of Nina Zolten, who developed the programs for the Tektronix 4014 interactive graphics terminal. They also thank Ruth Foltz and Phyllis Chen, whose editorial contributions greatly improved the manuscript, and Susan DeHart and Barbara Salbego, for typing the manuscript. Finally, they wish to express their appreciation to Michael Wilkey and Jean Bogner, both of Argonne National Laboratory, who served as technical monitors for the project.

Questions or comments concerning this report should be directed to Michael Wilkey, Energy and Environmental Systems Division, Argonne National Laboratory, 9700 South Cass Avenue, Argonne, Illinois 60439 . 


\title{
DEVELOPMENT OF COMPUTER SIMULATIONS FOR LANDFILL METHANE RECOVERY
}

by

Joel W. Massmann, Charles A. Moore, and Robert M. Sykes

\begin{abstract}
Two- and three-dimensional finite-difference computer programs simulating methane recovery systems in landfills have been developed. These computer programs model multicomponent combined pressure and diffusional flow in porous media. Each program and the processes it models are described in this report. Examples of the capabilities of each program are also presented. The two-dimensional program was used to simulate methane recovery systems in a cylindrically shaped landfill. The effects of various pump locations, geometries, and extraction rates were determined. The three-dimensional program was used to model the Puente Hills landfill, a field test site in southern California. The biochemical and microbiological details of methane generation in landfills are also given. Effects of environmental factors, such as moisture, oxygen, temperature, and nutrients on methane generation are discussed and an analytical representation of the gas generation rate is developed.
\end{abstract}

\section{INTRODUCTION}

Methane gas generated within landfills constitutes a hazard when it migrates through the adjacent soil. Design criteria have been presented (Moore, 1979) for control facilities to alleviate this problem. However, facilities constructed solely to control methane migration represent a significant expenditure of funds that provides no financial return. Only recently, with the growing need for new energy sources, has a potential for profit been discerned in controlling landfill methane migration in conjunction with a methane recovery program. As this opportunity has become more widely recognized, interest has grown, in the energy recovery aspects of landfill operation.

The recovery of landfill methane for energy use adds complexity to the analytical approaches that must be developed to optimize methane production. Landfills have historically been constructed in an uncontrolled manner, resulting in a high degree of uncertainty with respect to the types and distribution of materials, geometry of the fill boundaries, and control of moisture routing through the fill. In contrast, in many manufacturing processes, a high degree of control is maintained over operations. The heterogeneities inherent in landfills must be explicitly incorporated, into the analytical techniques for optimizing methane production. 
Another important contrast between landfills and conventional manufacturing processes is that landfills are one-batch systems. In' a conventional manufacturing process, it is relatively easy to make major process modifications from run to run. However, for any given landfill, there is only one opportunity to perform methane extraction; thus, the process must be carried out in the opt imum manner initially. Moreover, because of variations among sites, lessons learned at one site may have limited applicability to another.

It is thus important that a strong analytical basis be provided for designing operating procedures to recover methane from landfills. The techniques designed will then insure that methane recovery will be maximized. Moreover, the analytical basis can be used to predict conditions that signal irregularities in recovery operations so that remedial measures can be taken before irreparable damage has been done to the landfill. 


\section{GAS FLOW IN A POROUS MĖDIUM}

\subsection{MECHANICS OF FLOW IN A SINGLE CAPILLARY TUBE}

Because of the small total pressure gradients and large partial pressure gradients generally found in landfills, the flow processes involved in gas migration from these fills are complex. Both diffusional and pressure flow contribute equally to the transport process and must therefore both be investigated (Alzaydi, Moore, and Rai, 1978). Further complicating the flow process, the pores found in soils are of such a size that, in flows at atmospheric pressure, the gas molecules collide with soil as well as with each other.

\subsubsection{Diffusional Flow}

Concentration gradients are the driving forces behind diffusional flow. Gases flow isobarically from points of higher to lower concentration. Several physical mechanisms may interact to impede this flow. Figure 2.1 illustrates the various flow mechanisms of the diffusion process as it occurs in a single capillary tube of radius $r$ under a constant total pressure.

Figure 2.1a shows the process known as Knudsen diffusion. The gas molecules collide only with the walls of the capillary tube and behave independently of each other. The retardation effect depends upon the molecular weight and temperature of the gas and the radius of the capillary tube and is not influenced by the presence of other species of gas.

The molecular diffusion process is illustrated in Fig. 2.1b. The gas molecules collide only with other gas molecules; however, these collisions may occur between either like or unlike molecules. The retardation effect depends on the molecular weights and temperature of the gases in the capillary tube and is unaffected by the physical nature of the pore walls.

The more general process of transition region diffusion is illustrated in Fig. 2.1c. Molecules collide with each other and with the capillary wall. The flow depends on the radius of the pore, the molecular weights and temperature of the gases, and the physical nature of the pore walls.

In summary, the various types of diffusional flow can be categorized according to the type of collisions that the gas molecules experience. Knudsen diffusion is characterized by molecule-to-wall collisions, while molecular diffusion involves collisions berween like or unlike molecules. Transition region diffusion is a combination of Knudsen and molecular diffu$s$ ion and therefore involves both types of collisions.

\section{1 .2 Pressure Flow}

If a total pressure gradient exists in a capillary tube, gases will flow from points of higher pressure to points of lower pressure. Viscous flow (Poiseuille flow) and slip flow along the capillary walls are the "two" mechanisms involved in the pressure flow process. 


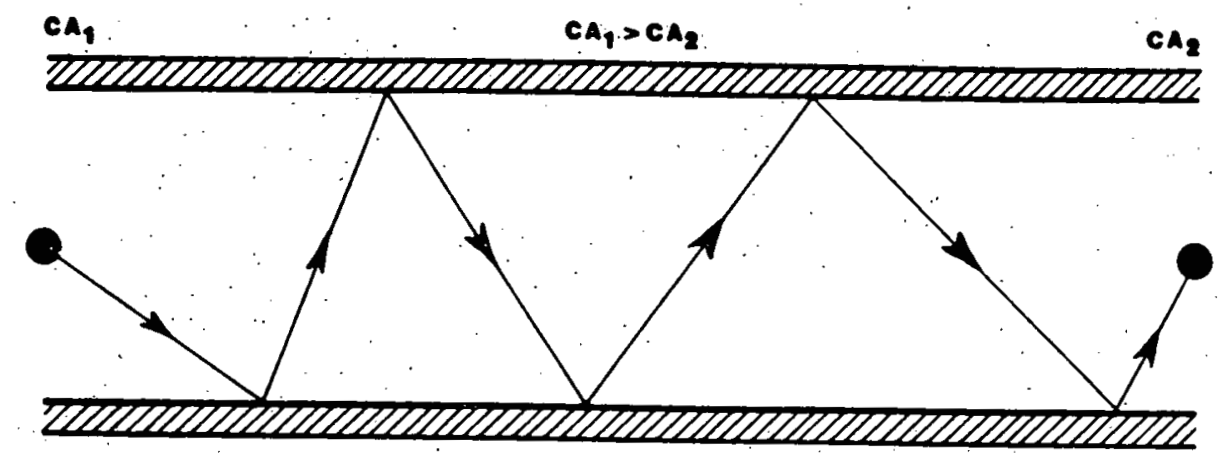

(a) Knudsen Diffusion

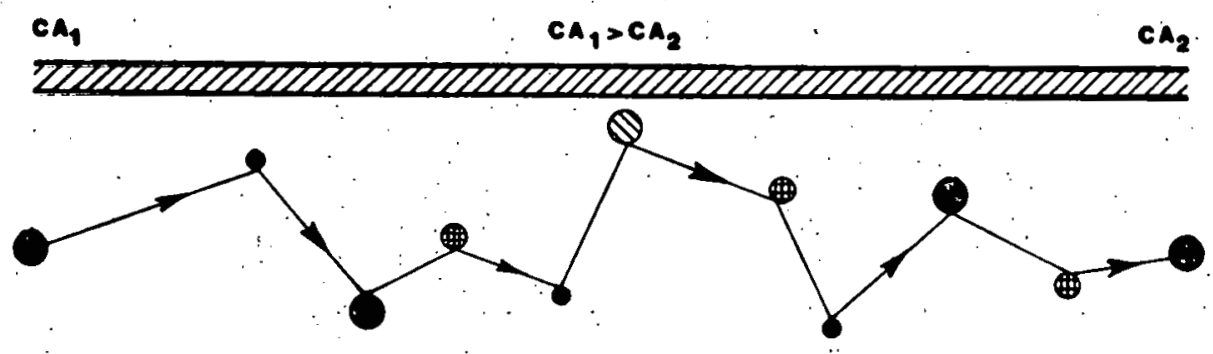

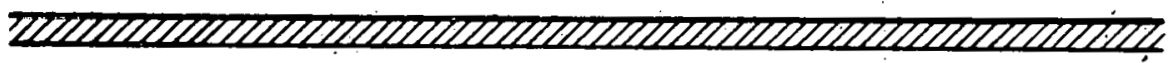

(b) Molecular Diffusion

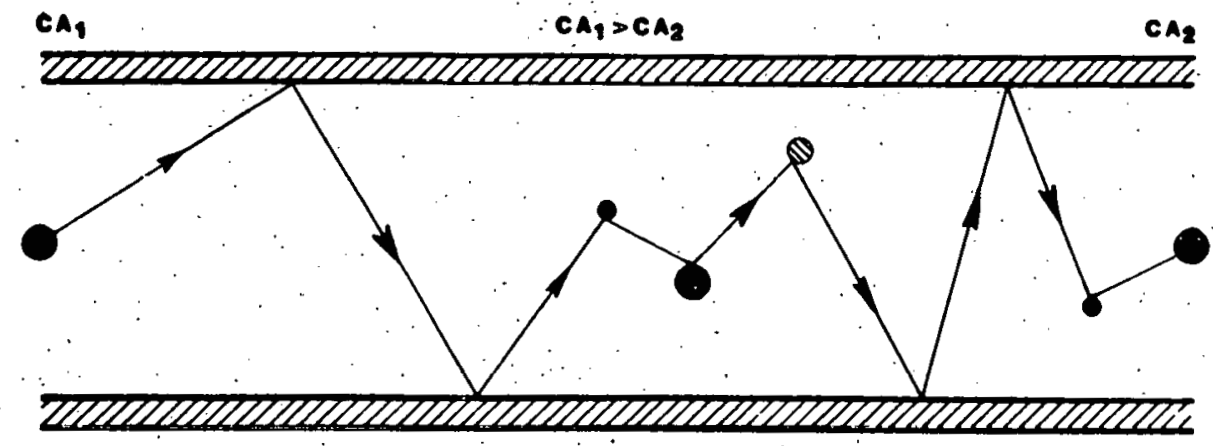

(c) Transition Region Diffusion

Fig. 2.1 Diffusional Flow Mechanisms

Poiseuille flow is analogous to the flow of compressible fluids in tubes: The driving force behind Poiseuille flow is the total pressure gradient, while the resistance is caused by the viscosity, of the gas and the drag created by the small pores of the mediun.

If the radius of the capillary tube is very small, the gas molecules will frequently collide with the walls of the tube and will behave as though in the Knudsen region. The slip flow mechanism, whereby the molecules slide along the capillary walls, is of increased importance under these conditions. 


\subsubsection{Combined F1ow}

If both partial pressure and total pressure gradients are present in a capillary tube, the transport process will involve a combination of diffusional and pressure flows. Figure 2.2 illustrates possible flow mechanisms when such conditions exist.

In Fig. 2.2a, the partial pressures of gases $A$ and $B$, as well as the total pressure of the gas mixture, decrease from left to right. The direction of flow for both components under these conditions is also from left to right.

Figure 2.2b illustrates the more general case of partial pressure and total pressure gradients existing in opposite directions. Both the total pressure and the partial pressure of gas A decrease from left to right. However, the partial pressure of gas B decreases from right to left. Gas A will clearly migrate to the right under both partial and total pressure gradients. The flow direction of gas $B$ is not so easily determined. The diffusional process will transport gas B from right to left while pressure flow tends to move the gas from left to right. The net direction of flow for gas $B$ cannot be determined a priori but is dependent upon the predominating flow mechanism.

\subsection{EQUATIONS OF FLOW IN A SINGLE CAPILLARY TUBE}

The mechanics of flow of a gas in a single capillary tube were described in Sec. 2.1. Included were diffusional flow, pressure flow, and combined flow. This section introduces the mathematical expressions that govern each of these flow processes.

\subsubsection{Concept of Mean Free Path of a Molecule}

To determine which type of flow predominates under a given set of conditions; a quantitative measure is needed for the average distance a molecule travels before it collides with another molecule. This average distance is ralled the mean free path of the molecule, and is given by Bird, Stewart, and Lightfoot $(1960)$ and Geankoplis (1972) as:

$$
\lambda=\frac{3.2 \mu}{\mathrm{P}} \sqrt{\frac{\mathrm{RT}}{2 \pi \mathrm{gM}}}
$$

where:

$$
\begin{aligned}
& \lambda=\text { mean free path }(\mathrm{cm}) \\
& \mu=\text { viscosity }(\text { poise }) \\
& P=\text { pressure }\left(\mathrm{g} / \mathrm{cm}^{2}\right), \\
& T=\text { temperature }(\mathrm{K}), \\
& \mathrm{g}=\text { gravitational constant }(980 \mathrm{~cm} / \mathrm{s}), \\
& M=\text { molecular weight }(\mathrm{g} / \mathrm{gmn} / \mathrm{e}), \text { and } \\
& \mathrm{R}=\text { gas constant }(84,780 \mathrm{~g}-\mathrm{cm} / \mathrm{K}-\mathrm{gmole}) .
\end{aligned}
$$




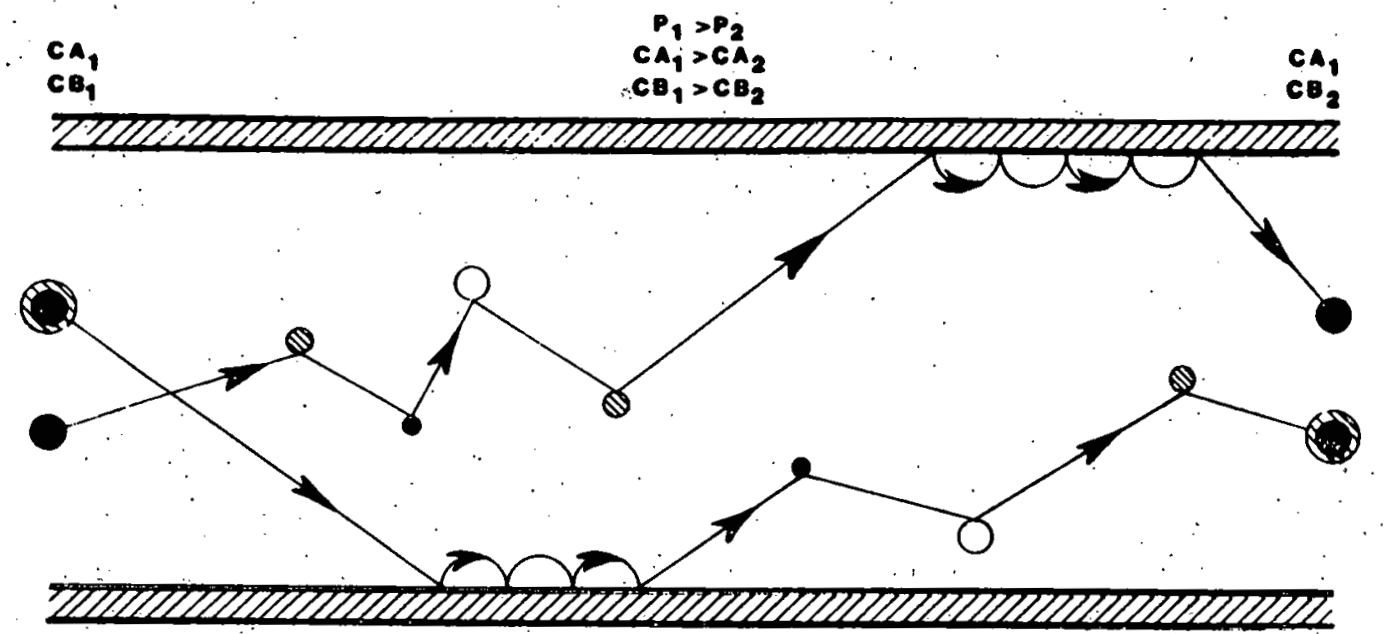

(a)

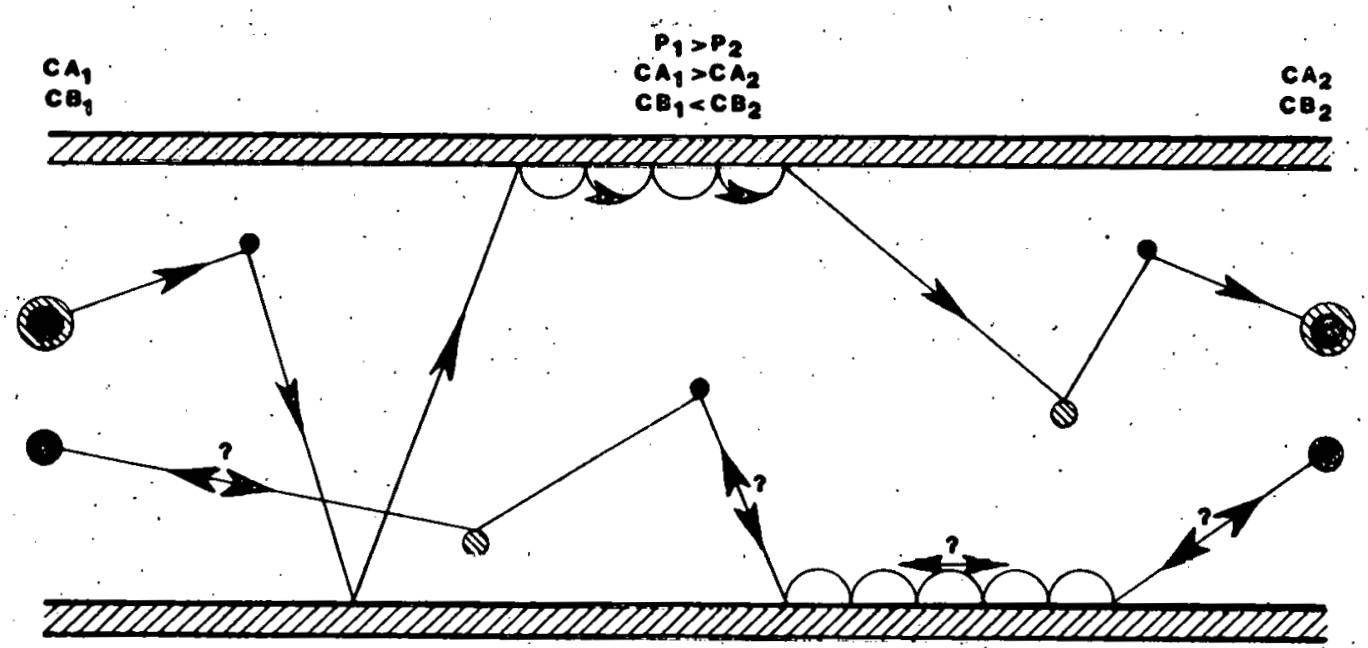

(b)

Fig. 2.2 Flow under Partial Pressure and Total Pressure Gradients

\subsubsection{Equations of Diffusional Flow}

Under a given set of. conditions, the type of diffusional flow that will predominate (Knudsen, molecular; or transition region flow) depends on the relationship between the mean free path of a molecule $(\lambda)$ and the diameter of the capillary tube. If $\lambda$ is on the order of 10 times the capillary diameter; molecule-to-wall collisions will predominate. Molecule-to-molecule collisions will prevail if the ratio of $\lambda / 2 \mathbf{r}$ is on the order of 0.01 . Both types of collisions will be present if the $\lambda / 2 \mathrm{r}$ ratio is between 0.01 and 10 .

(1975)

The governing equation describing Knudsen diffusion is given by Alzaydi as : 


$$
\mathrm{N}_{i}^{\mathrm{K}}=9.7 \cdot 10^{-5}\left(\overline{\mathrm{r}} \sqrt{\frac{\mathrm{T}}{\mathrm{M}_{\mathrm{i}}}}\right)\left(\frac{\partial \mathrm{C}_{\mathrm{i}}}{\partial \mathrm{Z}}\right)
$$

where:

$$
\begin{aligned}
\mathrm{N}_{\mathrm{i}}^{\mathrm{K}} & =\text { Knudsen flow rate for component } \mathrm{i}\left(\mathrm{gmole} / \mathrm{cm}^{2}-\mathrm{s}\right), \\
\overline{\mathbf{r}} & =\text { average pore radius }(\mathrm{A}), \\
\mathrm{T} & =\text { temperature }(\mathrm{K}), \\
\mathrm{M}_{\mathrm{i}} & =\text { molecular weight of component } \mathrm{i}(\mathrm{g} / \mathrm{gmole}), \\
\mathrm{C}_{\mathrm{i}} & =\text { concentration of component } \mathrm{i}\left(\mathrm{gmole} / \mathrm{cm}^{3}\right), \text { and } \\
\mathrm{Z} & =\text { distance }(\mathrm{cm}) .
\end{aligned}
$$

This equation assumes $\lambda \gg 2 r$, cosine wall reflection (i.e., the molecules leave the wall in a direction independent of their incident direction but with an equal probability for all directions), slowly varying pressure gradients along the capillary tube, and no radial pressure gradient (Knudsen, 1909).

If the mean free path of a molecule is very small relative to the diameter of the capillary tube $(\lambda / 2 \mathrm{r}<<0.01)$, the primary impedance to flow will be produced by molecule-to-molecule collisions. The equation describing this molecular diffusion is given by Alzaydi (1975) as:

$$
\frac{-\partial c_{i}}{\partial z}=\sum_{\substack{j=1 \\ i \neq j}}^{n} \frac{N_{i}^{M} x_{j}-x_{i} N_{j}^{M}}{D_{i j}}
$$

where:

$$
\begin{aligned}
& \begin{aligned}
N_{i}^{M}= & \text { total molecular diffusion of } i \text { relative to fixed } \\
& \text { coordinates (gmole/ } \left./ \mathrm{cm}^{2}-\mathrm{s}\right),
\end{aligned} \\
& c_{i}=\text { concentration of component } i\left(g m o l e / \mathrm{cm}^{3}\right) \text {, } \\
& z=\text { distance }(\mathrm{cm}) \text {, } \\
& x_{i}=\text { mole fraction of component } i\left(c_{i} / \Sigma c_{i}\right) \text {, and } \\
& D_{i j}=\text { molecular diffusion coefficient of component } i \\
& \text { diffusing in component } \mathrm{j}(\mathrm{cm} / \mathrm{s}) \text { (Geankoplis, 1972). }
\end{aligned}
$$

As can be seen from Eq. 3, molecular diffusion depends on the physical properties of each of the gas species present in the capillary tube and is independent of the physical or geometrical properties of the pore.

Alzaydi (1975). used a momentum balance proposed by Rothfield (1963) and Scott and Dullien (1962) to derive an equation describing transition region diffusion for those cases when $\lambda / 2 \mathrm{r}$ is between 0.01 and 10: Alzaydi showed that the total concentration.gradient causing flow in the transition region is the sum of the concentration gradient causing Knudsen flow plus the concentration gradient causing molecular flow: 


$$
\frac{-\partial C_{i}}{\partial z}=\frac{N_{i}^{D}}{D K_{i}}+\sum_{\substack{j=1 \\ i \neq j}}^{n} \frac{N_{i}^{D} x_{j}-x_{i} N_{j}^{D}}{D_{i j}}
$$

where:

$$
\begin{aligned}
N_{i}^{D} & =\text { total diffusional flow rate }\left(\text { gmole } / \mathrm{cm}^{2}-s\right) \text {, and } \\
D_{i} & =\left(9.7 \cdot 10^{-5}\right) \bar{r} \sqrt{\frac{T}{M_{i}}}
\end{aligned}
$$

\subsubsection{Equations of Pressure Flow}

Two mechanisms contribute to the forced flow transport process when total pressure gradients exist in a capillary tube. Poiseuille flow and $s$ ip flow along the capillary wall combine to give the total pressure flow.

Alzaydi (1975) gives the Poiseuille flow equation as:

$$
F_{p}=\frac{-\bar{r}^{2} P}{8 \mu_{\operatorname{mix}}{ }^{R T}}\left(\frac{\partial P}{\partial Z}\right)
$$

where:

$$
\begin{aligned}
F_{\mathrm{P}} & =\text { Poiseuille flow rate }\left(\mathrm{gmole} / \mathrm{cm}^{2}-\mathrm{s}\right), \\
r & =\text { average radius of pores, } \\
\mathbf{P} & =\text { total pressure }\left(\text { dyne } / \mathrm{cm}^{2}\right), \\
\mu_{\mathrm{mix}} & =\text { viscosity of mixture }(\mathrm{poise}), \\
\mathbf{R} & =\text { gas constant }(\text { dyne } \mathrm{cm} / \text { gmole-K), and } \\
\mathrm{T} & =\text { temperature }(\mathrm{K}) .
\end{aligned}
$$

The viscosity of the mixture is given by a semiempirical formula developed by: Wilke (1950):

$$
\mu_{\operatorname{mix}}=\sum_{i=1}^{n} \frac{x_{i} \mu_{i}}{\sum_{j=1}^{n} x_{j} \phi_{i j}}
$$

where:

$$
\begin{aligned}
\phi_{i j} & =\frac{1}{\sqrt{8}}\left(1+\frac{M_{i}}{M_{j}}\right)^{-\frac{1}{2}}\left[1+\left(\frac{\mu_{i}}{\mu_{j}}\right)^{\frac{1}{2}} \cdot\left(\frac{M_{j}}{M_{i}}\right)^{\frac{3}{4}}\right]^{2} \\
\mu_{i} & =\text { viscosity of component } i \text { (poise), and } \\
x_{i} & =\text { mole fraction of component } i .
\end{aligned}
$$


Equation 5 represents an extension of the equations that describe the flow of fluids in tubes. It assumes that the gas behaves as a compressible continuum in relatively. large capillaries. It also assumes that the total pressure gradients are small so that the flow is laminar. This assumption is valid if the Reynolds number is less than 2100 (Geankoplis, 1972).

Should the pressure or capillary diameter be reduced so that the mean free path becomes an appreciable fraction of the capillary diameter, Eq. 5 will underestimate the experimental flow rate. The excess flow is due to slippage along the capillary walls. An additional term to include this slip flow was given by Scott and Dullien (1962) as:

$$
F_{s}=\frac{-4 \bar{r}}{3 \sum_{i=1}^{n} M_{i} \bar{V}_{i} \dot{X}_{i}}\left(\frac{\partial P}{\partial Z}\right)
$$

where:

$$
\begin{aligned}
F_{s} & =\text { slip flow rate }\left(\mathrm{gmole} / \mathrm{cm}^{2}-\mathrm{s}\right), \\
r & =\text { average pore radius }(\mathrm{cm}), \\
M_{i} & =\text { molecular weight of gas } i(g / g m o l e), \\
V_{i} & =\text { mean thermal velocity of component } i(\mathrm{~cm} / \mathrm{s}), \\
X_{i} & =\text { mole fraction of component } i, \text { and } \\
P & =\text { total pressure }\left(\text { dyne } / \mathrm{cm}^{2}\right) .
\end{aligned}
$$

The mean thermal velocity, as defined by the kinetic theory of gases, is given by Scott and Dullien (1962) as:

$$
\bar{V}_{i}=\left(\frac{8 R T}{\pi M_{i}}\right)^{\frac{1}{2}}
$$

The total forced flow rate $\left(F_{T}\right)$ due to a total pressure gradient is simply the sum of the flow rate due to Poiseuille flow plus the flow rate due to slip flow:

$$
F_{T}=-\left(\frac{\bar{r}^{2} P}{8 \mu_{\operatorname{mix}}}+\frac{4 \bar{r} R T}{3 \sum_{i=1}^{n} M_{i} \bar{V}_{i} x_{i}}\right)\left(\frac{1}{R T}\right)\left(\frac{\partial P}{\partial z}\right)
$$

\subsubsection{Equations of Combined Flow.}

In a generalized flow, the transport process is a combination of diffusional and pressure flows. Evans, Watson, and Mason (1962) have shown that the equation for combined flow can be expressed as a summation of the flow rate due to pressure flow plus the flow rate due to diffusional flow, provided that. the pressure dependency of the $D_{i j}$ term in Eq. 3 is accounted for: 


$$
\begin{aligned}
D_{i j} & =\frac{\text { constant }}{P} \\
& =\frac{\bar{D}_{i j}}{P}
\end{aligned}
$$

Substitution of Eq. 10 into Eq. 4 and solving for $\mathrm{N}_{\mathrm{i}}^{\mathrm{D}}$ gives:

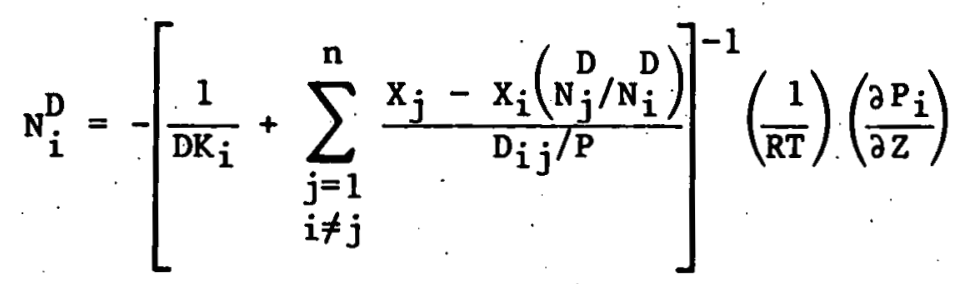

For component $i$, the combined flow is:

$$
\begin{aligned}
\mathbf{N}_{\mathbf{T}}^{\mathrm{T}} & =\mathbf{N}_{\mathrm{i}}^{\mathrm{D}}+\mathrm{X}_{\mathbf{i}} \mathrm{F}_{\mathrm{T}} \\
& =\mathbf{N}_{\mathrm{i}}^{\mathrm{D}}+\mathbf{N}_{\mathrm{i}}^{\mathrm{P}}
\end{aligned}
$$

Substituting Eqs. 9 and 11 into.Eq. 12 gives:

$$
\begin{aligned}
N_{i}^{T}= & -\left[\frac{1}{D_{i}}+\sum_{\substack{j=1 \\
i \neq j}}^{n} \frac{x_{j}-x_{i}\left(N_{j}^{D} / N_{i}^{D}\right)}{D_{i j} / P}\right]^{-1}\left(\frac{1}{R T}\right)\left(\frac{\partial P_{i}}{\partial Z}\right) \\
& -x_{i}\left(\frac{\bar{r}^{2} P}{8 \mu_{m i x}}+\frac{4 \bar{r} R T}{3 \sum_{i=1}^{n} M_{i} \bar{V}_{i} x_{i}}\right)\left(\frac{1}{R T}\right)\left(\frac{\partial P}{\partial Z}\right)
\end{aligned}
$$

Equation 13. represents all of the mechanisms involved in gas transport in a single capillary, including Knudsen diffusion, molecular diffusion, transition region diffusion, viscous flow, and slip flow.

\subsection{MECHANICS OF FLOW IN A POROUS MEDIUM}

The concepts introduced in Sec. 2.1 to describe the flow of gas in a single capillary are extended in this section to describe flow in a porous medium. A physical model representative of the porous medium is assumed. The gas transport process discussed in Secs. 2.1 and 2.2 is then applied to this model.

\subsubsection{Flow in a Porous Medium}

The flow of gas through a porous medium such as soil differs in several respects from flow in a single capillary. Figure 2.3 illustrates a general example of gas flow in a porous medium. 


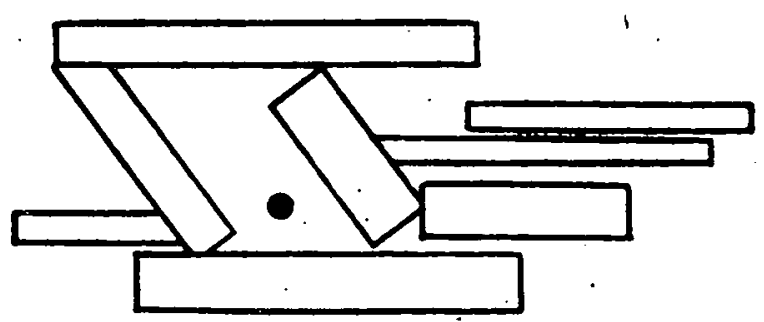

orction c-c

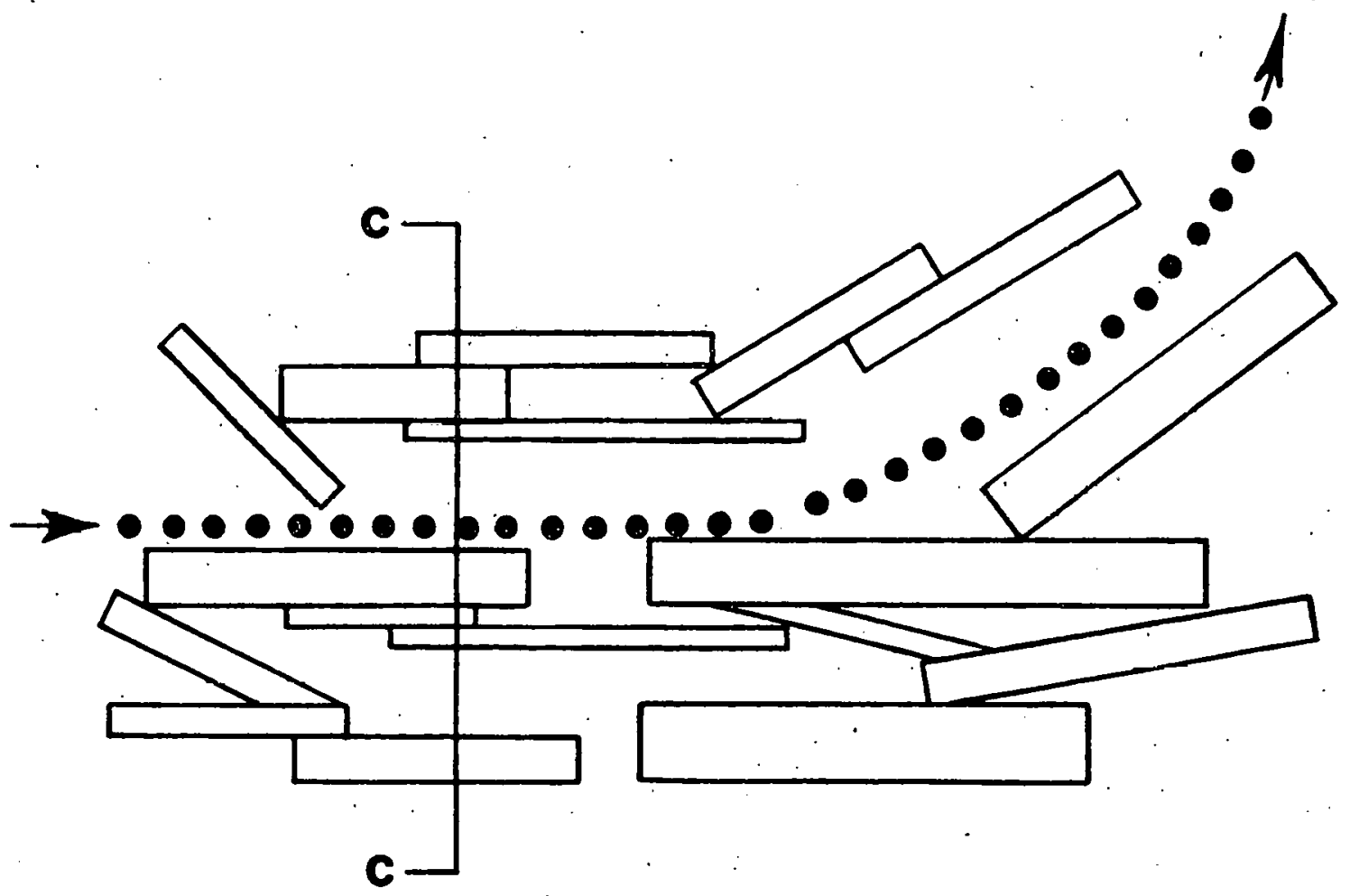

Fig. 2.3 Flow of Gas Particles through a Porous Medium

As the gas molecule approaches point a, its flow domain is reduced because the size of the pore space decreases, thereby effectively reducing the cross sectional area available for flow. The porosity of the soil ( $\varepsilon$ ) is used as a quantitative measure for the area available for flow per unit area of soil and is defined as the volume of voids divided by the total volume:

$$
\varepsilon=\frac{v_{v}}{v_{T}}
$$

where:

$$
\begin{aligned}
\varepsilon & =\text { porosity, } \\
\dot{V}_{V} & =\text { volume of voids in the soil, and } \\
v_{T} & =\text { total volume of ooil. }
\end{aligned}
$$


At point b, the direction of flow for the gas molecule is changed because of the arrangement of soil particles. A tortuosity factor is introduced to account for the circuitous path that the gas molecule must travel. Tortuosity is a function of the average size of the soil particles. The tortuosity factor $(\tau)^{\prime}$ is defined as the effective length the gas molecule must travel, divided by the length of the soil sample:

$$
\tau=\frac{\mathrm{L}_{\mathrm{e}}}{\mathrm{L}}
$$

where:

$$
\begin{aligned}
\tau= & \text { tortuosity, } \\
\mathrm{L}_{\mathrm{e}}= & \text { effective path length of a gas element flowing through } \\
& \text { a pore space, and } \\
\mathrm{L}= & \text { length of a porous sample in the direction of flow. }
\end{aligned}
$$

Between points $a$ and $b$, the transport process involves any or all of the flow mechanisms shown in Fig. 2.2. However, because of the scales of length involved, slip flow is of negligible importance in gas migration in soils. The pore sizes of soils and the distances the gas travels from 1 andfills are very large compared to the small spatial scales necessary before slip flow will contribute significantly to the transport process:

\subsubsection{Modeling the Porous Medium}

Before applying the mechanics and equations for flow in a single capillary to that in a porous medium, it is necessary to introduce a physical model that will idealize the interactions between the transport processes and the porous medium. Several models have been proposed, the majority of which are variations of the series and/or parallel pore model (Alzaydi, 1975).

The model used in this study (shown in Fig: 2.4) assumes that:

- The porous medium consists of a bundle of capillary tubes of various radii,

- The radius of each capillary is constant along its length, and

- The mechanics and equations of flow in a single capillary can be. applied to each of these capillaries.

The total flow consists of a summation over the entire pore size distribution. The flow per unit area of soil is then determined by multiplying the total flow by the porosity and dividing it by the tortuosity. The porosity of a porous medium consisting of capillaries of various radii is given by:

$$
\varepsilon=\sum_{r=r_{\min }}^{r_{\max }} f v(r)
$$




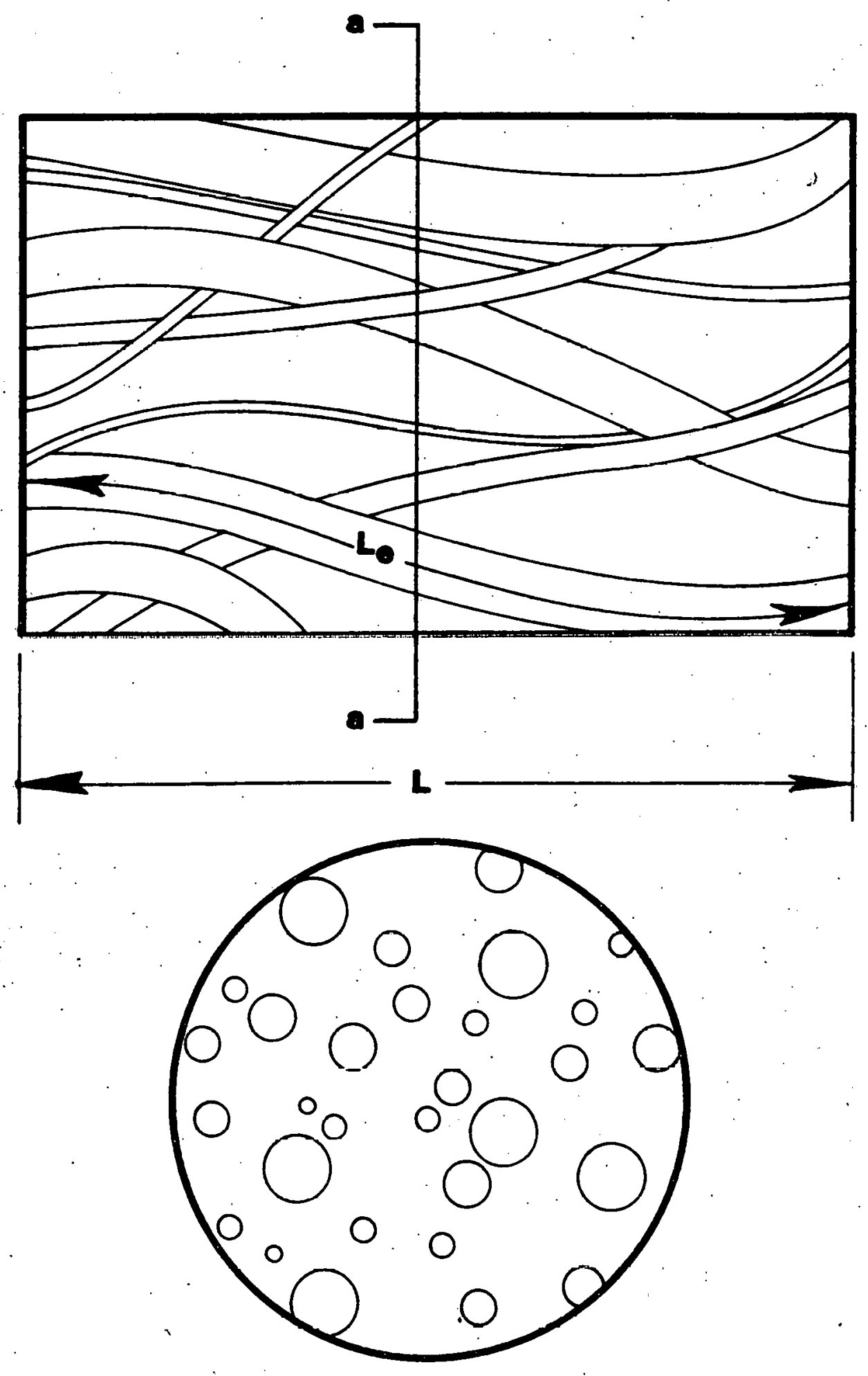

ecction a-a

Fig. 2.4 Model Used to Represent the Porous Medlum 
where:

$$
\begin{aligned}
\varepsilon & =\text { porosity, and } \\
f v(r) & =\text { void fraction of radius } r
\end{aligned}
$$

\subsection{EQUATIONS OF FLOW IN A. POROUS MEDIUM}

In Secs. 2.2.2 and 2.2.3, the general equations for diffusional and pressure flow in a single capillary were introduced. By combining these. equations with the porous medium model discussed in Sec. 2.3 , the equations for diffusional and forced flow in a porous medium can be developed. This can be accomplished by summing the flows in each of the pores over the entire pore size distribution.

Equation 11 gives the diffusional flux for component $i$ in a single capillary as:

$$
N_{i}^{D}=-\left[\frac{1}{D_{i}}+\sum_{\substack{j=1 \\ i \neq j}}^{n} \frac{x_{j}-x_{i}\left(N_{j}^{D} / N_{i}^{D}\right)}{\bar{D}_{i j} / P}\right]^{-1}\left(\frac{\partial C_{i}}{\partial z}\right)
$$

where:

$$
\begin{aligned}
\mathrm{DK}_{\mathrm{i}} & =9.7 \cdot 10^{-5}\left(\mathrm{r} \sqrt{\frac{\mathrm{T}}{\mathrm{M}_{\mathrm{i}}}}\right) \\
& =\mathrm{K}_{\mathrm{i}} \mathrm{r}
\end{aligned}
$$

The flow in a porous medium is given by summing the flows in each of the pores, multiplying this summation by the porosity, and dividing it by the tortuosity. Combining Eqs. 16, 17, and 18 and introducing the tortuosity factor gives:

$$
N_{i}^{D}=\frac{1}{\tau}\left[\sum_{r_{\min }}^{r_{\max }} \frac{-f v(r)}{\frac{1}{k_{i} r}+\sum_{\substack{j=1 \\ i \neq j}}^{n} \frac{x_{j}-x_{i}\left(N_{j}^{D} / N_{i}^{D}\right)}{\bar{D}_{i j} / P}}\right] \frac{\partial c_{i}}{\partial z}
$$

Equation 18 represents the diffusional flow of a multicomponent gas in a porous medium.

As discussed in Sec. 2.3.1, the equation for forced flow in a single capillary can be simplified by neglecting the slip flow term when applied to a porous medium. Combining Eqs. 5 and 16 and again introducing tortuosity gives: 


$$
F_{p}=\frac{1}{\tau} \sum_{r_{\min }}^{r_{\max }}\left[\frac{-r^{2} \operatorname{pfv}(r)}{8 \mu_{\operatorname{mix}} R T}\left(\frac{\partial P}{\partial z}\right)\right]
$$

The equation for both diffusional and forced flow is obtained by combining Eqs. 12, 18, and 19 as follows:

$$
\left.\begin{array}{rl}
N_{i}^{T}=\frac{1}{\tau} \sum_{r_{\min }}^{r_{\max }}\left[\frac{-f v(r)}{\frac{1}{k_{i} r}+\sum_{\substack{j=1 \\
i \neq j}}^{n} \frac{x_{j}-x_{i}\left(N_{j} / N_{i}^{D}\right)}{\bar{D}_{i j} / P}}\left(\frac{1}{R T}\right)\left(\frac{\partial P_{i}}{\partial Z}\right)\right. \\
-\frac{r^{2} P}{8 \mu_{\operatorname{mix}}}\left(\frac{x_{i}}{R T}\right)\left(\frac{\partial P}{\partial Z}\right)
\end{array}\right]
$$

Equation 20 represents all the relevant mechanisms involved in gas transport in a porous medium, including Knudsen, molecular, and transition region diffusion as well as viscous flow. 


\section{FINITE DIFFERENCE FORMULATION}

The equations introduced in Chapter 2 to describe pressure and diffusional flow of a multicomponent gas through a porous medium are classified as parabolic partial differential equations. These equations can be solved analytically if the diffusion coefficient and the boundary conditions remain constant. However, if the diffusion coefficient is a function of gas concentration or if the boundary conditions change with time, analytical solutions are virtually impossible. Such is the case for the equations presented in Chapter 2.

Numerical methods involving finite differences are often used to solve noniinear partial differential equations similar to those describing gas flow in a porous medium. In this chapter are formulated the finite difference algorithms necessary to solve the equations in Chapter 2.

\section{EQUATIONS OF FLOW IN MATRIX FORM}

The general equations describing multicomponent gas flow in a porous medium are given by Eqs, 18, 19, and 20. These expressions can be rewritten in a more tractable form for solution by a finite difference method.

Equation 18 can be rewritten as:

$$
N_{i}^{D}=\sum_{r_{\text {min }}}^{r_{\text {max }}} \frac{f v(r)}{\tau}\left[\frac{\left(\sum_{j=1}^{n} \frac{x_{i} N_{j} P}{\bar{D}_{i j}}\right)-\frac{\partial C_{i}}{\partial z}}{\frac{1}{k_{i} r}+\sum_{j=1}^{n} \frac{x_{j} P}{\bar{D}_{i j}}}\right], i \neq j
$$

By definition,

$$
x_{i}=\frac{p_{i}}{P}
$$

and

$$
\frac{\partial C_{i}}{\partial Z}=\left(\frac{1}{R T}\right)\left(\frac{\partial P_{i}}{\partial Z}\right)
$$


Substituting Eqs. 22 and 23 into Eq. 21 gives:

$$
N_{i}^{D}=\sum_{r_{\min }}^{r_{\max }} \frac{f v(r)}{\tau}\left[\frac{\left(\sum_{j=1}^{n} \frac{N_{j} P_{i}}{\bar{D}_{i j}}\right)-\left(\frac{1}{R T}\right)\left(\frac{\partial P_{i}}{\partial z}\right)}{\frac{1}{K_{i} r}+\sum_{\substack{j=1 \\ i \neq j}}^{n} \frac{P_{j}}{\bar{D}_{i j}}}\right]
$$

Equation 24 in matrix form is written as:

$$
[\mathrm{A}]\left\{\tilde{\mathrm{N}}^{D}\right\}=-\frac{1}{\mathrm{RT}}\{\nabla \tilde{\mathrm{P}}\}
$$

where:

$$
\begin{aligned}
& \tilde{\mathrm{N}}^{\mathrm{D}}=\mathrm{N}_{1}^{\mathrm{D}}, \mathrm{N}_{2}^{\mathrm{D}}, \ldots, \mathrm{N}_{\mathrm{n}}^{\mathrm{D}}, \text { and } \\
& \tilde{\mathrm{P}}=\mathrm{P}_{1}, \mathrm{P}_{2}, \ldots, \mathrm{P}_{\mathrm{n}},
\end{aligned}
$$

The elements of matrix [A] are:

$$
a_{i i}=\sum_{r_{\min }}^{r_{\max }}\left(\frac{f v(r)}{\tau} \frac{1}{K_{i} r}\right)+\sum_{\substack{j=1 \\ 1 \neq j}}^{n} \frac{P_{j}}{\bar{D}_{i j}}
$$

and

$$
a_{i . j}=-P_{i} / \bar{D}_{i j}
$$

Solving Eq. 25 for the diffusive flux vector gives:

$$
\left\{\tilde{N}^{D}\right\}=\frac{1}{R T}\left[A^{-1}\right]\{\nabla \tilde{P}\}
$$

In a similar manner, the term representing pressure flow in Eq. 20 can also be written in matrix form. The pressure flow term is given as:

$$
\mathrm{N}_{\mathrm{i}}^{\mathrm{P}}=\frac{-\mathrm{C}_{\mathrm{o}}}{\mathrm{H}_{\mathrm{mix}}} \cdot \frac{\mathrm{PX}_{\mathrm{i}}}{\mathrm{RT}} \frac{\partial \mathrm{P}}{\partial \mathrm{Z}}
$$


where:

$$
c_{0}=\sum_{r_{\min }}^{r_{\max }} \frac{r^{2} f v(r)}{8}
$$

Combining Eq. 28 with. Eq. 22 gives, in matrix form:

$$
\{\tilde{\mathrm{N}} \mathrm{P}\}=\frac{-\mathrm{C}_{\mathrm{o}}}{\mathrm{RT} \mu_{\operatorname{mix}}} \nabla \mathbf{P}\{\tilde{\mathrm{P}}\}
$$

Total flow rate can now be expressed in matrix form by combining diffusive and pressure fluxes as follows:

$$
\{\tilde{\mathrm{N}} \mathrm{T}\}=\frac{-1}{\mathrm{RT}}\left[\mathrm{A}^{-1}\right]\{\nabla \tilde{\mathrm{P}}\}-\frac{\mathrm{C}_{\mathrm{o}} \nabla \mathrm{P}}{\mathrm{RT} \mu_{\operatorname{mix}}}\{\tilde{\mathrm{P}}\}
$$

Substituting $\left[A^{-1}\right]=[D]$ gives:

$$
\left\{\tilde{\mathrm{N}}^{\mathrm{T}}\right\}=\frac{-1}{\mathrm{RT}}\left(D\{\nabla \tilde{\mathrm{P}}\}-\frac{\mathrm{C}_{\mathrm{o}} \nabla \mathrm{P}}{\mathrm{RT} \mu_{\operatorname{mix}}}\{\tilde{\mathrm{P}}\}\right)
$$

The continuity equation for component $i \cdot$ is:

$$
\frac{1}{R T} \frac{\partial P_{i}}{\partial t}=-\nabla_{i}
$$

Combining Eq. 32 with the spatial derivative of Eq. 31 gives:

$$
\frac{\partial P_{i}}{\partial t}=\nabla \cdot \sum_{j=1}^{n} D_{i j} \nabla P_{i}+\nabla \cdot\left(\frac{C_{j} P_{i} \nabla P}{\mu_{\operatorname{mix}}}\right)+s_{i}
$$

where $s_{i}$ is the change in pressure of component $i$ per unit volume due to a sink/source term.

Equation 33 gives the general system of equations for flow in a porous medium. The elements of $D_{i j}$ are determined by inverting matrix [A]. Both $D_{i j}$ and $C_{o} P_{i} / \mu_{m i x}$ are functions of $P$.

\subsection{LANDFILL GEOMETRY AND BOUNDARY CONDITIONS}

Before a finite difference solution for the equations of flow in a porous medium can be developed, a geometrical representation of the landfill must be assumed. This representation must be flexible enough to approximate the wide variety of actual landfili geometries, yet simple enough to permit solution by a numerical method. The geometry and boundary. conditions for modeling the landfill are developed in this section. 


\subsubsection{Geometric Simulation of Landfills}

This study treats the geometry of the landfill as a cylindrical volume that is circular in plan with a radius $r_{f}$ and a depth $d_{f}$, as shown in Fig. 3.1. The soil surrounding the fill extends radially to a distance $r_{s}$ and vertically to a depth $d_{s}$. Gas wells extending to a depth $d_{v}$ may be placed at any radial distance $r_{v}$. These wells are assumed to be equally spaced around the circle of radius $r_{v}$. The spacing of these wells can attain any value, and any number of well circles can be used; however, the spacing in all circles must be constant.

\subsubsection{Land fil1 Boundary Conditions}

The landfill boundary conditions can be divided into three general types: boundaries with prescribed concentrations, boundaries with prescribed convective flows, and boundaries with sinks or sources such as wells or vents.

At boundaries with prescribed concentrations, the mole fraction of the gas component under consideration at a given time and coordinate is known. (For example, the concentration of methane at a radial boundary far from the fill may be assumed to be zero.)

Boundaries with prescribed convective flows generally either are impervious (e.g., at the interface between the water table and the dry soil below a fill) or have convective flows that are linearly related to. the difference in gas concentrations across the boundary (e.g., at the ground surface). The coefficients that relate the amount of convective flow to the concentration gradient are unique for each gas component considered. Mackay and Matsugu (1973) developed the following semiempirical formula to determine these convection coefficients:

$$
\mathrm{CK}_{\mathrm{i}}=0.0292 \mathrm{~V}^{0.78} \mathrm{~L}^{-0.11_{\mathrm{Sc}_{\mathrm{i}}}-0.67}
$$

where:

$$
\begin{aligned}
\mathrm{CK}_{\mathrm{i}} & =\text { convection coefficient for component } \mathrm{i}, \\
\mathrm{V} & =\text { wind velocity at } 10 \mathrm{~m} \text { above ground surface }(\mathrm{m} / \mathrm{hr}), \\
\mathrm{L} & =\mathrm{fill} \text { size }(\mathrm{m}), \text { and } \\
S \mathrm{C}_{\mathrm{i}} & =\text { Schmidt number for component } \mathrm{i} .
\end{aligned}
$$

Sink/source boundaries are used to accommodate either the generation or loss of material at a given point (e.g., a well location). These sink or source terms give the change in concentration of a given gas component per unit volume of soil. They can be functions of time, space, or gas concentration.

Figure 3.1 illustrates the various boundary conditions imposed on the landfill gcometry. The base of the snil is assumed impervious, while the edge of the soil at a radial distance $r_{s}$ can have either prescribed concentrations 

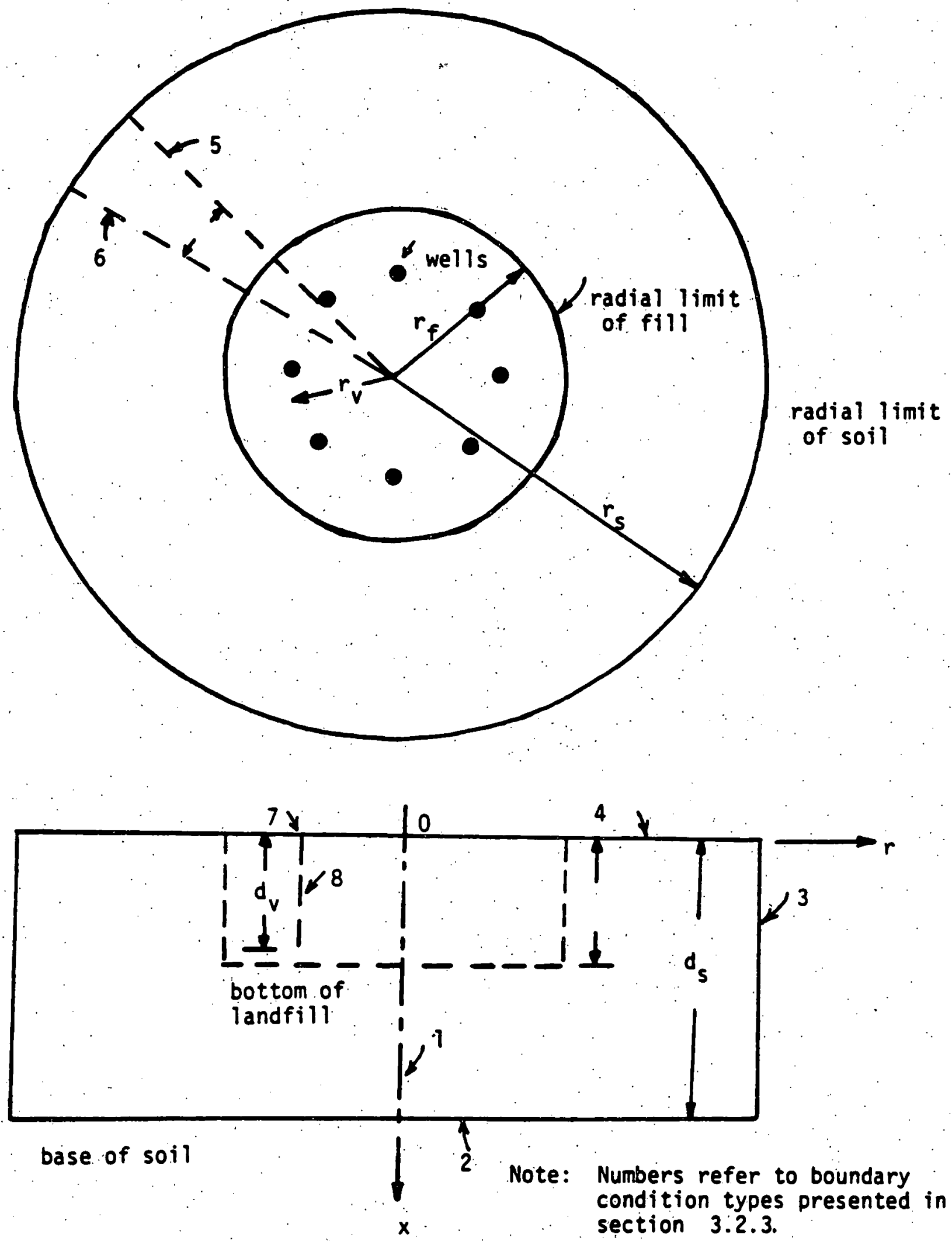

Fig. 3.1 Landfill Geometry and Boundary Condition Types 
or prescribed convective flows. The soil surface is assumed to be a prescribed convective flow boundary, and the axis of the fill is impervious by symmetry. The well locations are sink/source boundaries.

\subsubsection{Mathematical Representation of Boundary Conditions}

In this section, the boundary conditions described above are represented mathematically. The condition numbers refer to the boundaries shown in Fig. 3.1.

Condition 1: Axisymmetry

$\partial \mathrm{X}_{\mathrm{i}} / \partial \mathrm{r}=0$ for $\mathrm{r}=0$ and $0 \leq \mathrm{z} \leq \mathrm{d}_{\mathrm{s}}$

In this case the Laplacian operator with respect to $r$ becomes:

$\nabla^{2}=2\left(\partial^{2} / \partial r^{2}\right)$

Condition 2: Impervious Base of Soil

$$
\partial X_{i} / \partial z=0 \quad \text { for } z=d_{s}
$$

Condition 3: Prescribed Concentration at Radial Soil Boundary

$$
x_{i}=\text { constant. for } r=r_{s} \text { and } z \leq d_{s}
$$

Condition 4: Convective Flow at Ground Surface

$$
2 \mathrm{CK}_{i}\left(\partial \mathrm{X}_{i} / \partial z\right)=s_{i} . \text { for } z=0
$$

Condition 5: No Circumferential Flow at Radial Line through Vent/Pump

$$
\partial \mathrm{X}_{\mathrm{i}} / \partial \theta=0 \text { for } \theta=0 \text { and } \mathbf{r} \neq \mathrm{r}_{\mathrm{v}}
$$

Condition 6: No Circumferential Flow at Radial Line Midway between

Vent/Pump Pairs

$$
\partial \mathrm{x}_{\mathrm{i}} / \partial \theta=0 \text { for } 0=\theta_{\mathrm{v}} / 2
$$

Condition 7: Imperviousness at Surface of Pump Location

$$
\partial x_{i} / \partial z=0 \text {, for } r=r_{p} \text { and } z=0
$$

Condition 8: Sink/Source Terms at Wel1: Location

$$
\mathrm{QX}_{\mathrm{i}}=\mathrm{s}_{\mathrm{i}} \quad \text { for } \mathrm{r}=\mathrm{r}_{\mathrm{v}} \text { and } 0<\mathrm{z} \leq \mathrm{d}_{\mathrm{v}}
$$




\subsection{FINITE DIFFERENCE ALGÖITHMS}

Various finite difference methods are available to solve partial differential equations. The optimum method depends, among other things, on the degree of nonlinearity inherent in the equations. Equation 33 is solved in this study by using a modified version of the alternating direction implicit (ADI) method applied by Rai (1975) to the solution of the gas flow problem with uniform total pressure.

Because the transport coefficients in Eq. 33 have a large variation with respect to concentration, a predictor-corrector technique (Douglas and Jones, 1963) is used. Concentrations are predicted for the mid-time interval through several explicit steps. Transport coefficients and total pressure gradients are based on these concentrations, and a corrector step is applied to give concentrations at the end of the time interval. This procedure differs from Rai's solution of the flow problem with uniform total pressure in which transport coefficients were based on concentrations at the beginning of the time step.

To reduce the solution time, the $A D I$ method is used for the corrector step; however, the ADI methods developed by Brian (1961), Douglas and Gunn (1964), and Brakat and Clark (1966) are not directly applicable because of the presence of additional terms due to total pressure gradients and pumping.

The predictor and corrector steps used to solve Eq. 33 are detailed in secs. 3.3.1 and 3.3.2. The more general three-dimensional case is also described, along with the modifications necessary to represent the twodimensional case.

\subsubsection{Predictor Step$$
\frac{P_{i}^{n+(1 / 2 k)}-P_{i}^{n}}{\Delta T / 2 k}=\nabla \cdot \sum_{j=1}^{n} D_{i j}^{n} \nabla P_{i}^{n}+\nabla \cdot\left(\frac{C_{0} P_{i}^{n}}{\mu_{\text {mix }}^{n}} \nabla P^{n}\right)+s_{i}^{n}
$$

where:

$$
\begin{aligned}
P_{i}^{n}= & \text { partial pressure of component } i \text { at time } n, \\
k= & \text { number of predictor steps required to reach the } \\
& \text { mid-interval of corrector steps, } \\
D_{j}^{n}= & \text { effective diffusion coefficient based on partial } \\
& \text { pressure at time } n, \\
\mu_{m i x}^{n}= & \text { viscosity of mixture at time } n, \text { and } \\
s_{i}^{n}= & \text { sink/source term at time } n .
\end{aligned}
$$

Knowing $P_{i}^{n}$, the partial 'pressure of each component, at time $n$, the elements of matrix A (Eq. '25) are evaluated for each pore radius and are summed over all pore radii. Inversion of matrix A gives elements of $D_{i j}^{n}$, 
and $\mathrm{P}_{i}^{\mathrm{n}+(1 / 2 k)}$ is then calculated. This process is repeated $k$ times to reach time $n+(1 / 2)$, yielding $P_{i}^{n+(1 / 2)}$.

$\Delta \mathrm{T}$ is selected in such a way that:

$$
\lambda=\mathrm{D}_{\max } \Delta \mathrm{T}\left(\Delta \mathrm{X}^{-2}+\Delta \mathrm{Y}^{-2}+\Delta \mathrm{Z}^{-2}\right) / \mathrm{k} \leq 0.5
$$

\subsubsection{Corrector Step}

$$
\begin{aligned}
\frac{P_{i}^{n+1}-P_{i}^{n}}{\Delta T}= & \nabla \cdot \sum_{j=1}^{n}\left[D_{i j}^{n+(1 / 2)} \cdot \nabla\left(\frac{P_{j}^{n+1}+P_{j}^{n}}{2}\right)\right] \\
& +\nabla \cdot\left[\frac{C_{0} P_{i}^{n+(1 / 2)}}{\left.\mu_{\operatorname{mix}}^{n+(1 / 2)} \nabla P^{n+(1 / 2)}\right]+s_{i}^{n+(1 / 2)}}\right]
\end{aligned}
$$

The terms $P_{i}^{n+(1 / 2)}, P^{n+(1 / 2)}, s_{i}^{n+(1 / 2)}, D_{i j}^{n+(1 / 2)}$, and $\mu_{m i x}^{n+(1 / 2)}$ are based on the predictor step calculations. Equation 46 can be solved for. $P_{i}^{n+(1 / 2)}$ using the implicit technique. However, for large bandwidths, particularly in three-dimensional problems, implicit. solutions require large computational times. The ADI method, which is also known as operator-splitting, is used to reduce computational times and resultant computer costs.

In cylinderical coordinates:

$$
\begin{aligned}
\nabla(D \nabla \phi) & =\left[\frac{1}{r} \frac{\partial}{\partial r}\left(D r \frac{\partial}{\partial r}\right)+\frac{1}{r} \frac{\partial}{\partial \theta}\left(\frac{D}{r} \frac{\partial}{\partial \theta}\right)+\frac{\partial}{\partial z}\left(\frac{D \partial}{\partial z}\right)\right] \phi \\
& =\frac{2}{\Delta T}\left(\lambda_{A}+\lambda_{r}+\lambda_{z}\right) \phi
\end{aligned}
$$

where:

$$
\begin{aligned}
& \lambda_{r}=\frac{\Delta T}{2} \frac{1}{r} \frac{\partial}{\partial r}\left(D r \frac{\partial}{\partial r}\right), \\
& \lambda_{\theta}=\frac{\Delta T}{2} \frac{1}{\partial r} \frac{\partial}{\partial r}\left(\frac{D}{r} \frac{\partial}{\partial \theta}\right), \text { and } . \\
& \lambda_{z}=\frac{\Delta T}{2} \frac{\partial}{\partial z}\left(D \frac{\partial}{\partial z}\right) .
\end{aligned}
$$


Let :

$$
\begin{aligned}
\frac{C_{0} P_{i}^{n+(1 / 2)}}{\mu_{\operatorname{mix}}^{n+(1 / 2)}} & =\bar{D}_{i}, \\
\eta_{r} & =\frac{\Delta T}{2} \frac{1}{r} \frac{\partial}{\partial r}\left(\bar{D}_{i} \frac{\partial}{\partial r}\right), \\
\eta_{\theta} & =\frac{\Delta T}{2} \frac{1}{r} \frac{\partial}{\partial \theta}\left(\frac{\bar{D}_{i}}{r} \frac{\partial}{\partial \theta}\right), \text { and } \\
\eta_{z} & =\frac{\Delta T}{2} \frac{\partial}{\partial z} \cdot\left(\bar{D}_{i} \frac{\partial}{\partial z}\right) .
\end{aligned}
$$

Substituting Eqs. 47 and 48 into Eq. 46 gives:

$$
\begin{aligned}
P_{i}^{n+1}-P_{i}^{n}= & \left(\lambda_{r}+\lambda_{\theta}+\lambda_{z}\right)\left(P_{i}^{n+1}+P_{i}^{n}\right) \\
& +2\left(n_{r}+n_{\theta}+n_{z}\right) P^{n+(1 / 2)}+\Delta T s_{i}^{n+(1 / 2)}
\end{aligned}
$$

or

$$
\left(1-\lambda_{\mathbf{r}}-\lambda_{\mathbf{z}}-\lambda_{\theta}\right) \mathrm{P}_{i}^{\mathrm{n}+1}=\left(1+\lambda_{\mathbf{r}}+\lambda_{\mathbf{z}}+\lambda_{\theta}\right) \mathbf{P}_{\mathbf{i}}^{\mathrm{n}}+\mathbf{f}_{\mathbf{i}}
$$

where:

$$
\begin{aligned}
f_{i} & =2 \sum_{j}^{m}\left(\bar{\lambda}_{r}+\bar{\lambda}_{z}+\bar{\lambda}_{\theta}\right) p_{j}^{n}+\left(n_{r}+n_{z}+n_{\theta}\right) p^{n+(1 / 2)} \\
& +\Delta \operatorname{Ts}_{i}^{n+(1 / 2)}, \quad j \neq i
\end{aligned}
$$

where: $m=$ number of gas components.

Now add $\left(\dot{\lambda}_{\mathbf{r}} \lambda_{z}+\lambda_{z} \lambda_{\theta}+\dot{\lambda}_{\theta} \lambda_{r}-\lambda_{r} \lambda_{z} \lambda_{\theta}\right) P^{n+1}$ to the left side and $\left(\lambda_{r} \lambda_{z}+\lambda_{z} \lambda_{\theta}\right.$ $\left.+\lambda_{\theta} \lambda_{r}-\lambda_{r} \lambda_{2} \lambda_{\theta}\right) P^{n}$ to the right side of Eq. 50. Direct substitution yields:

$$
\begin{aligned}
& \left(1-\lambda_{\mathbf{r}}\right) \mathbf{P}_{\mathbf{i}}^{*}=\left(1+\lambda+2 \lambda_{r}+2 \lambda_{i}\right) P_{i}^{n}+f_{i} \\
& \left(1-\lambda_{z}\right) P_{i}^{* *}=P_{i}^{*}-\lambda_{z} P_{i}^{n} \\
& \left(1-\lambda_{\theta}\right) \mathbf{P}_{i}^{n+1}=P_{i}^{* *}-\lambda_{\theta} P_{i}^{n}
\end{aligned}
$$


Equation 52 gives a tridiagonal system of equations using the Crank-Nicholson method (Carnahan, Luther, and Wilkes, 1969). The finite difference analogues for operators $r, z$, and $\theta$ are given by:

$$
\begin{aligned}
\lambda_{r} f & =\frac{\Delta T}{2} \frac{1}{r} \frac{\partial}{\partial r}\left(D r \frac{\partial f}{\partial r}\right) \\
& =\frac{\Delta T}{2} \delta_{r} D \delta_{r} f+\frac{D}{r} \delta_{r} f+D \delta_{r}^{2} f \\
\delta_{x} f & \left.=\left(f_{\ell+1}-f_{\ell-1}\right) / 2 \Delta x\right) \\
\delta_{x}^{2} f & =\left(f_{\ell-1}-2 \dot{f}_{\ell}+f_{\ell+1}\right) /(\Delta x)^{2}
\end{aligned}
$$

where:

$$
\begin{aligned}
& \ell=i, j, \text { or } k, \\
& x=r, \theta, \text { or } z, \text { and } \\
& x=r, r \Delta \theta, \text { or } \Delta z .
\end{aligned}
$$

Therefore:

$$
\begin{aligned}
& \lambda_{r} f=\frac{\Delta T}{2 \Delta r^{2}}\left\{\left[\frac{D_{i}^{\prime}}{4}+\frac{(2 i-1) D}{2 i-2}\right] f_{i+1}-2 D f_{i}+\left[\frac{(2 i-3) D}{2 i-2}-\frac{D^{\prime}}{4}\right]\right\} f_{i-1} \\
& \lambda_{z} f=\frac{\Delta T}{2 \Delta Z^{2}}\left[\left(\frac{D_{j}^{\prime}}{4}+D\right) f_{j+1}-2 D f_{j}+\left(D-\frac{D_{j}}{4}\right) f_{j-1}\right] \\
& \lambda_{\theta} f=\frac{\Delta T}{2[(i-1) \Delta r \Delta \theta]^{2}}\left[\left(\frac{D_{k}^{\prime}}{4}+D\right) f_{k+1}-2 D f_{k}+\left(D-\frac{D_{k}^{\prime}}{4}\right) f_{k-1}\right]
\end{aligned}
$$

Similar expressions are written for $n_{r}, n_{z}$, and $n_{\theta}$ by replacing $D$ with $\bar{D}_{i}$. In the two-dimensional codes, due to axisymmetry, $\lambda_{\theta} P_{i}^{\mathfrak{n}}$ vanishes, and Eq. 51 reduces to:

$$
\left(1-\lambda_{r}\right) P_{i}^{*}=\left(1+\lambda_{r}+2 \lambda_{z}\right) P_{i}^{n}+f_{i}
$$

and

$$
\left(1-\dot{\lambda}_{z}\right) P_{i}^{n+1}=P_{i}^{*}-\lambda_{z} P_{i}^{n}
$$

Only small changes in the algorithm are required, i.e., all terms containing derivatives with respect to $\theta$ are dropped. The solution requires only two sweeps, one in the r-direction and the other in the $z$-direction.

\subsubsection{Finite Difference Algorithms for Boundaries}

This section gives the finite difference algorithms for the boundary conditions described in Sec. 3.2.3. 
Condition 1

To avoid a singularity, the boundary must be placed one grid point beyond $r=0$ and the boundary $r=\Delta r$ treated as an impervious boundary. Therefore Eq. 53 reduces to:

$$
\lambda_{\mathrm{r}} \mathrm{f}=\frac{\mathrm{D} \Delta \mathrm{T}}{2} \delta_{\mathrm{r}}^{2} \mathrm{f}
$$

and Eq. 56 becomes:

$$
\lambda_{\mathbf{r}} \mathbf{f}=\frac{D \Delta T}{\Delta \mathbf{r}^{2}}\left(\mathrm{f}_{\mathrm{i}+1}-\mathrm{f}_{\mathrm{i}}\right)
$$

Condition 2

In Eq. 57,

$$
\lambda_{z} f=\frac{D \Delta T}{\Delta z^{2}}\left(f_{j-1}-f_{j}\right)
$$

Condition 3

$$
v=\text { constant }
$$

\section{Condition 4}

In Eq. 51,

$$
s_{i}^{n+(1 / 2)}=2 \mathrm{CK}_{1} \frac{\left(v_{i 1}-v_{i 0}\right)}{z}
$$

where:

$$
\begin{aligned}
v_{i 1}= & \text { partial pressure of component } i \text { outside the fill } \\
& \text { above the ground surface, and } \\
v_{i 0}= & \text { partial pressure of component } i \text { just below the } \\
& \text { ground surface. }
\end{aligned}
$$

\section{Condition 5}

In Eq. 58;

$$
\lambda_{\theta} f=\frac{D \Delta T}{[(i-1) \Delta r \Delta \theta]^{2}}\left(f_{k+1}-f_{k}\right)
$$


27

Condition 6

In $\mathrm{Eq} .58$;

$$
\lambda_{\theta} f=\frac{D \Delta T}{[(i-1) \Delta r \Delta \theta]^{2}}\left(f_{k-1}-f_{k}\right)
$$

Condition 7

In Eq. 47,

$$
\lambda_{z} f=\frac{D \Delta T}{\Delta z^{2}}\left(f_{j+1}-f_{j}\right)
$$

Condition 8

In Eq. 51,

$$
\mathrm{S}_{i}^{\mathrm{n}+(1 / 2)}=Q \mathrm{P}_{i}^{\mathrm{n}+(1 / 2)}
$$

where $Q=$ flow rate. 


\section{FINITE DIFFERENCE COMPUTER CODES}

The finite difference computer codes used to solve the gas transport equations (see Eq. 33) are presented in this chapter. The codes use the finite difference algorithms introduced in Secs. 3.3.3 and 3.3.4 to determine gas concentration as a function of time and distance from the landfill. The computer programs described are as follows:

- Code IV: A two-dimensional, finite difference code that can be applied in Cartesian coordinates for relatively long, straight-sided fills with trench-type recovery systems, or that can be applied in cylindrical coordinates to fills that are circular in plan view with annular trench-type recovery systems.

- Code V: A three-dimensional, finite difference code that can be applied in cylindrical coordinates to fills that are circular in plan view and that have circular pipe recovery systems.

\subsection{CODE IV}

As previously noted; the transport coefficients of Eq. 33 are highly dependent upon gas concentration. In particular, the pressure flow of a given component is directly proportional to the concentration of that component at the point under consideration. Because of this nonilinearity, Code IV uses explicit predictor steps to evaluate the transport. coeffficients at the middle of the time interval. These coefficients are then used in an alternatingdirection implicit corrector step to determine the gas concentrations at the end of the time interval. The time increment for the predictor step is based on the following limitations established by Carnahan, Luther, and Wilkes (1969):

$$
\lambda=D_{\max } T\left(\Delta X^{-2}+\Delta Y^{-2}+\Delta Z^{-2}\right) / K \leq 0.5
$$

where:

$$
\begin{aligned}
& \mathrm{D}=\text { transport coefficient } \\
& \mathrm{T}=\text { predictor step time increment, } \\
& \dot{\mathrm{X}}=\text { horizontal grid size, and } \\
& \mathrm{Z}=\text { vertical grid size. }
\end{aligned}
$$

The time increment for the corrector step is restricted to four times that used by each predictor step.

Code IV can accommodate trench-type recovery systems or hybrid systems consisting of trenches with adjacent low permeability barriers. The program can handle ten different pore radii; however, more pore radii can be treated by simply changing several program statements. It should be noted that the effective transport coefficients are obtained by summing the elements of a 
matrix over pore radii, the elements being obtained by inverting a square matrix of a size equal to the number of gas components considered. As such, the cost. of running the program increases rapidly with an increasing number of pore radii.

The program user can specify the time steps taken between printouts. At each printout, the partial pressures and the total pressure are given. At the soil surface, partial pressures are modified to make the total pressure atmospheric; however, at the location of. the pump this pressure is allowed to float, assuming that the trench top can be sealed so that pumping effectiveness can be realized. Pump characteristic curves can be used to determine the relationship between pressure at the pump and pumping rates. These characteristic curves allow the specific attributes of the pump being used to be introduced into the program.

Program execution is terminated after a.specific time has been reached or after, a specified number of steps have been computed, whichever occurs first.

A 1 isting of Code IV is given in Appendix A.

\subsubsection{Principal Variables}

The principal variables used in Code IV are listed below.

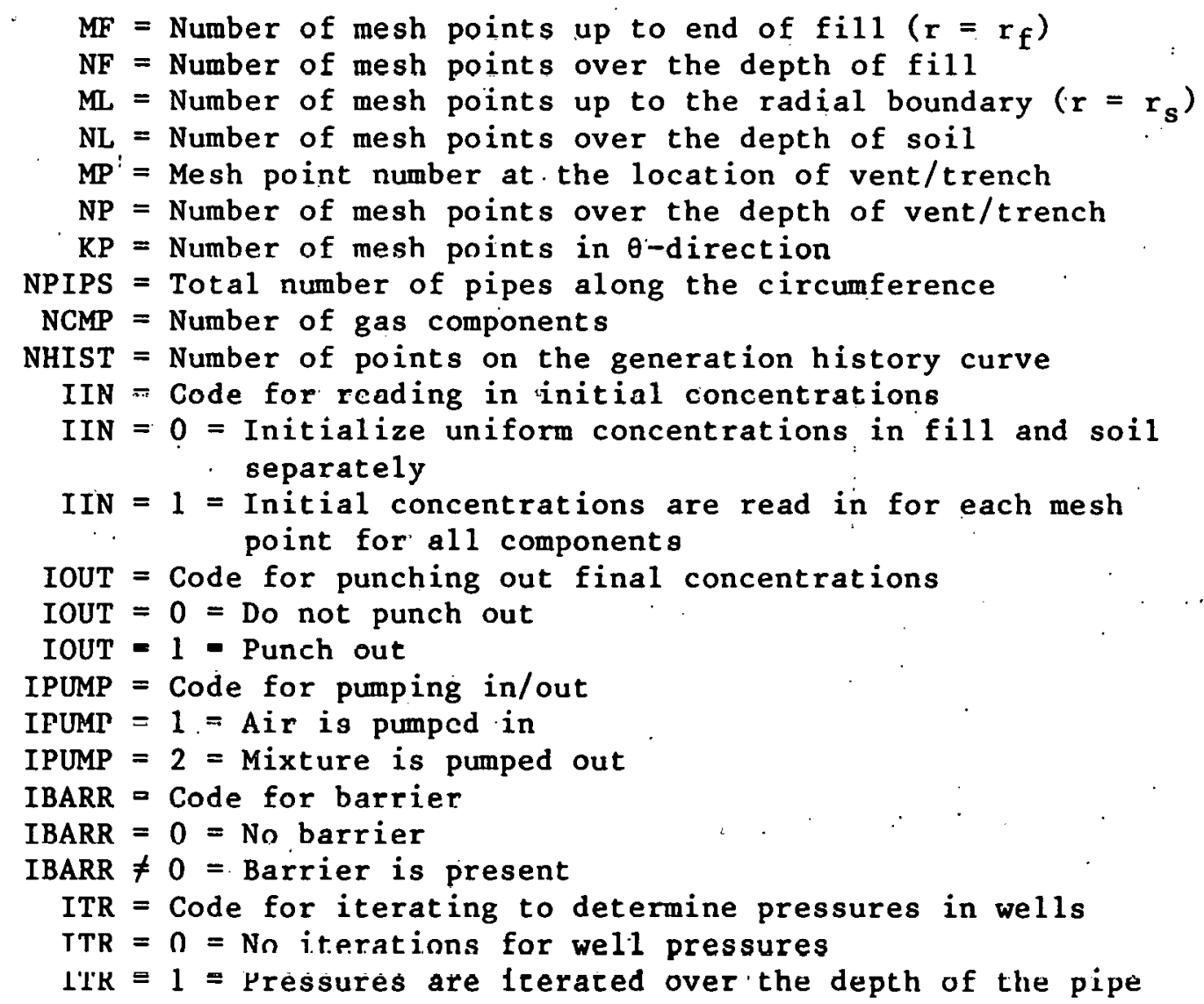




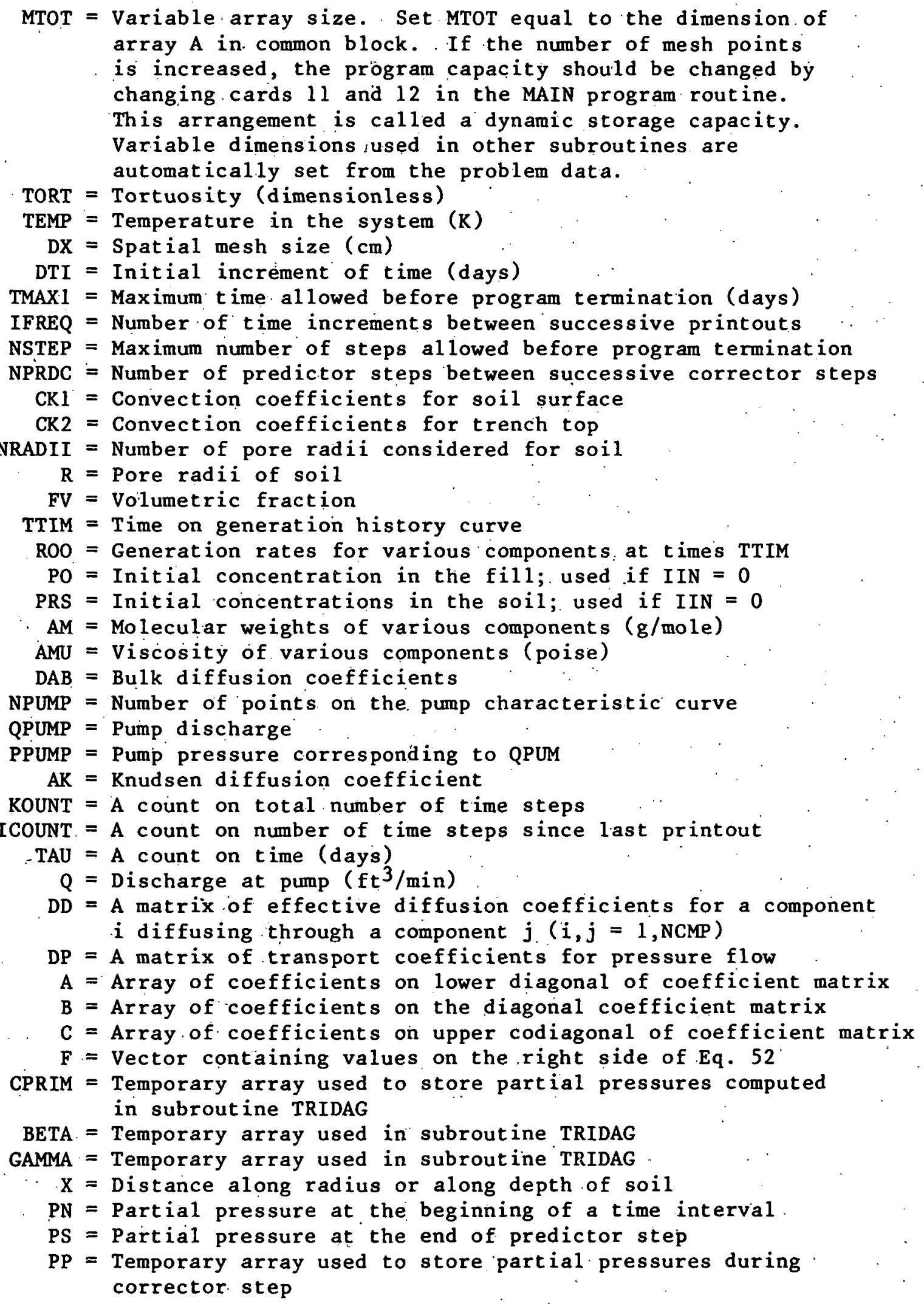




\subsubsection{Flow Chart}

Code IV consists of ten subroutines, including the MAIN program and subroutines SOLV, CFIL, PREDIC, PRBDIC, CORECT, CORBCT, PUMP, INVERT, and TRIDAG. The flow charts for each of these subroutines are given in Figs. $4.1-4.7$.

\subsubsection{Instructions for Data Preparation}

The sequence of punched cards shown in Table 4.1 contains the problem data for input to the program.

\subsection{CODE V}

Code $V$ can accommodate landfills that are circular in plan view and use we11-type recovery systems. It is assumed that the wells are located in a circular pattern with equal distances between the wells. The user can specify the number of pipe sets and the depth, location, and discharge for each set. Any number of pipe sets can be specified; however, the number of pipes in each circle (NPIPS) must be the same for all sets.

An explicit numerical scheme is used in Code $V$ to solve the threedimensional finite difference algorithms given in Chapter 2. Code $V$ requires approximately four times as much computer time as Code IV and therefore. should be used only when a three-dimensional analysis is required. The addition of the $\theta$-direction is accomplished by dividing a slice subtending an angle equal to $\theta$ /NPIPS into KL mesh points. The axis $(r=0)$ is a singular point and is excluded from analysis.

A modified version of Code $V$, Code VB, can be used to model landfills with irregular geometries. Initial pressures and generation rates are specified at each nodal point.

The general input and output format for Code $V$ is similar to that given in Sec. 4.1 for Code IV.

A listing of Code $V$ is given in Appendix $B$.

\subsubsection{Principal Variables}

The principal variables listed in Sec. 4.1.1 for Code IV are also used in Code V. Several additional variables must be introduced to accommodate the extra dimension in code $V$. These variables are:

$\mathrm{KL}=$ Number of mesh points along the $\theta$-direction,

NPIPS = Number of pipes over the circumference,

NPOR = Point of symmetry for maximum resolution output, and

NPS $=$ Number nf pipe sets. 


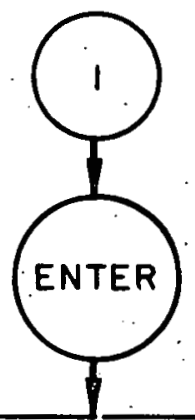

TORT, TEMP, DX, TMAXI, DTI, IFREQ, NSTEP, NPRDC, CK I;CK 2 , NRADII, $R_{i}, F V_{i}, N C M P, T T I M_{i}, Q O O_{i j}, P O_{i}, P S_{i}, A M_{i}, A M U_{i}, D A B_{i j}$

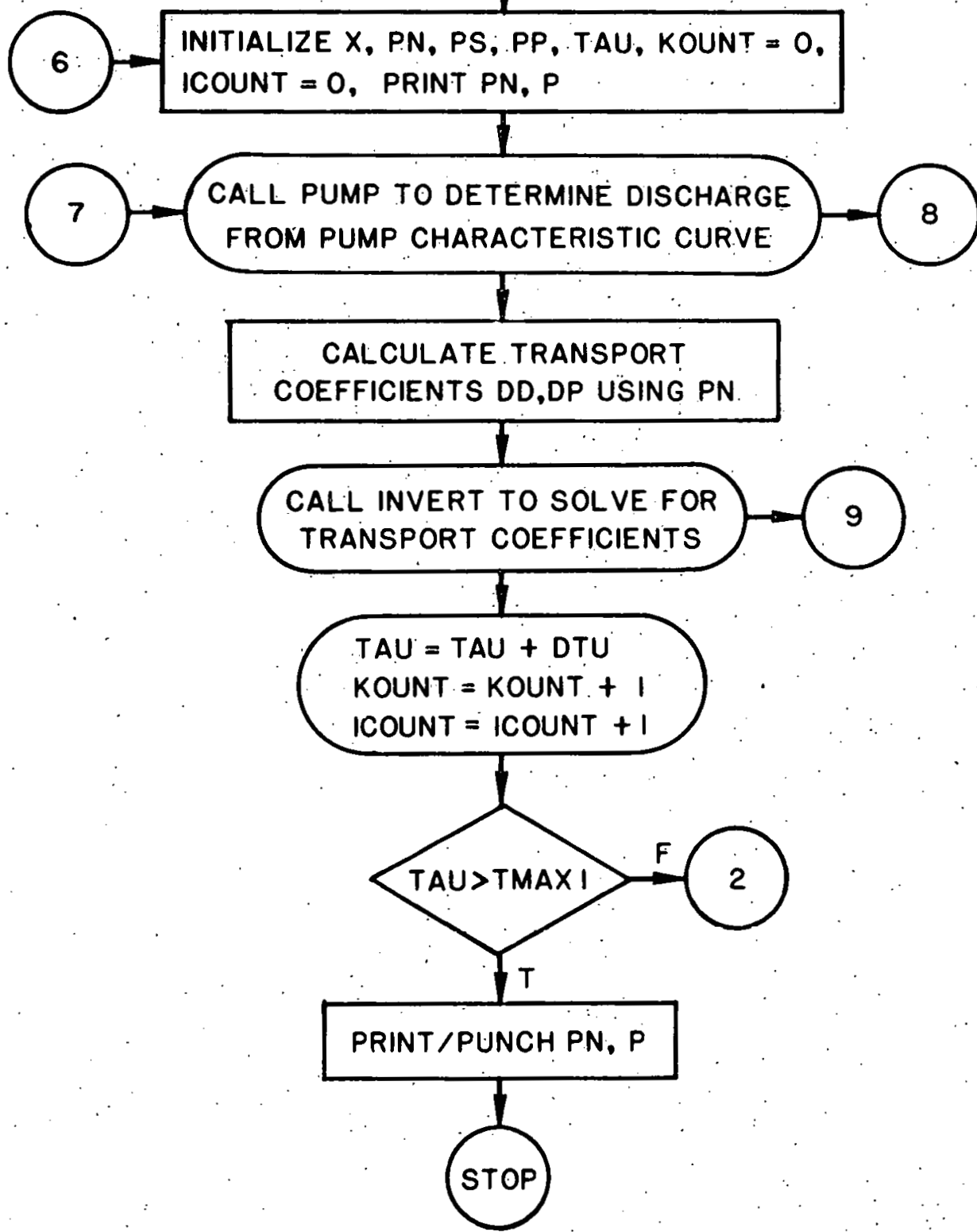

Fig. 4.1 Code IV, Subroutine SOLV 


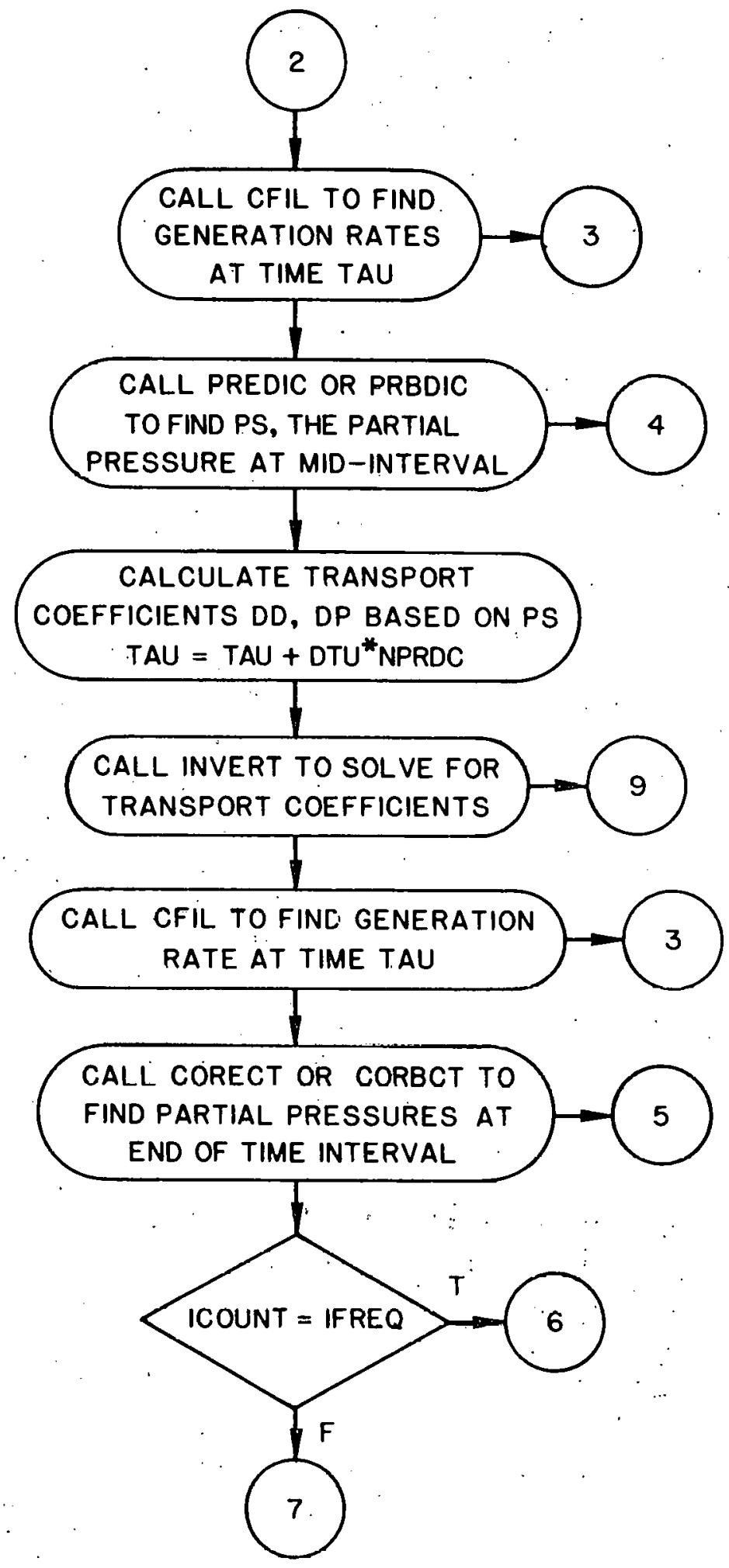

Fig. 4.1 (Cont'd) 


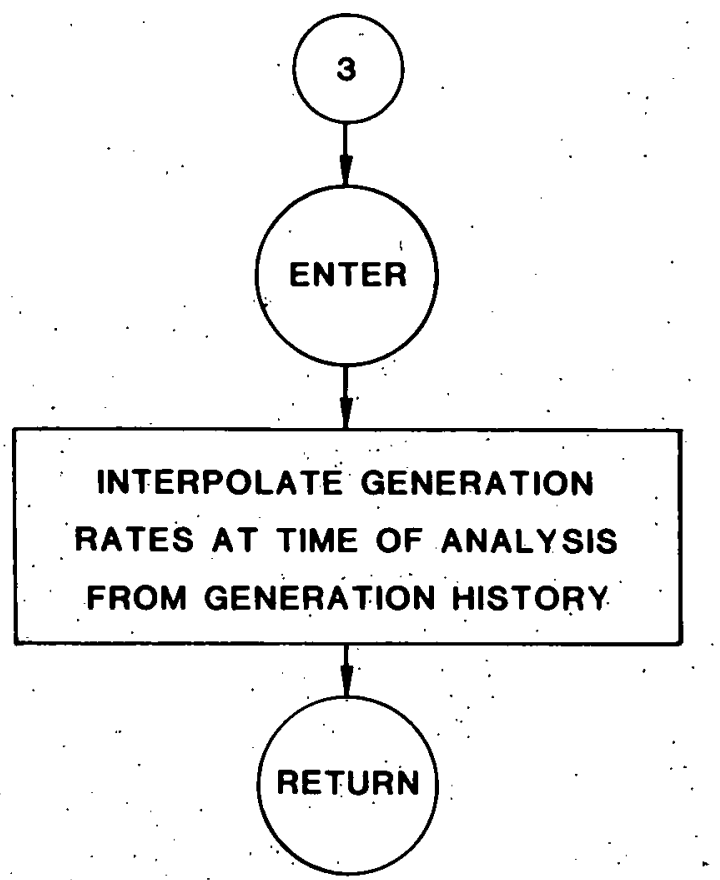

Fig. 4.2 Code IV, Subroutine CFIL

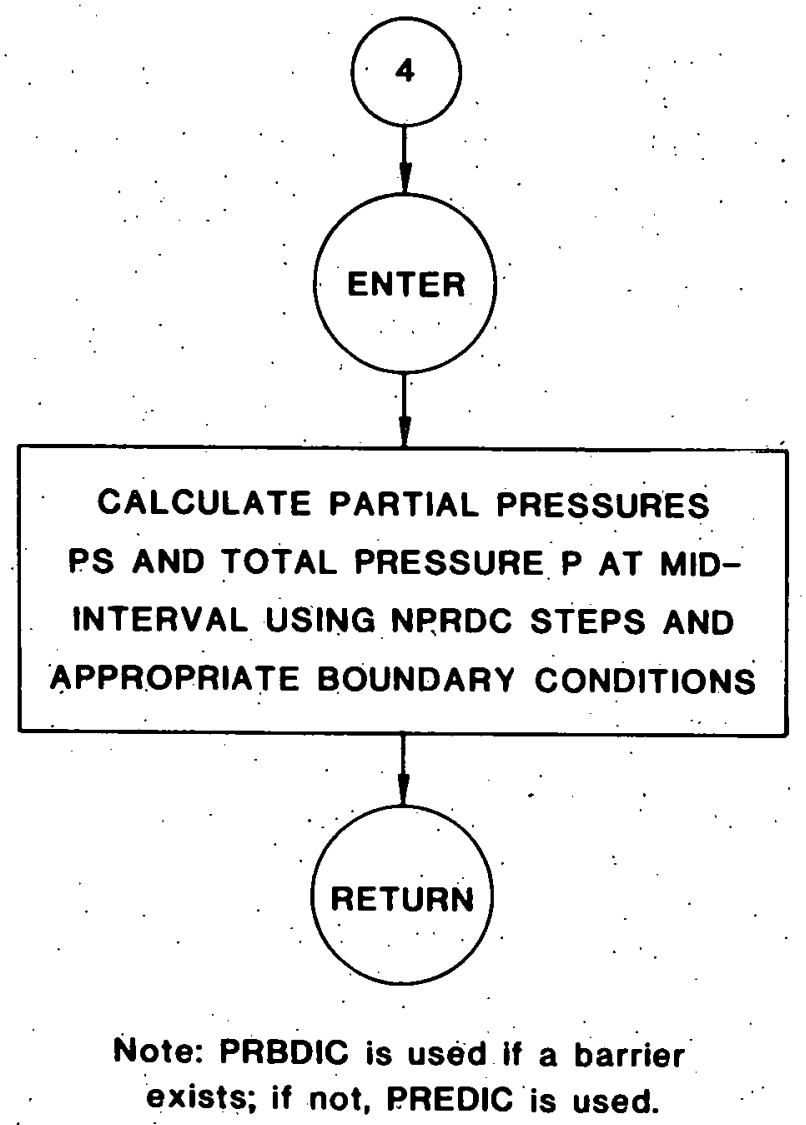

Fig. 4.3 Code IV, Subroutine PREDIC/PRBIC 


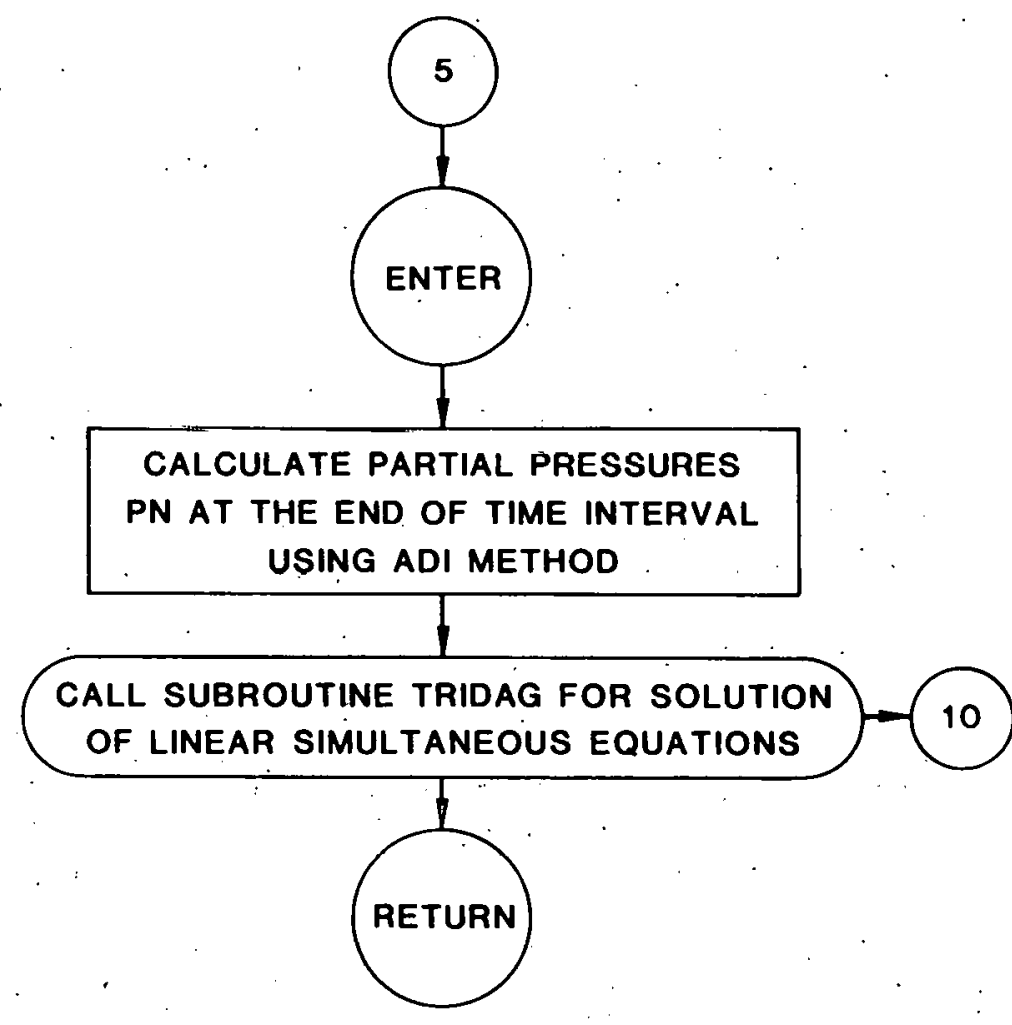

Note: CORBCT is used if a barrier exists; if not, CORECT is used.

Fig. 4:4 Code IV, Subroutine CORECT/CORBCT

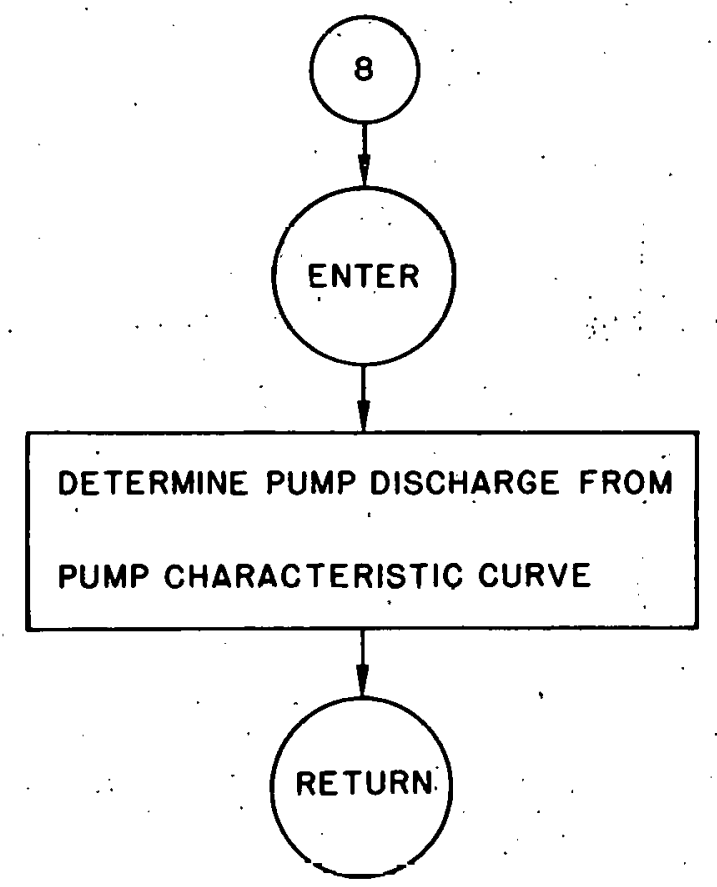

Fig. 4.5 Code IV, Subroutine PUMP 


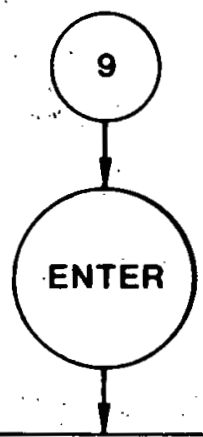

USING A GAUSSIAN ELIMINATION PROCEDURE, IN!/ERT NCMP $X$ NCMP MATRIX TO DETERMINE TRANSPORT COEFFICIENTS

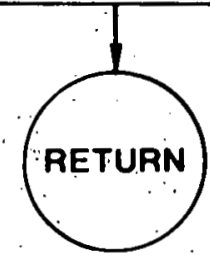

Fig. 4.6 Code IV, Subroutine INVERT

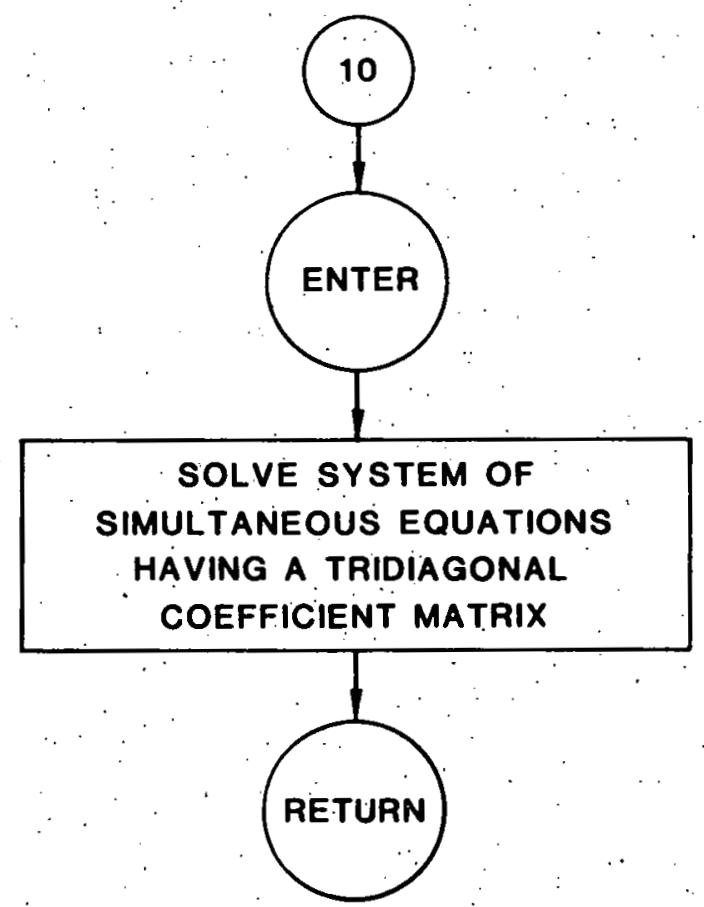

Fig. 4.7 Code IV, Subroutine TRIDAG 
Table 4.1 Instructions for Data Preparation, Code IV

Card, Field Description

Columns

Card 1: Contro1 data (13I5)

$\begin{array}{lr}\text { Number of mesh points up to the end of fill (MF) } & 1-5 \\ \text { Number of mesh points up to the depth of fill (NF) } & 6-10 \\ \text { Number of mesh points up to the end of soil boundary (ML) } & 11-15 \\ \text { Number of mesh points up to the depth of soil boundary (NL) } & 16-20 \\ \text { Number of mesh points up to the vent (MP) } & 21-25 \\ \text { Number of mesh points over the depth of vent (NP) } & 26-30 \\ \text { Number of gas components considered (NCMP) } & 31-35 \\ \text { Number of points on the fill history curve (NHIST) } & 36-40 \\ \text { Code for inputting the initial concentrations (IIN) } & 41-45 \\ \text { Code for punching out the partial pressures at the end of } & 46-50 \\ \text { time of analysis (IOUT) } & 51-55 \\ \text { Code for pumping in or out (IPUMP) } & 56-60 \\ \text { Code for barrier (IBARR) } & 61-65\end{array}$

Card 2: Title card (10A8)

Arbitrary descriptive identification. of the job $\quad 1-80$

Card 3: Partial pressures outside the fill (8F10.0)

Initial discharge at well, $\mathrm{ft}^{3} / \mathrm{min}(\mathrm{Q})$

1-10

Partial pressure for component 1 outside fill (POUT 1 ) $11-20$

$\begin{array}{ll}\text { Partial pressure for component } 2 \text { outside fill (POUT } 2 \text { ) 21-30 } & \text { 2 }\end{array}$

etc.

Card 4: (8F10.0)

Tortuosity of soil, dimensionless (TORT)

Temperature of gases, K (TEMP)

1-10

Spatial mesh size, cm (DX)

$11-20$

Period of anslysis, days (TMAX)

21-30

Time step, days (DTI)

31-40

41-50

Card 5:' (3I5)

Number of steps between printouts (IFREQ)

$1-5$

Maximum number. of steps of analysis (NSTEP)

6-10

Number of predictor steps (NPRDC)

$11-15$

Card Set 6 (total of NCMP cards): Surface transfer coefficients for each component $(2 \mathrm{~F} 10.0)^{a}$

Mass transfer coefficients for top of fill (CK1)

Mass transfer coefficients for top of vent (CK2)

1-10

$11-20$

Card 7: (I5)

Total number of pore radii (NRADII)

$1-5$ 
Table 4.1 (Cont'd)

Card, Field Description

Columns

Card Set A: Pore size distribution (2F10.0)

Pore radius, $\AA\left(R_{\mathbf{i}}\right)$

Volumetric fraction, dimensionless $\left(\mathrm{FV}_{i}\right)$

$1-10$

$11-20$

Card Set B (total of NHIST cards): Fill history (8F10.0)

Time (days)

Rate of generation for component 1

$1-10$

Rate of generation for component 2

$11-20$

Rate of generation for component 3

$21-30$

etc.

Card Set C (total of NCMP cards): (8F10.0)a

Initial partial pressure in the fill ( $\left(\mathrm{PO}_{\mathrm{i}}\right)$

Initial partial pressure in the soil (PRS $\left.{ }_{i}\right)$

$1-10$

Molecular weight. ( $\left.A M_{i}\right)$

$11-20$

Viscosity $\left(\mathrm{AMU}_{\mathrm{i}}\right)$

$21-30$

$31-40$

Card Set.D (total of NCMP cards): (8F10.0)

Card 1

- Bulk diffusion coefficient of component 1 through 1 .

Bulk diffusion coefficient of component 1 through 2

Bulk diffusion coefficient of component 1 through 3

etc.

Card 2

Bulk diffusion coefficient of component 2 through 1

Bulk diffusion coefficient of component 2 through 2 .

etc.

:

Card NCMP

Card Set E: Pump characteristic curve

Card 1: (I5)

Number of points on pump characteristic curve (NPUMP)

$1-5$

Cards 2 through (NPUMP+1): (2F10.0)

Discharge of pump ( $\left.Q P U M P_{i}\right)$

$1-10$

Pressure at pump (PPUMP $i)$

$11-20$

ane card for each component. 


\subsubsection{Flow Chart}

Code $V$ consists of six subroutines, including the MAIN program and subroutines SOLV, CFIL, INVERT, PREDIC, and PUMP. The flow charts for each of these subroutines are similar. to those given in Sec. 4.1.2, the primary difference being $a$ sweep in the $\theta$-direction in addition to the $r-$ and $z$ directions. This changes subroutine PREDIC, but the general format as indicated by the flow charts does not differ from that given for Code IV.

\subsubsection{Instructions for Data Preparation}

The sequence of punched cards shown in Table 4.2 contains the problem data for input to the program.

Table 4.2 Instructions for Data Preparation, Code V

\section{Card, Field Description}

\section{Card 1: (11 I5)}

Number of mesh points up to end of fil1. (MF)

Number of mesh points up to depth of fill (NF)

Number of mesh points up to end of soil boundary (ML)

Number of mesh points up to depth of soil boundary (NL)

Number of mesh points along $\theta$-direction (KL)

Total number of pipes over circumference (NPIPS)

Number of gas components considered (NCMP)

Number of points on the fill history curve(NHIST).

Code for inputting initial concentrations (IIN).

Code for punching out partial pressures at the end

of the time of analysis (IOUT)

Point of symmetry for maximum resolution output (MPOR)

Card 2: (I5)

Number of pipe sets (NPC)

Card Set A (total of NPC cards): (2I5,F5.0)

Number of mesh points over depth of pipe (NP)

Number of mesh points to location of pipe- (MP)

Discharge at pipe (Q)

Card 4: Title card (10A8)

Arbitrary descriptive identification of job

Card 5: (8F10.0)

Partial pressure for component 1 outside fill (POUT 1 )

Partial pressure for component 2 outside fill (POUT 2 )

etc.
$1-5$

$1-5$

$6-10$

$11-15$

$1-80$

$1-10$

Columns

$$
\begin{gathered}
1-5 \\
6-10 \\
11-15 \\
16-20 \\
21-25 \\
26-30 \\
31-35 \\
36-40 \\
41-45 \\
46-50 \\
51-55
\end{gathered}
$$

$$
-5
$$

$11-20$ 
Table 4.2 (Cont'd)

Card, Field Description

Columns

Card 6: (8F10.0)

Tortuosity of soil, dimensionless (TORT)

Temperature of gases, K (TEMP)

$1-10$

Spatial mesh size, cm (DX)

$11-20$

Period of analysis, days (TMAX1)

$21-30$

Period of analysis, days (TMAX2)

$31-40$

$41-50$

Initial time step (DTI)

$51-60$

Card 7: (3I5)

Number of steps between printouts: (IFREQ)

$1-5$

Maximum number of steps of analysis (NSTEP)

6-10

Number of predictor steps (NPRDC)

$11-15$

Card 8: (I5)

Total number of pore radii (NRADII). $\quad \therefore 1-5$

Card Set B (total of NRADII cards): Pore size distribution (2F10.0)

Pore radius, $\AA$. $\left(R_{i}\right)$

Volumetric fraction, dimensionless $\left(\mathrm{FV}_{\mathbf{i}}\right)$

Card Set C (total of NHIST cards): Fill history (8F10.0)

Time (days)

Rate of generation for component 1

Rate of generation for component 2

21-30

Rate of generation for component 3

$31-40$

etc.

Card Set D (total of NCMP cards): (8F10.0)a

Initial partial pressure in the fill $\left(\mathrm{PO}_{\mathrm{i}}\right)$

Initial partial pressure in the soil (PRS $\left.{ }_{i}\right)$

$11-20$

Molecular weight $\left(\mathrm{AM}_{\mathbf{i}}\right)$

$21-30$

Viscosity ( $\mathrm{AMU}_{i}$ )

$31-40$

Surface convection coefficient for top of vent (CK1)

41-50

Surface convection coefficient for top of soil (CK2)

$51-60$

Card Set E (total of NCMP cards): (8F10.0)

Card 1: (8F10.0)

Bulk diffusion coefficient of component 1 through 1

Bulk diffusion coefficient of component 1 through 2

Bulk diffusion coefficient of component 1 through 3 
Table 4.2 (Cont'd)

Card, Field Description

Card Set E (Cont'd)

Card 2: (8F10.0)

Bulk diffusion coefficient of component 2 through 1

Bulk diffusion coefficient of component 2 through 2

$11-20$

Bulk diffusion coefficient of component 2 through 3

etc.

:

Card NCMP

Card Set F: Pump characteristic curve

Card 1: (I5)

Number of points on curve (NPUMP)

Cards 2 through (NPUMP+1): (2F10.0)

Discharge of pump (QPUMP $i)$

Pressure at pump (PPUMP $i)$

$11-20$

ane card for each component. 


\section{COMPUTER SIMULATIONS}

In this chapter, the finite difference computer codes introduced in Chapter 4 are applied to several landfills to simulate methane recovery systems. Code IV, the two-dimensional pressure flow program, is used to model a cylindrically shaped landfill. Code V, modified to accommodate irregular fill geometries, is used to model the Puente Hills landfill, a field test site that is being studied in conjunction with another project under sponsorship of the U.S. Department of Energy. (DOE).

\subsection{COMPUTER SIMULATION OF METHANE RECOVERY FOR A HYPOTHETICAL LANDF ILL}

Several methane recovery systems in a hypothetical landfill have been analyzed to illustrate the modeling capabilities of code IV. The landfill is assumed to be circular in plan view with a radius of $160 \mathrm{~m}$ and a depth of $16 \mathrm{~m}$. The soil surrounding.the 1 andfill is fine-grained and a gas-impervious layer is encountered at a depth of $37 \mathrm{~m}$. Initially, the 1 andfill has a concentration of $70 \%$ methane and $30 \%$ carbon dioxide. The atmosphere above the landfill and the soil surrounding the landfill initially contain air. As time progresses, the methane and carbon dioxide migrate outward, and air invades the landfill.

The soil is assumed to have a porosity of 0.4 , a tortuosity of 1.55 , and a pore size of $1450 \AA$. A surface convection coefficient corresponding to a wind velocity of $5 \mathrm{mph}$ is used.

Extraction wells are placed at different locations and depths and are subjected to different extraction rates, as shown in Table 5.1. These wells are illustrated in Figs. 5.1-5.4. All other data are consistent in each of the four computer runs made. The complete input deck used is given in Table 5.2.

Figure 5.1 presents the results for Well 1. Figure 5.1 a shows the relative total pressure, which refers to the ratio of the total pressure with the extraction well operating to that at the same point and time but without the well operating (expressed as a percentage). In Fig. 5.1a; the relatively low pumping rate of 1 $\mathrm{ft}^{3} / \mathrm{min}$ results in a small zone of influence around the extraction well. Figure $5.1 \mathrm{~b}$, which shows the relative percentage of methane, indicates that there is a significant reduction in that gas.* Thus, the well is more

*The term "relative percentage" is defined as the ratio of the concentration with the extraction well operating to that at the same point and time but without the well operating.

Table 5.1 Wells Examined in Code IV Landfill Simulation

\begin{tabular}{cccc}
\hline & $\begin{array}{c}\text { Distance } \\
\text { from } \\
\text { Center of } \\
\text { Wandfill } \\
\text { (m) }\end{array}$ & $\begin{array}{c}\text { Well } \\
\text { Depth } \\
\text { (m) }\end{array}$ & $\begin{array}{c}\text { Extraction } \\
\text { Rate } \\
\left(\mathrm{ft}^{3} / \mathrm{min}\right)\end{array}$ \\
\hline 1 & 120 & 12 & 1 \\
2 & 120 & 12 & 10 \\
3 & 120 & 8 & 2 \\
4 & 152 & 16 & 10 \\
\hline
\end{tabular}




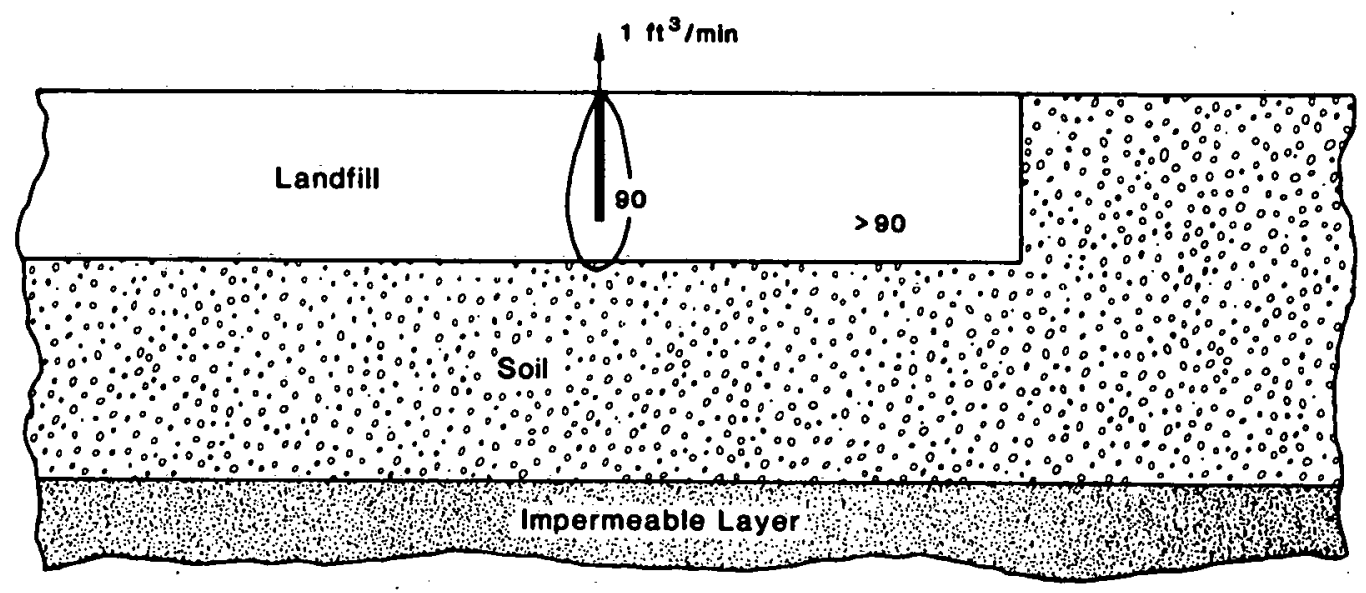

(a) Relative Total Pressure (\%)

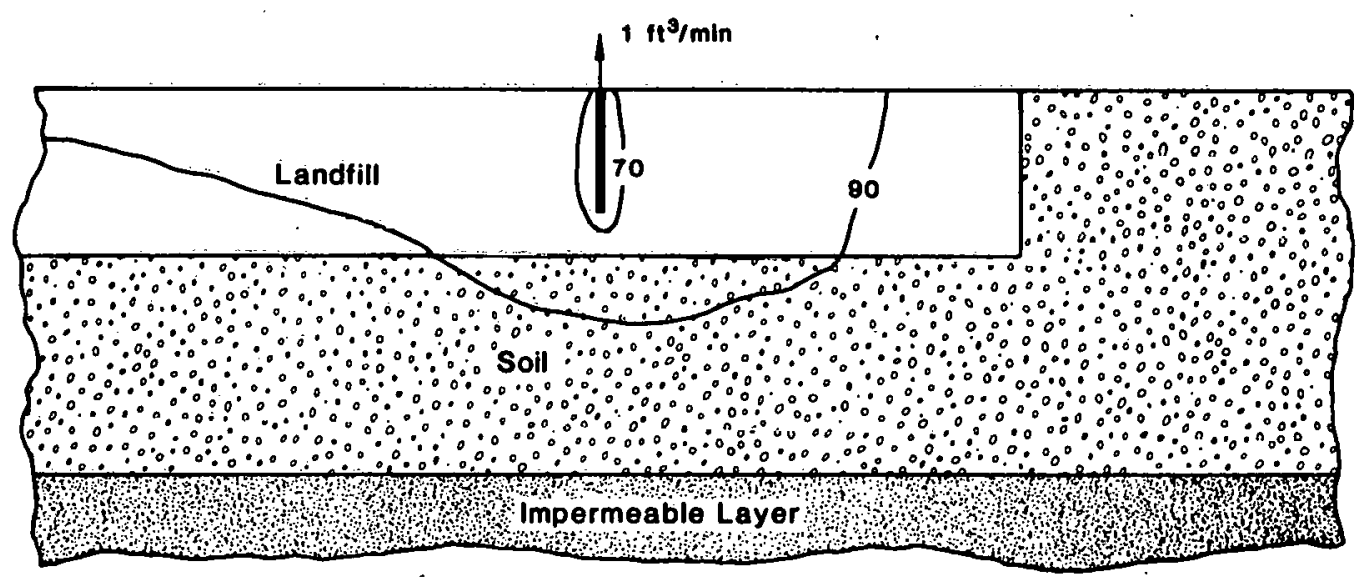

(b) Relative Percentage of Methane

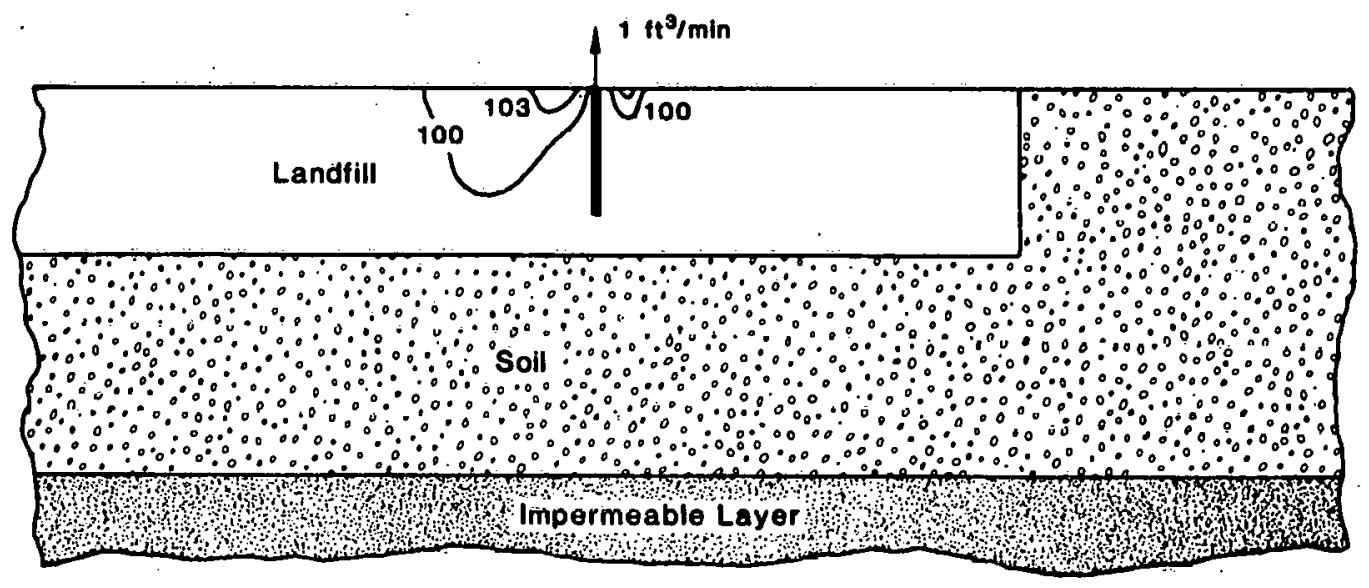

(c) Relative Percentage of Oxygen

Fig. 5.1 Code IV Landfill Simulation, Well 1 (vertical section) 


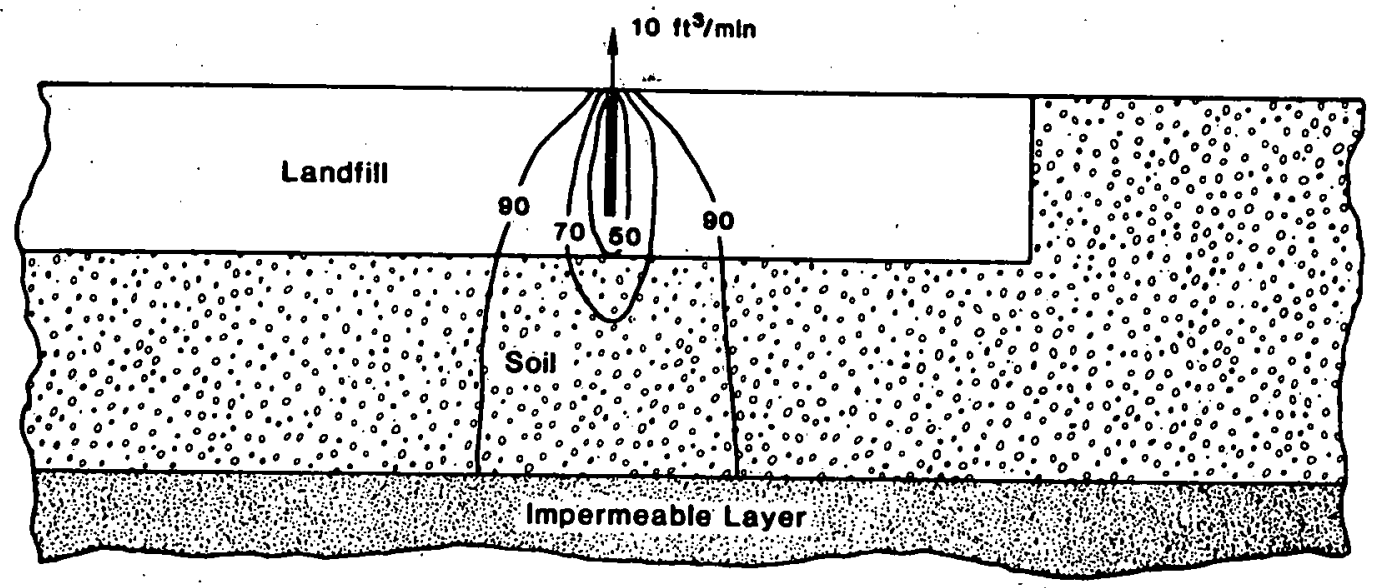

(a) Relative Total Pressure (\%)

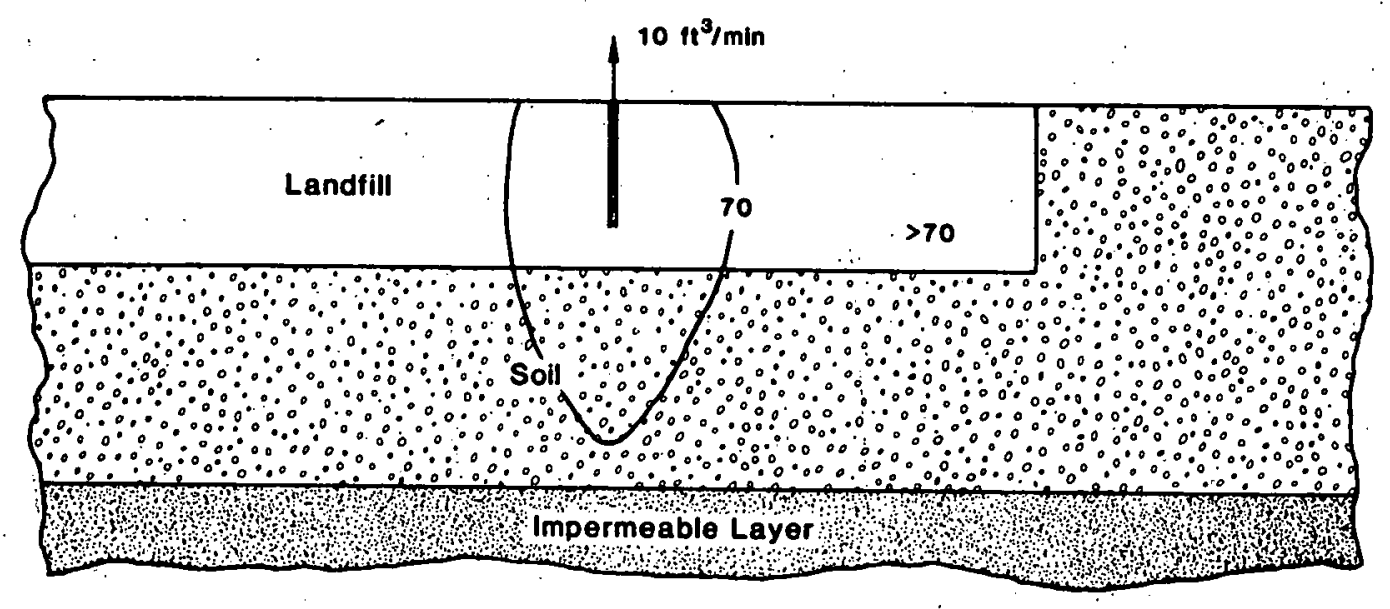

(b) Relative Percentage of Methane

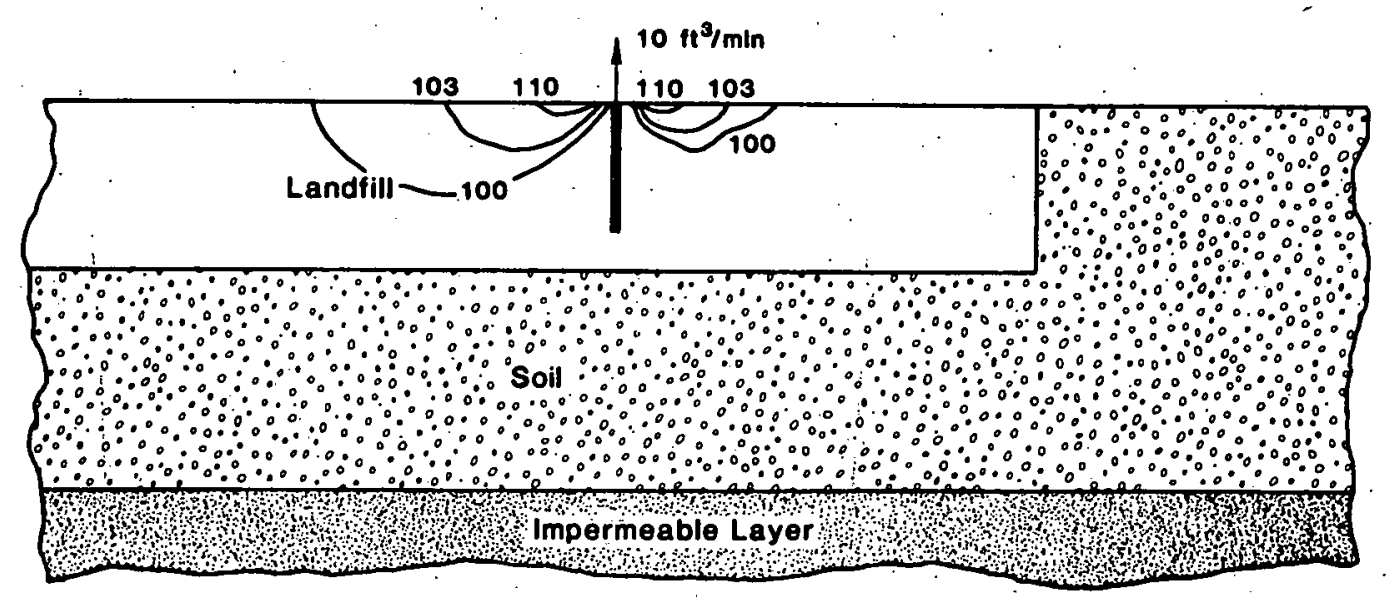

(c) Relative Percentage of Oxygen

Fig. 5.2 Code IV Landfill Simulation, Well 2 (vertical section) 


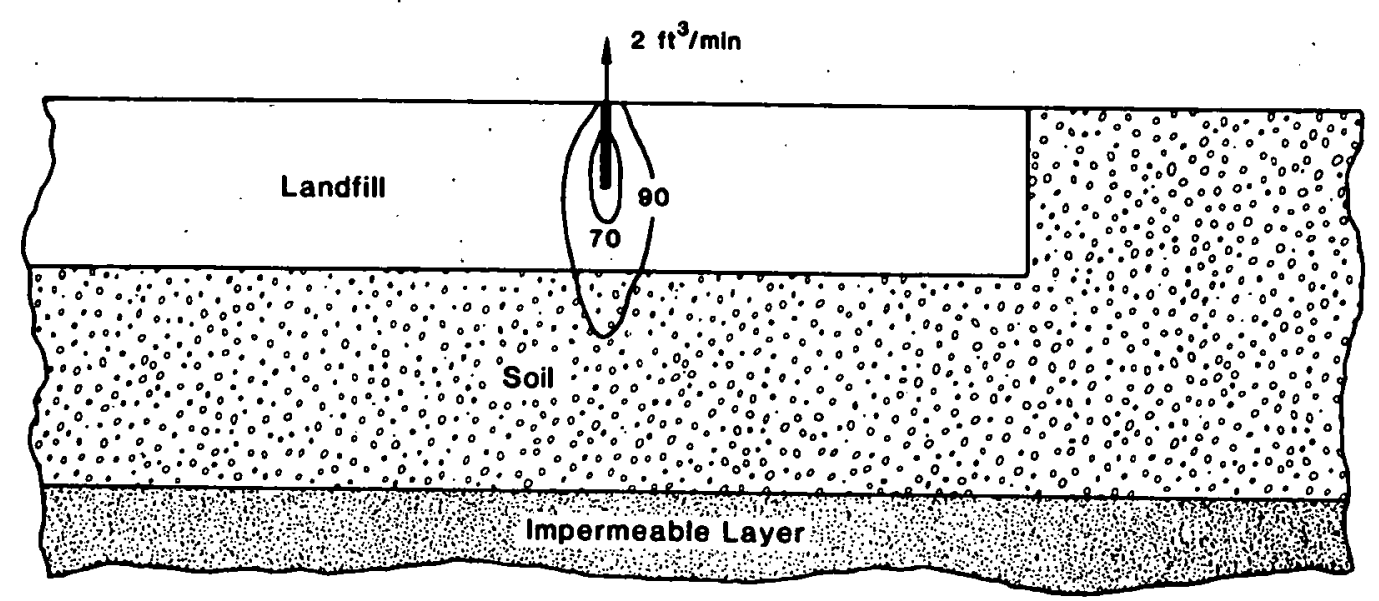

(a) Relative Total Pressure (\%)

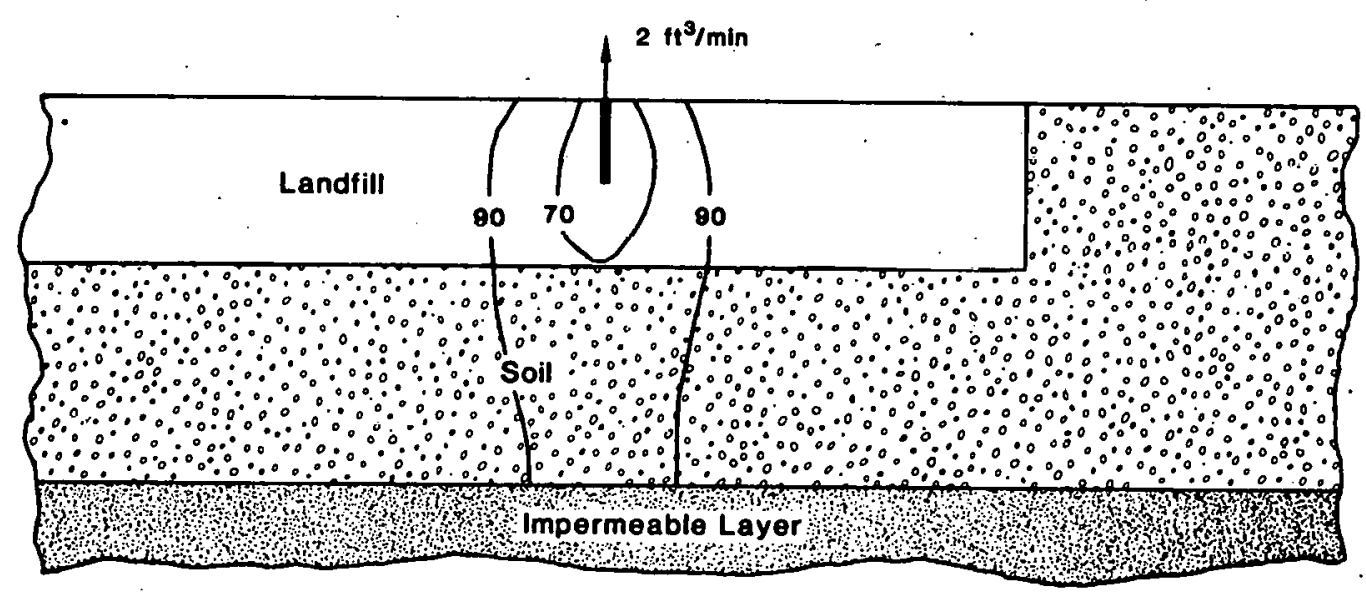

(b) Relative Percentage of Methane

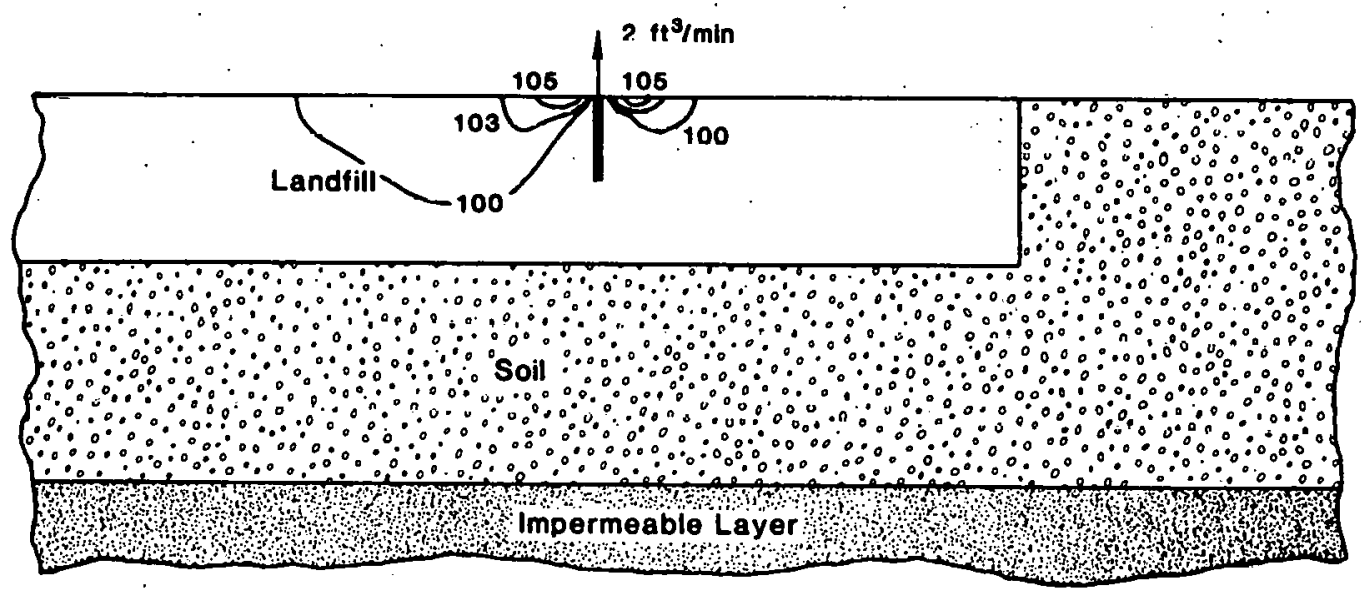

(c) Relative Percentage of Oxygen

Fig. 5.3 Code IV Landfill Simulation, Well 3 (vertical section) 


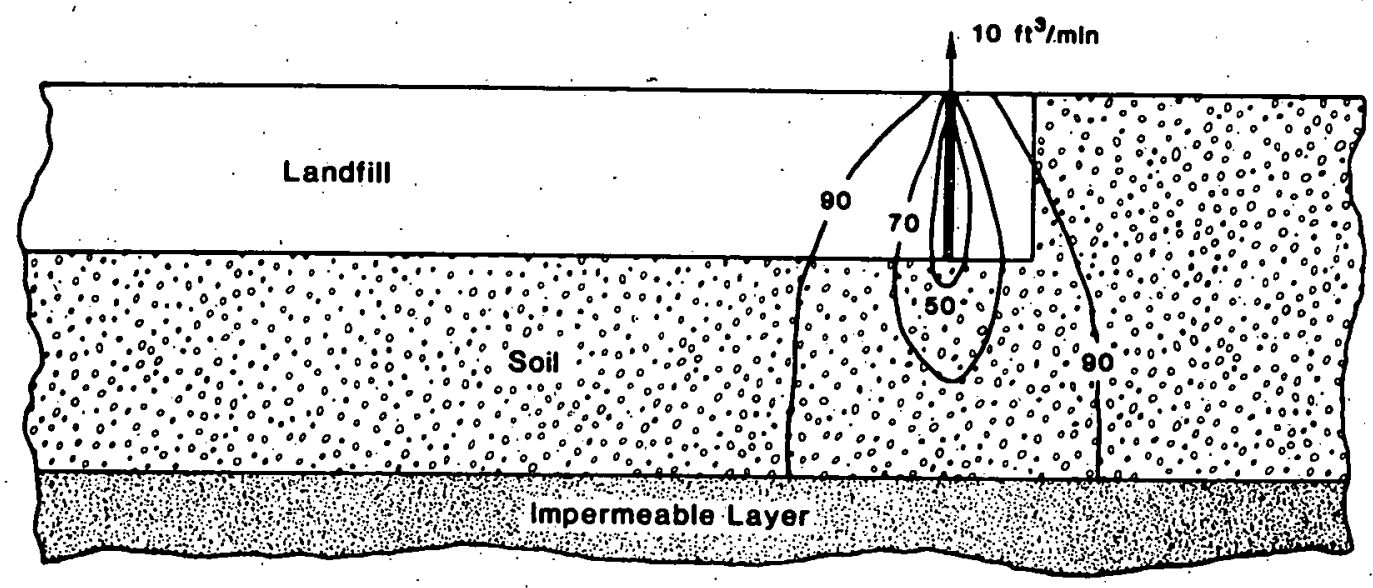

(a) Relative Total Pressure (\%)

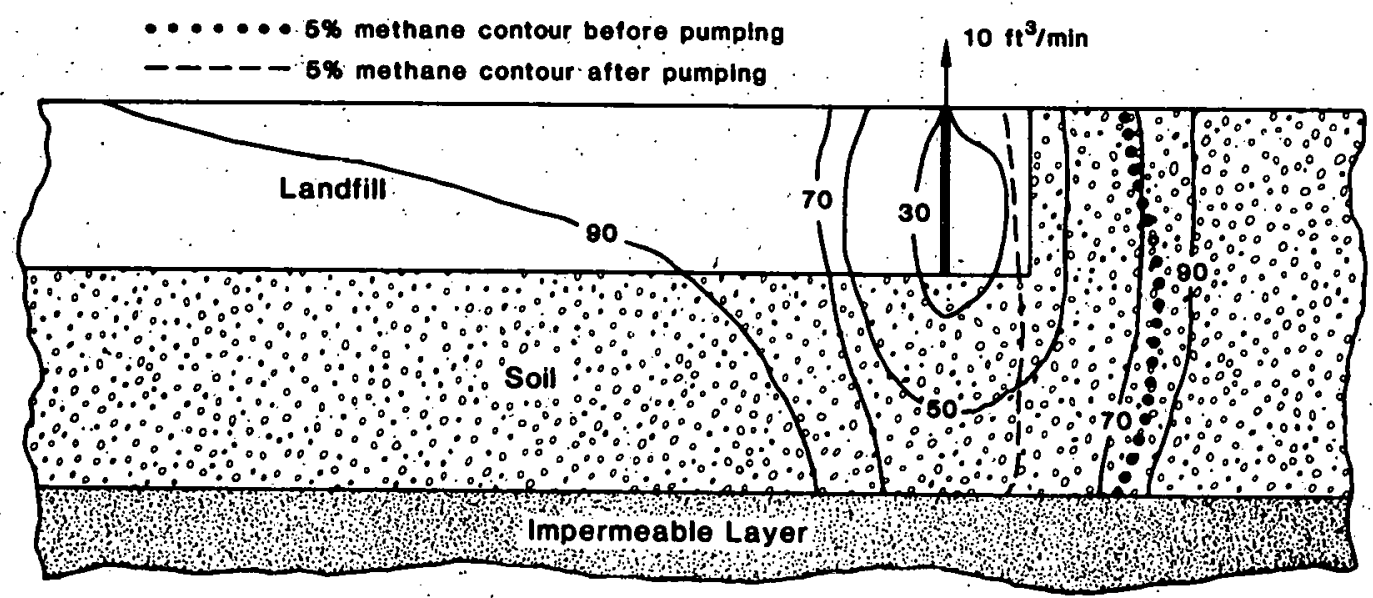

(b) Relative Percentage of Methane

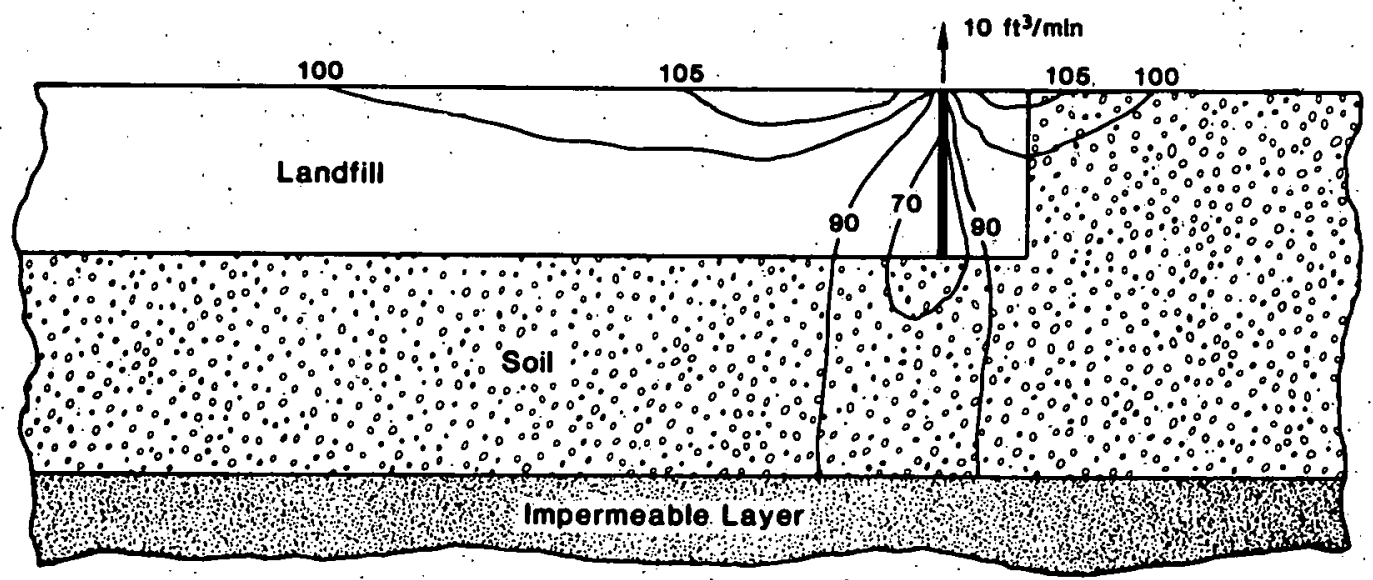

(c) Relative Percentage of Oxygen

Fig. 5.4 Code IV Landfill 'Simulation; Wel1 4 (vertical section) 
Table 5.2 Code IV Data Deck

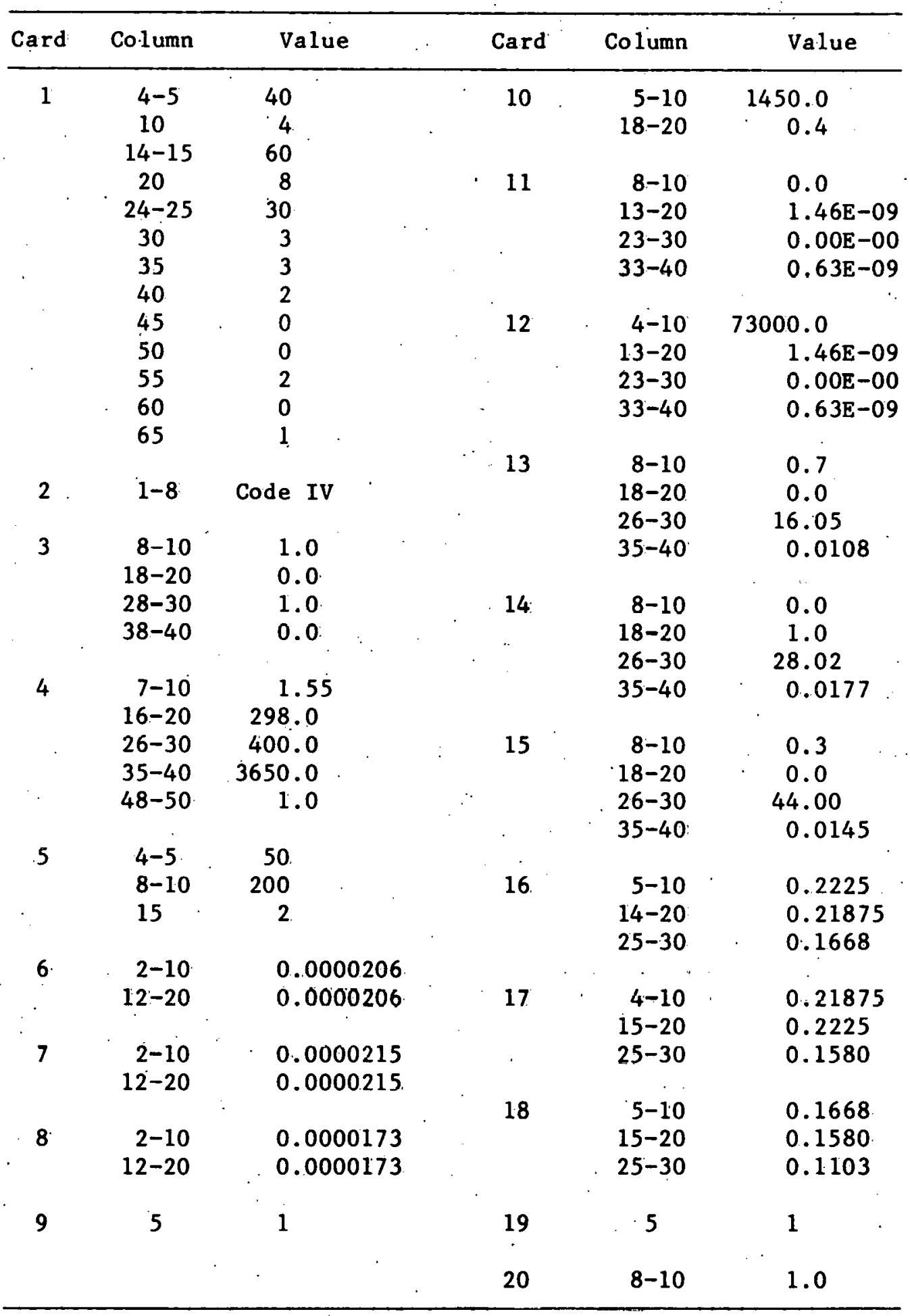


efficient at extracting methane than it is in reducing the total pressure; this is a desirable situation in practice. Figure 5.1c shows the relative percentage of oxygen. The extraction well draws in a limited amount of oxygen from. the surface of the landfill. This process is undesirable because oxygen can quench the anaerobic methane generation processes and thus arrest the production of gas in the landfill.

Figure 5.2 shows the same geometric configuration as Fig. 5.1 but with the pumping rate increased to $10 \mathrm{ft} / \mathrm{min}$. Figure $5.2 \mathrm{a}$ shows the relative total pressure; a large zone of influence extending into the soil beneath the landfill is apparent. Figure 5.2b shows that methane concentrations are reduced over an equally large area. Figure $5.2 \mathrm{c}$. shows that a considerable amount of oxygen is drawn into the landfill surface by this relatively high pumping rate.

Figure 5.3 illustrates an extraction well at the same location as those in Figs. 5.1 and 5.2 , but only half as deep. The pumping rate is $2 \mathrm{ft}^{3} / \mathrm{min}$. This arrangement was chosen as a compromise between the previous two cases with the hope that methane production would be increased. Figure 5.3a shows that the zone of influence with respect to total pressure lies primarily within the landfill. Figure $5.3 \mathrm{~b}$ indicates that methane is being extracted over a large portion of the landfill. Figure $5.3 \mathrm{c}$ shows that a moderate amount of oxygen is being drawn into the landfill surface.

Figure 5.4 shows a configuration that was designed both to recover methane and to control its migration into the soil beyond the 1andfill. In Fig. 5.4a, a total pressure zone of influence extends to a large area around the we11. Figure $5.4 \mathrm{~b}$ shows an equally. large area of reduced methane concentrations; it is evident that a significant reduction in methane migration has been achieved.

\subsection{COMPUTER SIMULATION OF METHANE RECOVERY FOR THE PUENTE HILLS LANDF ILL}

Although studies similar to the one discussed in Sec. 5.1 are valuable in determining the effects of various pump locations, geometries, and extraction rates, actual landfills are seldom as geometrically simple or homogeneous as the hypothetical one used to illustrate code IV. In this section, Code V, modified to accommodate multiple pipe sets and irregular fill geometries, is used to model a landfill with a relatively complex geometry.

Although detailed descriptions of the geometry, soil conditions, gas generation rates, and initial gas concentrations and pressures for the Puente Hills landfill are not presently available, sufficient information to illustrate some of the capabilities of the modified version of code $V$ has been obtained or assumed. A more refined analysis will be possible as more information becomes available.

The Puente Hills landfill (Fig. 5.5) was formed by filling a 2000-ft long canyon that juts into the side of a hill in Whittier, California. The floor of the canyon slopes in a north-south direction from an elevation of 525 $\mathrm{ft}$ at its closed end to $275 \mathrm{ft}$ at the open end. A horizontal cut was made into the canyon walls at elevation $525 \mathrm{ft}$, and approximately $125 \mathrm{ft}$ of $\mathrm{fill}$ 


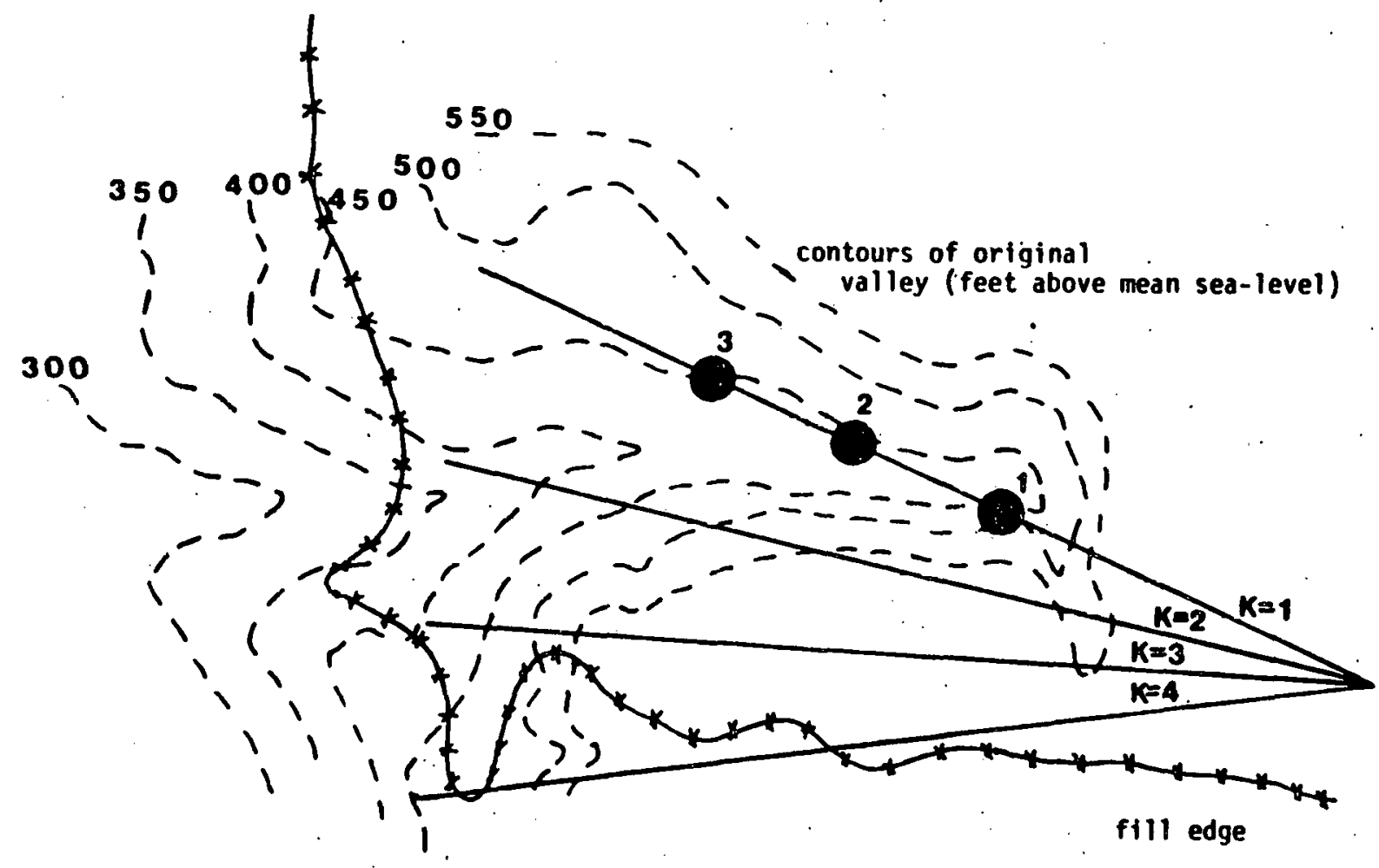

Fig. 5.5 Plan View of Puente Hills Landfill (showing locations of extraction wells and cross sections [K $=1-4]$ used for computer simulation)

were placed onto this cut. The western edge of the fill meets the side of the hill approximately $400 \mathrm{ft}$ from the wall of the canyon, while the eastern edge extends from the canyon for an undesignated but relatively large distance. At the open end of the canyon, the fill has a $2: 1$ slope.

Three wells (Fig. 5.6), each $105 \mathrm{ft}$ deep, have been placed in the fill, and a network of 34 probes surroundo the line of wells. These probes were placed in borings that are also $105 \mathrm{ft}$ in depth.

For the Code V simulation, the landfill was divided into four cross sections (Fig. 5.7), each of which was subdivided by a series of nodes spaced at $8-\mathrm{m}$ intervals.* Gas generation rates, initial concentrations, and total pressures were then assigned to each nodal point. The boundary conditions used were a prescribed convection at the fill top and prescribed concentra$t$ ions at the edge of the fill.

The soil was assumed to have a porosity of 0.4 , a tortuosity of 1.55 , and a pore size of $40,000 \AA$. A surface convection coefficient corresponding to a wind velocity of $5 \mathrm{mph}$ was used. The same generation rates as those used for the hypothetical landfill presented in Sec. 5.1 gave pressures of between

*The vertical scale has been doubled in this and subsequent figures; the landfill is actually much shallower in relationship to its length than depicted. 


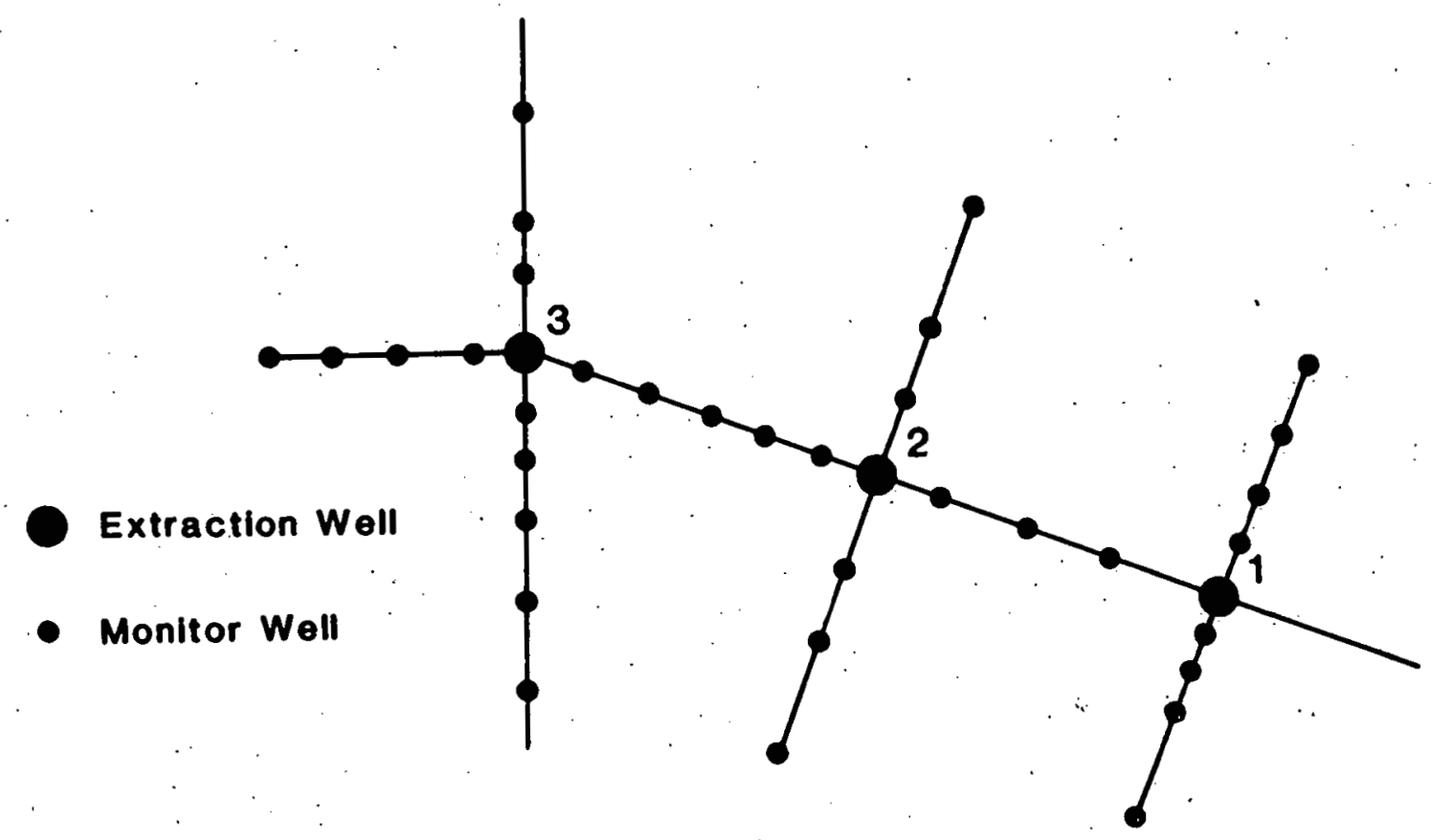

(a) P1 an View

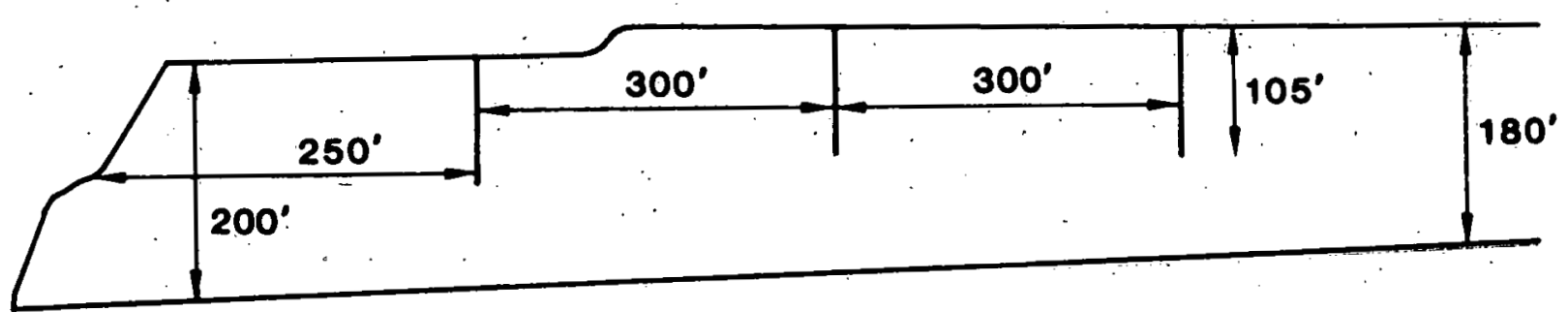

(b) Cross Section

Fig. 5.6 Extraction Wells in Puente Hills Landfill

$1.00 \mathrm{~atm}$ and $1.02 \mathrm{~atm}$, which corresponds to a maximum gauge pressure in the fill of 8.1 in. of water.

The complete input deck used in the Puente Hills simulation is given in Table 5.3.

Figure 5.8 illustrates the $5 \%$ - and $50 \%$-methane contours after 100 days with no pumping at the wells, assuming that the initial methane concentration in the landfill was $7.0 \%$. Figure 5.9 gives pressure contours at We 112 for extraction rates of $20 \mathrm{ft}^{3} / \mathrm{min}, 100 \mathrm{ft} / \mathrm{min}$, and $200 \mathrm{ft}^{3} / \mathrm{min}$ after 10 days of pumping. Comparing the one-inch vacuum contours shows that increasing the extraction rate by a factor of ten has a: relatively small effect upon the size of the sphere of influence. The spheres of influence in Figs. 5.9c and $5.9 \mathrm{e}$ are virtually identical. However, increasing the pumping rate affects the size of the pressure gradients within the sphere of influence. Comparison of the 10-in. contour in Fig. 5.9c with the 20-in. contour in Fig. 5.9e 


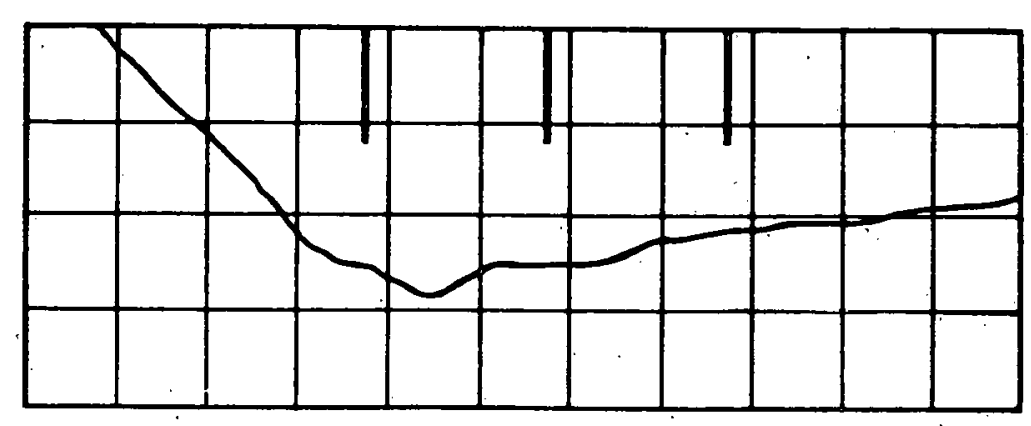

(a) Cross Section 1

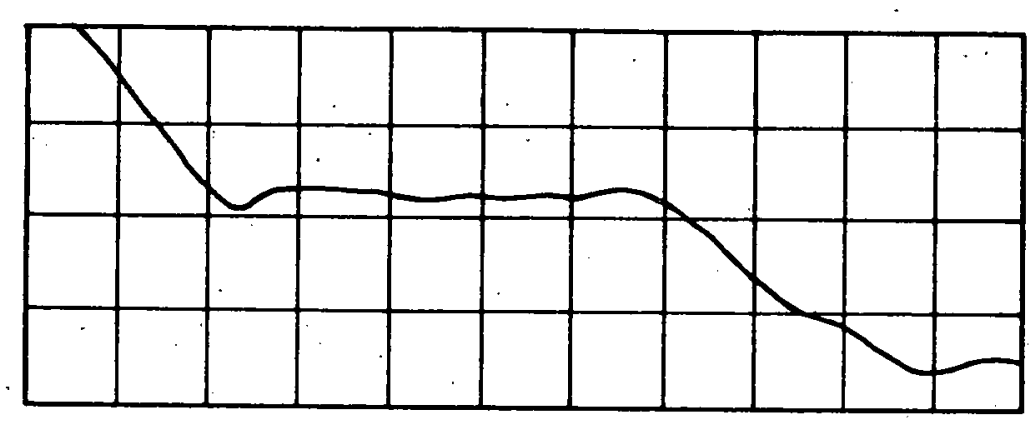

(b) Cross Section 2

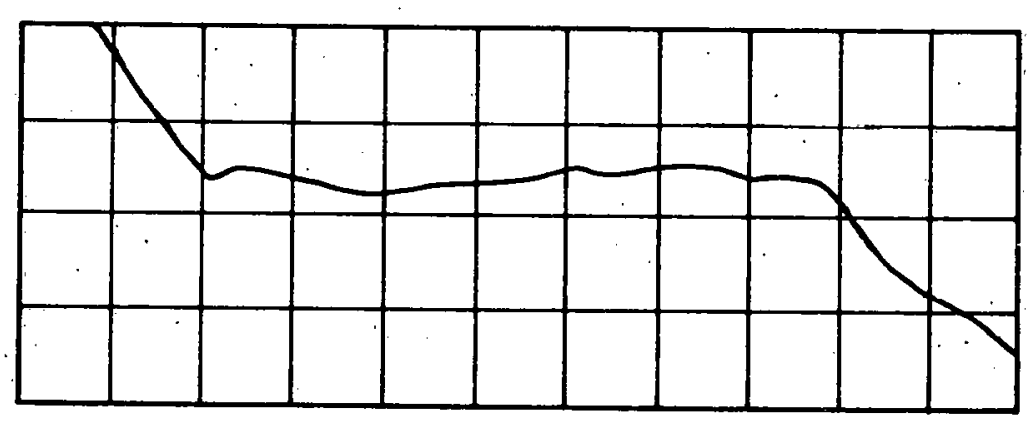

(c) Croos Section 3

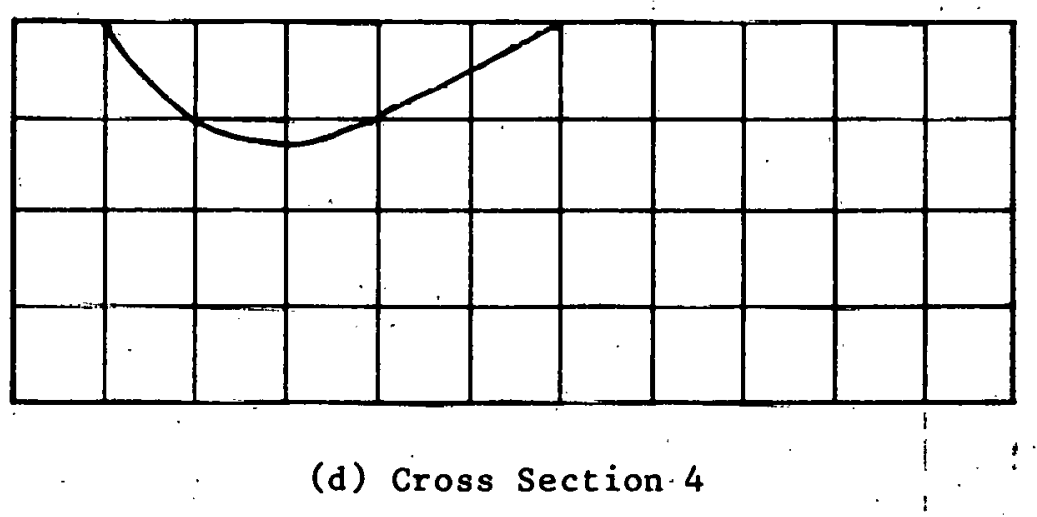

Fig. 5.7 Cross Sections through Landfill 
Table 5.3 Code V Data Deck

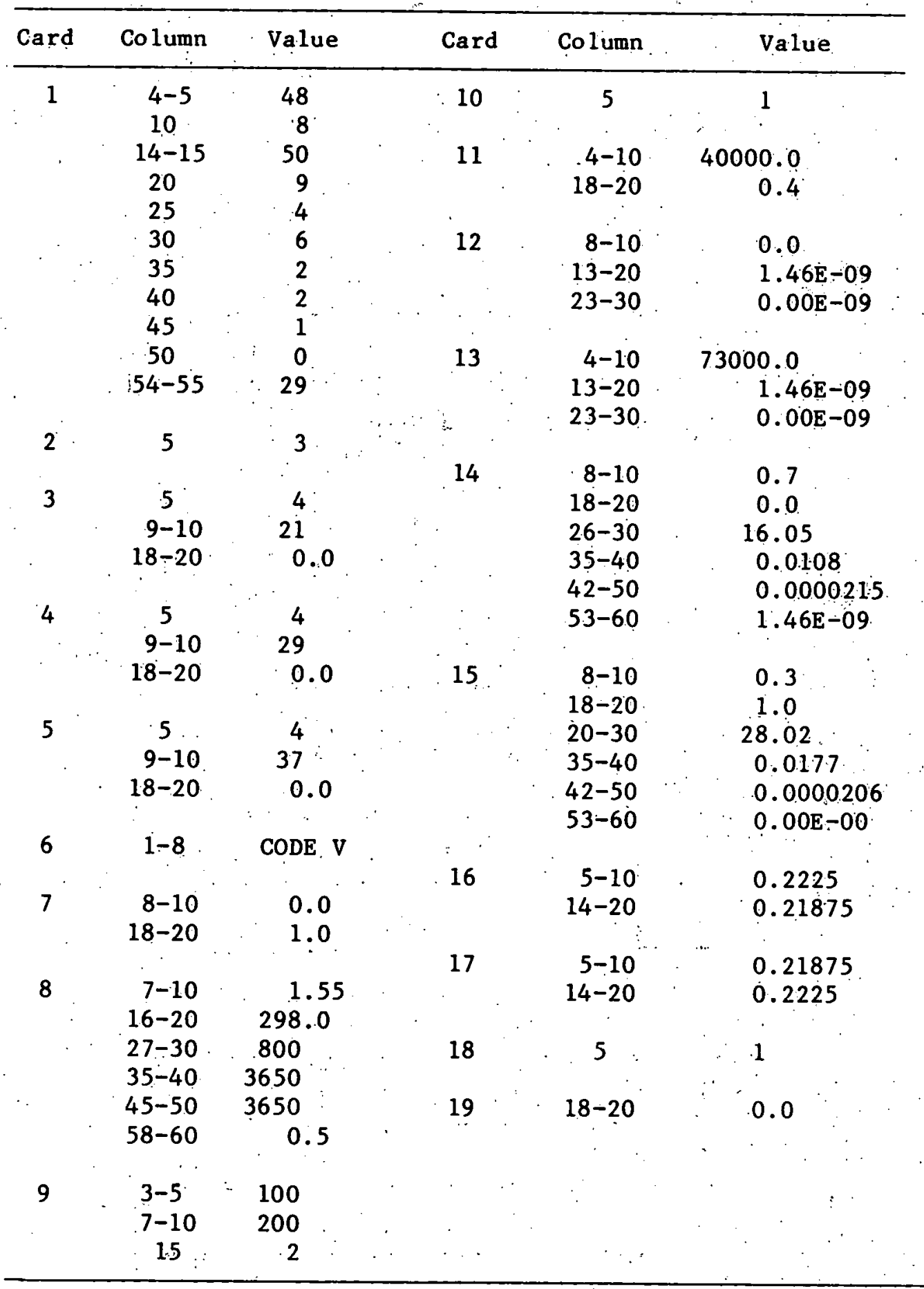




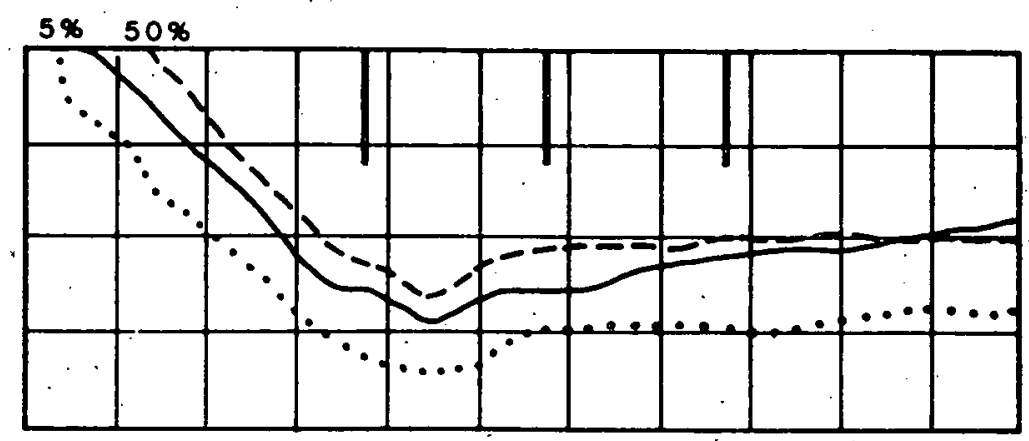

(a) Cross Section 1

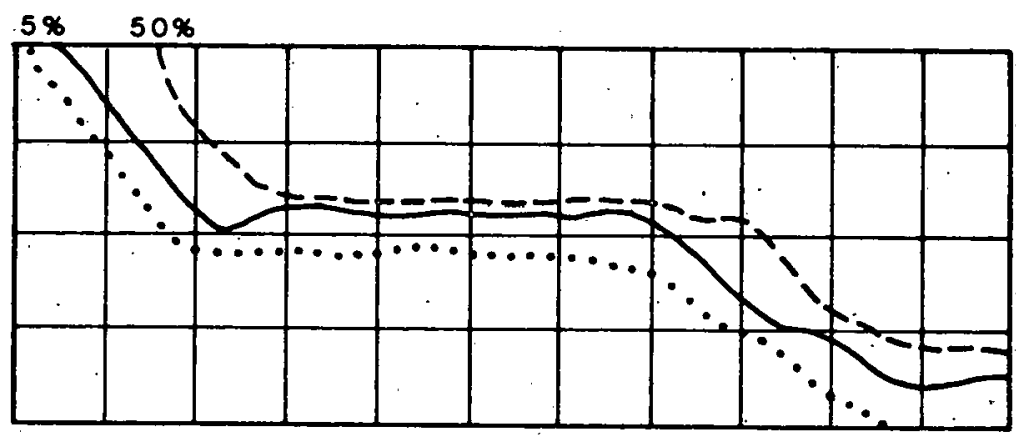

(b) Cross Section 2

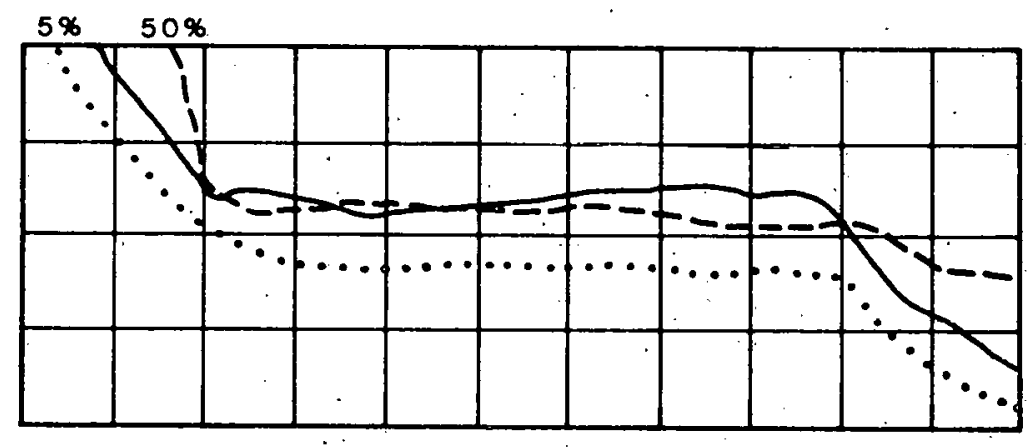

(c) Crose Section 3

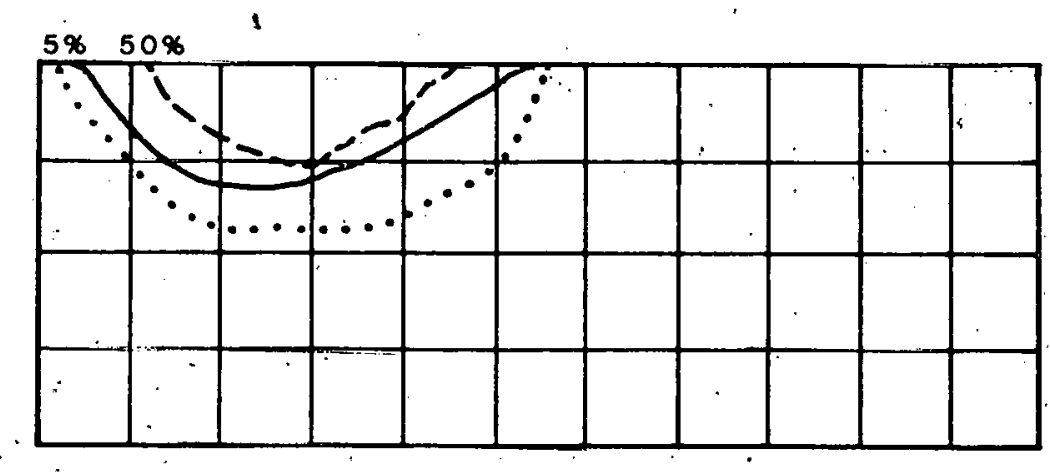

(d) Cross Section 4

Fig. 5.8 Percentage Methane Contours through Cross Sections (for assumed gas generalion rates and without pumping at wells) 


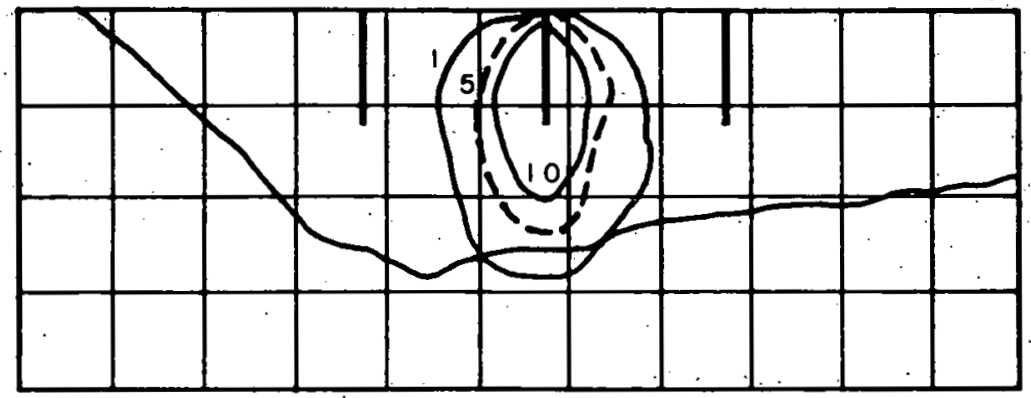

(a) Extraction Rate of $20 \mathrm{ft}^{3} / \mathrm{min}$, Cross Section 1

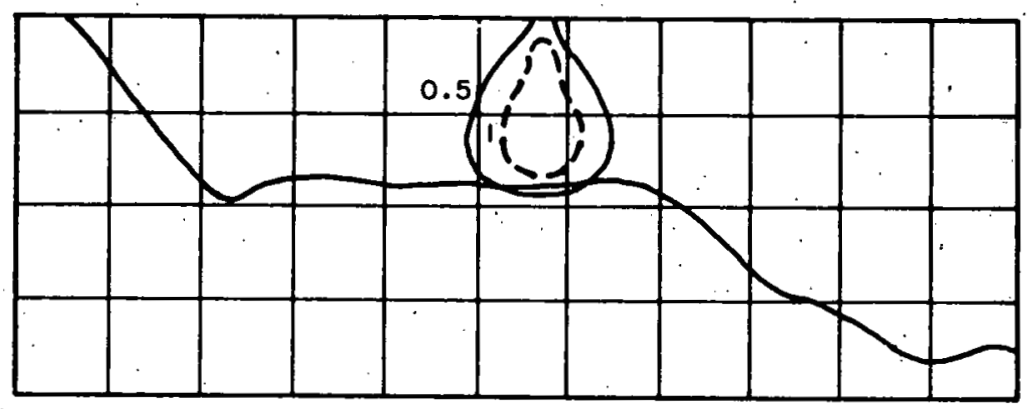

(b) Extraction Rate of $20 \mathrm{ft}^{3} / \mathrm{min}$, Cross Section 2

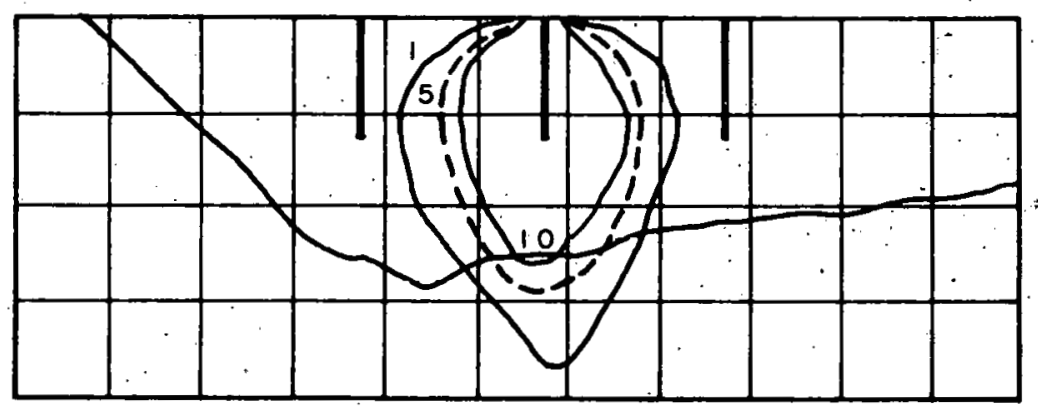

(c) Extraction Rate of $100 \mathrm{ft}^{3} / \mathrm{min}$, Cross Section 1 .

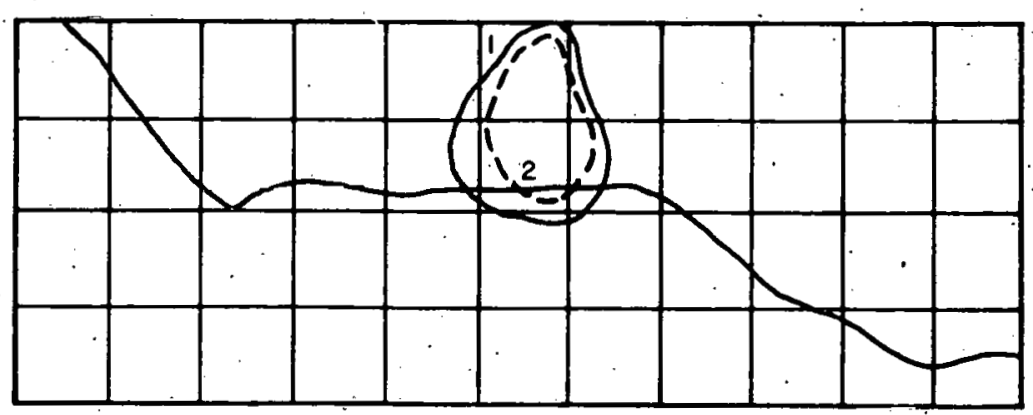

(d) Extraction Rate of $100 \mathrm{ft}^{3} / \mathrm{min}$, Cross Section 2

Fig. 5.9 Vacuum Contours at Well 2 (in. of water, for various extraction rates and cross sections) 


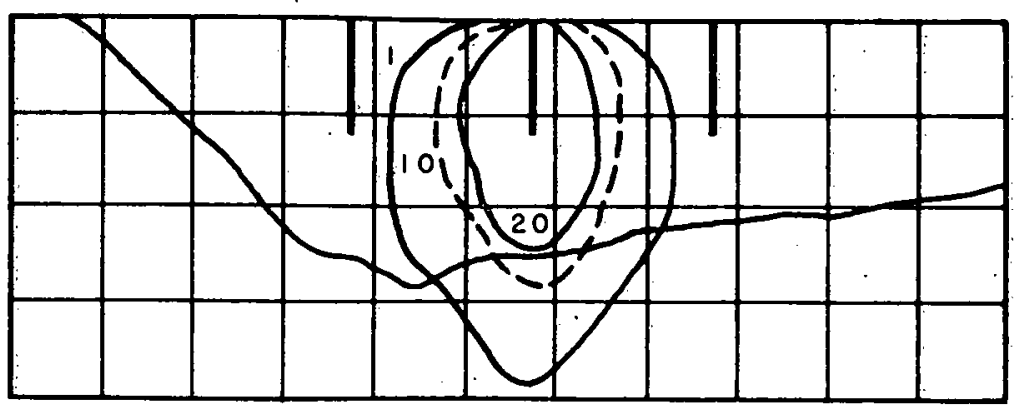

(e) Extraction Rate of $200 \mathrm{ft}^{3} / \mathrm{min}$, Cross Section 1

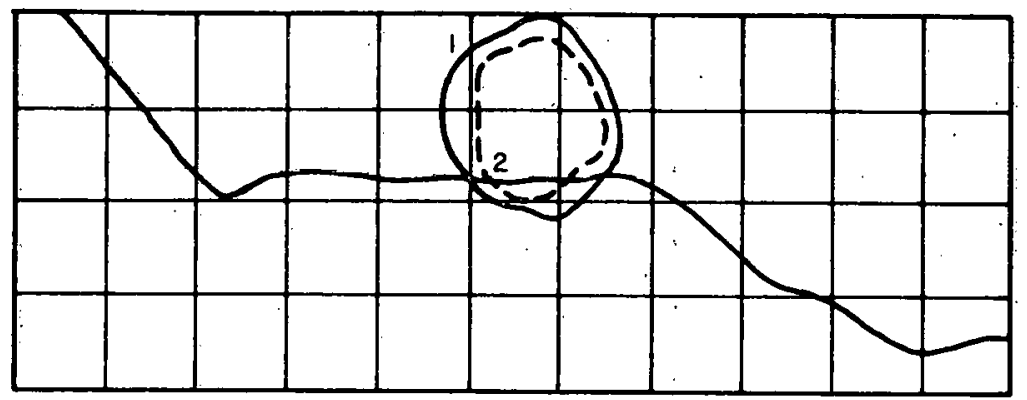

(f) Extraction Rate of $200 \mathrm{ft}^{3} / \mathrm{min}$, Cross Section 2

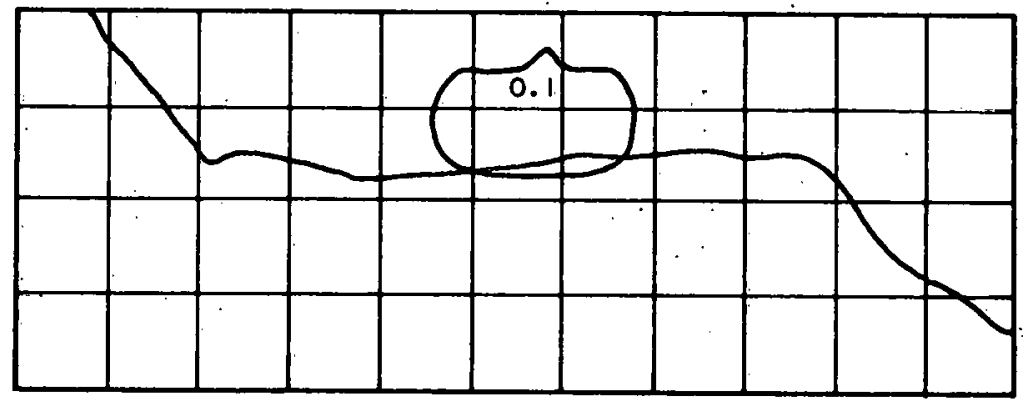

(g) Extraction Rate of $200 \mathrm{ft}^{3} / \mathrm{min}$, Cross Section 3

Fig. 5.9 (Cont'd)

suggests that higher pumping rates will remove the methane in the area of the. well more quickly, but will not substantially increase the net yield.

The relative percentages of methane and oxygen in the fill after 10 days of pumping at rates of $20 \mathrm{ft}^{3} / \mathrm{min}, 100 \mathrm{ft}^{3} / \mathrm{min}$, and $200 \mathrm{ft}^{3} / \mathrm{min}$ are given in Fig. 5.10.* Comparison of Figs. $5.10 \mathrm{c}$ and $5.10 \mathrm{e}$ shows that increasing the pumping rate from $20 \mathrm{ft}^{3} / \mathrm{min}$ to $100 \mathrm{ft}^{3} / \mathrm{min}$ will substantially increase the amount of methane removed after 10 days. However, doubling the rate of extraction from $100 \mathrm{ft}^{3} / \mathrm{min}$ to $200 \mathrm{ft}^{3} / \mathrm{min}$ seems to have only a slight effect

*As in the Code IV simulation study, the term "relative percentage" is defined as the ratio of the concentration with the extraction well operating to that at the same point and time but without the well operating. 


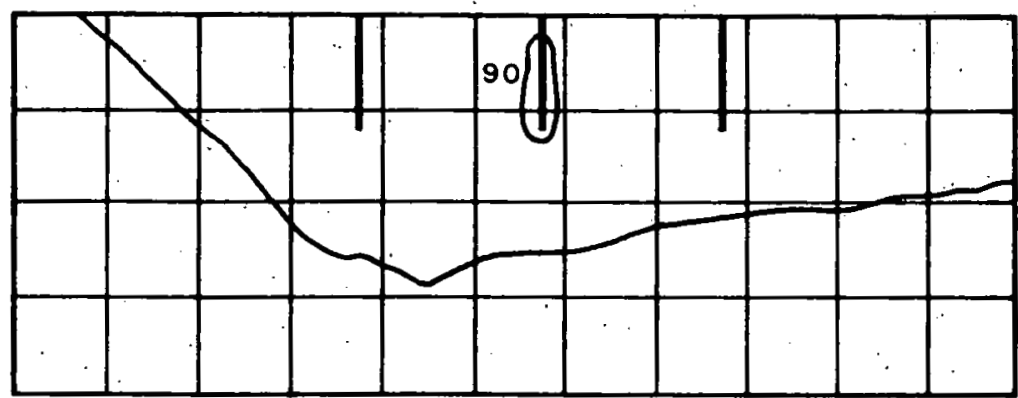

(a) Relative Percentage of Methane at Extraction Rate of $20 . \mathrm{ft}^{3} / \mathrm{min}$

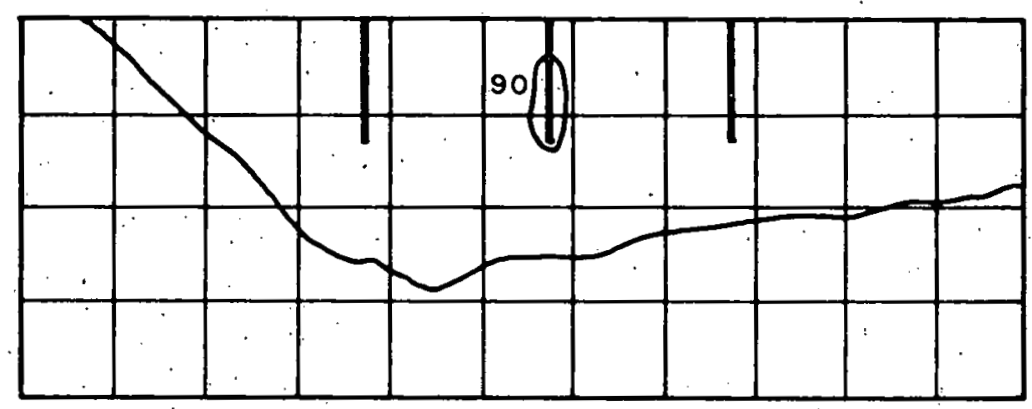

(b) Relative Percentage of Oxygen at Extraction Rate of $20 \mathrm{ft}^{3} / \mathrm{min}$

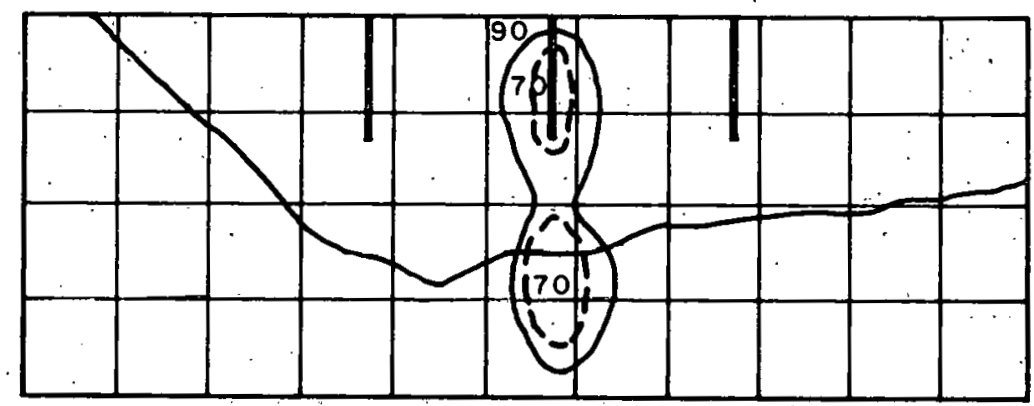

(c) Relative Percentage of Methane at Extraction Rate of $100 \mathrm{ft}^{3} / \mathrm{min}$

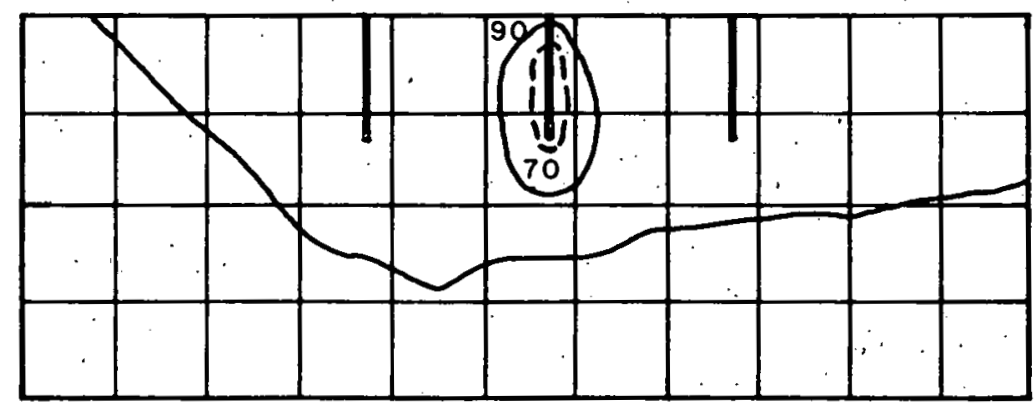

(d) Relative Percentage of Oxygen at Extraction Rate of $100 \mathrm{ft}^{3} / \mathrm{min}$

Fig. 5.10 Relative Percentages of Methane and Oxygen at We11 2,. Cross Section 1, for Various Extraction Rates: 


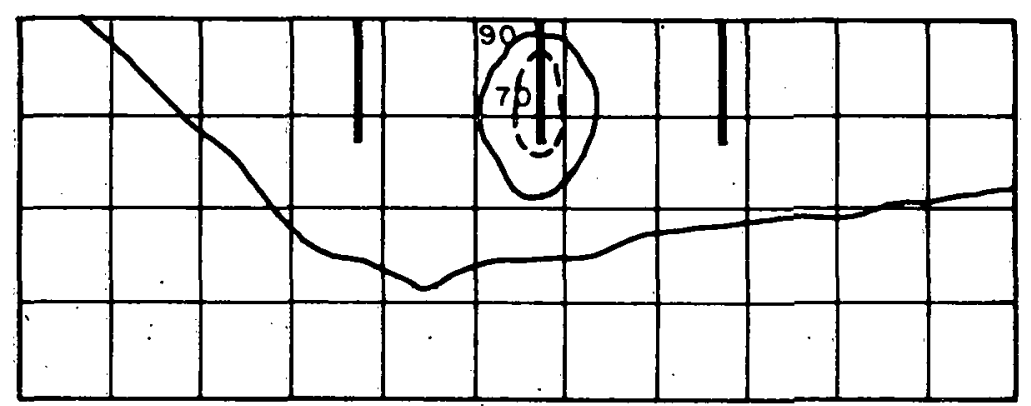

(e) Relative Percentage of Methane at Extraction Rate of $200 \mathrm{ft}^{3} / \mathrm{min}$

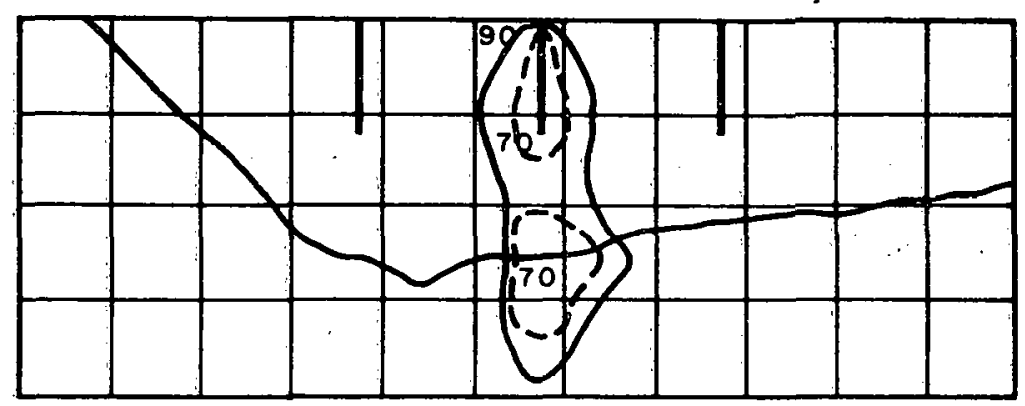

(f) Relative Percentage of Oxygen at Extraction Rate of $200 \mathrm{ft}^{3} / \mathrm{min}$

Fig. 5.10 (Cont'd)

upon the size or shape of the relative percentage contour.s. This is shown by comparing Figs. $5.10 \mathrm{c}$ and $5.10 \mathrm{~d}$ with Figs. $5.10 \mathrm{e}$ and $5.10 \mathrm{~g}$, respectively.

The "figure 8" contours seen in Figs. $5.10 \mathrm{c}$ and $5.10 \mathrm{e}$ initially suggest that methane movement in the vicinity of the wells occurs in "bubbles." This is not the case, however. These shapes are a manifestation of the method of data presentation and can be explained in the following manner.

A relatively eharp gradient. in methane concentration exists at the edge of the fill; outside, the methane concentration is quite low. Pumping rates less than $100 \mathrm{ft}^{3} / \mathrm{min}$ have no appreciable effect in this area after the relatively short pumping time of 10 days. Even for quite large pumping rates $\left(100 \mathrm{ft}^{3} / \mathrm{min}\right.$ and $\left.200 \mathrm{ft}^{3} / \mathrm{min}\right)$, the wells draw in only very small amounts of methane from this area. Even so, because of the low initial concentrations, this small removal of methane represents a rather large change in the relative percentage of methane. This creates an additional lobe in the we $11^{\prime} \mathrm{s}$ area of influence, as presented in terms of relative percentages.

As previously mentioned, a more detailed and refined analysis will be possible when more site-specific information becomes available. While this analysis, based upon assumed landfill properties, may be of limited quantitative value, it exhibits some of the qualitative aspects of various extraction rates. 


\subsection{KINETIC CONTROLS FOR LANDFILI METHANE GENERATION}

\section{1 .1 Microbiology}

The formation of methane gas from organic matter is due to the coupled activities of a variety of bacteria. These bacteria are usually divided into two functional groups: an acidogenic group that produces hydrogen, carbon dioxide, ammonia, hydrogen sulfide, and various volatile fatty acids (VFA) from the organic matter; and a methanogenic group that produces methane from the products of the acidogenic group.

The acidogenic group consists primarily of Gram-negative, nonsporulating, obligately anaerobic bacilli, generally of the family Bacteroidaceae (Kirsh and Sykes, 1971). However, obligately anaerobic members of the family Bacillaceae, especially the clostridium spp., are also common.

The methanogenic bacteria are Gram-negative or -positive rods, cocci, sarcina, or spinula, non-sporulating, and obligately anaerobic (Zeikus, 1977). Despite the wide variety in species characteristics; all the species are collected into a single family, the Methanobacteriaceae (Buchanan and Gibbons, 1974). This is justified by the biochemical unity of the group (Ferry and Wolfe, 1977). The species generally recognized include (Buchanan and Gibbons, 1974; Zeikus, '1977) the following:

- Methanobacterium formicum,

- Methanobacterium mobile,

- Methanobacterium ruminantium,

- Methanobacterium thermoautotrophicum,

- Methaosarcina barkeri, and

- Methanococcus vanniellii.

Other species have also been reported in the literature. However, they are not generally recognized because the type cultures have been lost, the available cultures have not been purified, or the species has not yet been approved by the Judicial Commission of the International Committee on systematic Bacteriology.

\subsubsection{Biochemistry}

While the acidogenic bacteria can produce a wide variety of metabolic products, those used by the methanogenic bacteria are limited to hydrogen, carbon dioxide, formic acid, and, perhaps, methanol and acetic acid (Mah et a.1., 1977; Zeikus, 1977).

Hydrogen gas is a common product of anaerobic fermentation. Bacteria that make it are able to accomplish a more complete "oxidation" of their organic substrates and thereby obtain more energy from them (as adenosine 
triphosphate, ATP). There are two basic ways to form hydrogen, the so-called "clostridial" and "coliform" systems (Gray and Gest, 1965). In the former system, pyruvic acid is oxidized to acetic acid, carbon dioxide and hydrogen. The oxidations occur with the pyruvate bound to the coenzyme thiamine pyrophosphate, and the electrons are transferred to hydrogen via ferrodoxin and hydrogenase. In the latter system, the electrons attached to ferrodoxin are first used to reduce biotin-bound carbon dioxide to formic acid. The formic acid is then oxidized to carbon dioxide and hydrogen by the hydrogenase enzyme. Both systems are inhibited by accumulated hydrogen, and this inhibition forces the bacteria to revert to non-hydrogen-forming fermentations, such as the homolactic.

All the methanogenic bacteria can reproduce autotrophically using carbon dioxide as the sole carbon source and obtaining energy from the reaction of hydrogen and carbon dioxide (Mah et al., 1977; Zeikus, 1977). In these cases, methane is a product of the energy metabolism of the microbes (Zeikus, 1977):

$$
\begin{aligned}
4 \mathrm{H}_{2}+\mathrm{HCO}_{3}^{-}+\mathrm{H}^{+} & =\mathrm{CH}_{4}+3 \mathrm{H}_{2} \mathrm{O} \\
\mathrm{G} & =-33 \mathrm{Kcal}
\end{aligned}
$$

Methanosarcina sarcina is the only methanogen believed to produce methane from acetate in pure culture (Mah et al., 1977). Radio tracer studies indicate that the methyl moiety of the acetate is converted intact directly to methane, but the conversion is very slow and may require hydrogen (Mah, Smith, and Baresi, 1978; Zeikus, 1977). The energy yield is smal1, which may explain the slow rate of conversion (Zeikus, 1977):

$$
\begin{aligned}
\mathrm{CH}_{3} \mathrm{COO}^{-}+\mathrm{H}^{+} & =\mathrm{CH}_{4}+\mathrm{CO}_{2} \\
\mathrm{G} & =-8.6 \mathrm{Kcal}
\end{aligned}
$$

\subsection{UNINHIBITED KINETICS}

It is generally helieved that the methanogenic bacteria reproduce much more slowly than the acidogenic bacteria, so that the overall kinetics of methane formation are those of the methanogens. Simple mass balances on any arbitrary culture configuration yield the following equations (Kirsch and Sykes, 1971):

$$
\begin{gathered}
\mu=\theta_{c}^{-1}+k_{d} \\
\dot{X} \theta_{h}=\frac{Y \theta_{c}\left(S_{i}-S_{e}\right)}{1+K_{d} \theta_{c}}
\end{gathered}
$$


where:

$$
\begin{aligned}
& \mu=\text { the specific reproduction rate of the methanogens (per } \\
& \text { day), } \\
& { }^{\theta_{h}}=\text { the hydraulic detention time of the culture vessel (days), } \\
& \mathrm{K}_{\mathrm{d}}=\text { the specific decay rate of the methanogens (per day), } \\
& X=\text { the concentration of the methanogens in the culture vessel } \\
& \text { - }\left(g \text { cells } / \mathrm{m}^{3}\right) \text {, } \\
& Y=\text { the growth yield of the methanogens ( } g \text { cells/g substrate), } \\
& \theta_{c}=\text { the cell retention time (days), } \\
& S_{i}=\text { the concentration of substrate in the influent flow } \\
& \text { (g substrate } / \mathrm{m}^{3} \text { ), and } \\
& S_{e}=\text { the concentration of substrate in the culture vessel } \\
& \text { effluent ( } g \text { substrate } / \mathrm{m}^{3} \text { ). }
\end{aligned}
$$

The specific reproduction rate is thought to be, among other variables, a function of the ambient substrate concentration:

$$
\mu=\frac{\mu_{m} S_{e}}{K+S_{e}}
$$

where:

$$
\begin{aligned}
& \mu_{\mathrm{m}}= \text { the maximum specific reproduction rate of the } \\
& \text { methanogens (per day), and } \\
&\left.\mathrm{K}=\text { the Monod half-velocity constant ( } \mathrm{g} \text { substrate } / \mathrm{m}^{3}\right) \text {. }
\end{aligned}
$$

Some empirical determinations of the various parameters in these equations are cited in Table 6.1. It is presumed that no inhibitors were present in these experiments. It should be noted that $k_{d}$ for growth on hydrogen plus carbon dioxide has the wrong sign.

\subsection{ENVIRONMENTAL EFFECTS}

The literature indicates that the dominant environmental variables affecting landfill methane production are moisture, oxygen, temperature, and nutrients.

\subsubsection{Moisture}

Interregional comparisons of landfills and lysimeter studies indicate that gas and leachate generation rates are strongly influenced by the amount of water in the landfill (DeWalle and Chian, 1978; Eliassen, 1942; Farquhar and Rovers, 1973; Leckie, Pacey, and Halvadakis, 1979; Rovers and Farquhar; 1973). The required moisture content for optimum methane production appears to be about $50-100 \%$ of the dry weight of the waste. Moisture levels much above field capacity cause increased leachate production. 
These observations are consistent with the known effects of drying upon bacterial survival (Pirt, 1975). Bacterial growth rates are influenced by the activity of water in the growth medium, because water activity affects the energy required to transport nutrients into the bacterial cell. The optimum water activity for bacterial growth is about 0.95 to 0.98 (dimensionless), and maximum specific reproduction rates decrease linearly and rapidly as the water activity decreases below that level.

The water activity in any system is equal. to the relative humidity of the gas phase. Thus, the effects of moisture upon bacterial growth can be approximated by a function of the following form:

$$
\mu_{m}=\mu_{m o}\left[1-K_{h}\left(H_{0}-H\right)\right]
$$

where:

$$
\begin{aligned}
\mu_{\mathrm{mo}}= & \text { the maximum specific } \\
& \text { reproduction rate under } \\
& \text { optimum conditions (per day), } \\
\mathrm{K}_{\mathrm{h}}= & \text { an empirical coefficient (reciprocal percent humidity), } \\
\mathrm{H}_{\mathrm{O}}= & \text { the optimum relative humidity (percent), and } \\
\mathrm{H}= & \text { the ambient relative humidity (percent). }
\end{aligned}
$$

ashea et al., 1968.

bawrence and McCarty, 1967.

cPer day.

$\mathrm{d}_{\mathrm{mm} \mathrm{Hg}}$ of $\mathrm{H}$.

$e_{\mathrm{mg}}$ acetate/L.

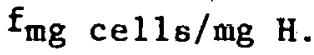

$g_{\mathrm{mg}}$ cells/mg acetate.

Landfill humidity can be affected by gas pumping. In some cases, high gas pumping rates may dry the fill and inhibit methane formation. Therefore, any valid kinetic model of methane formation must include subroutines for landfill moisture and temperature so that the relative humidity of the fill can be predicted.

\subsubsection{Oxygen and Temperature}

The available evidence indicates that newly placed solid wastes decompose aerobically as long as oxygen is available (Fungaroli and Steiner, 1971; Rovers and Farquhar, 1973), and that during the aerobic phase the fill may attain temperatures as high as $60^{\circ}$ to $80^{\circ} \mathrm{C}$ (E1iassen, 1942; Farquhar and Rovers, 1973; Fungaroli and Steiner, 1971). During this initial phase; no methane and little leachate are formed.

Oxygen is known to be very poisonous to acidogenic and methanogenic bacteria, but the cuncentration at which its toxic effects begin has not been established (Kirsch and Sykes, 1971). However, daca from landfill and: 
lysimeter studies suggest the toxic effects of oxygen begin around a few percent oxygen by volume in the gas phase (anon., 1969; Farquhar and Rovers, 1973; Fungaroli and Steiner, 1971; Rovers and Farquhar, 1973).

The optimum temperature for methane production is known to be about $35^{\circ}$ to $40^{\circ} \mathrm{C}$, but high rates of methane formation occur at temperatures as high as $55^{\circ}$ to $60^{\circ} \mathrm{C}$ (Miorin et al., 1977; Pfeffer, 1974; van den Berg, 1977). This suggests that the temperatures at tained during the aerobic phase may be inhibitory. On the other hand, in the older, deeper regions of the fill, the temperature is likely to be controlled by the surrounding soil and water. Deep ground temperatures in the northern states are usually less than $15^{\circ}$ to $20^{\circ} \mathrm{C}$, so methane production in the deeper, older regions may be temperature1 imited.

There are no formulae in the literature for the relationships among landfill gas production, oxygen, and temperature. However, arguing by analogy with other biological. processes, the following formulae may be suggested:

$$
\begin{aligned}
& \mu_{m}=\mu_{m o} \frac{\dot{K}}{K_{0}+P_{0}} \\
& \mu_{m}=\mu_{m o} \theta^{T-35}
\end{aligned}
$$

where:

$$
\begin{aligned}
\mathrm{K}_{\mathrm{O}} & =\text { an empirical constant (atm of } \mathrm{O}_{2} \text { ), } \\
\mathrm{P}_{\mathrm{O}} & =\text { the partial pressure of oxygen (atm), and } \\
\theta & =\text { an empirical constant. }
\end{aligned}
$$

Excessive gas pumping will draw atmospheric oxygen into the fill. This will quench methane production in two ways: (1) by the intrinsic toxicity of oxygen to the methanogens and acidogens, and (2) by the increased temperature due to aerobic decay. The oxygen entering the fill may also react with the methane present, causing fires and explosions.

\subsubsection{Nutrients}

The materials placed in landfills usually contain large amounts of carbon (about 40-50\%) and small amounts of nitrogen (1ess than $1 \%$ ) and other nutrients (Golueke and McGauhey, 1967). The optimum level of nitrogen in the feed of anaerobic digesters is $5-10 \%$ by weight (Sanders and Bloodgood, 1965; Sievers and Brune, 1978). This nitrogen must be converted to ammonia before the methanogens can use it (Bryant et al., 1971). The methanogenic bacteria are also known to have rather high iron requirements (Hoban and van den Berg, 1979; Patel, Khan, and Roth, 1978; Taylor and Pirt, 1977). High concentrations of other minerals may also be required (Mah, Smith and Baresi, 1978).. The mineral requirements reported in these recent studies are so $h$ igh that it is likely that the early kinetic studies on methanogens employed iron-limited cultures. 
Nutrient deficiencies can be made good either by nutrient additions to the solid wastes or by leachate recycling. Leachate recycling systems may be required to prevent groundwater contamination anyway, so the latter option may be the preferred solution to nutrient deficiencies. However, there is no evidence that landfill gas production is limited by nutrient deficiencies.

\subsection{ANALYTICAL REPRESENTATION OF' GAS GENERATION RATE}

Moisture, oxygen, and temperature are the most easily controlled landfill variables. They may be manipulated by adjustments to infiltration, gas recovery, and leachate recycling. For both infiltration and gas pumping there are intermediate levels that are optimum: water and gas fluxes that are substantially different from these optima lead to lowered gas generation rates.

The available literature suggests that landfill gas production is most sensitive to moisture and oxygen. Leachate analyses show acetic acid levels that are too high to be kinetically limiting, and these acid concentrations may be controllable via moisture and oxygen. Therefore, as a first approximation, the rate of methane production is taken to be proportional to each of the corrections indicated above for moisture, oxygen, and temperature, i.e.,

$$
r=r_{\mathrm{mo}}\left[1-\mathrm{K}_{\mathrm{h}}\left(\mathrm{H}_{\mathrm{o}}-\mathrm{H}\right)\right]\left(\frac{\mathrm{K}_{\mathrm{o}}}{\mathrm{K}_{\mathrm{o}}+\mathrm{P}_{\mathrm{o}}}\right) \theta^{\mathrm{T}-35}
$$

where:

$$
\begin{aligned}
r= & \text { the observed rate of methane production }\left(\mathrm{m}^{3} \mathrm{cH} / \mathrm{m}^{3}\right. \\
& \mathrm{fill} / \mathrm{day}) \text {, and } \\
\mathrm{r}_{\mathrm{mo}}= & \text { the maximum rate of methane production under optimum } \\
& \text { conditions }\left(\mathrm{m}^{3} \mathrm{CH} / \mathrm{m}^{3} \mathrm{fill} / \mathrm{day}\right) .
\end{aligned}
$$


7 CONCLUSIONS AND RECOMMENDATIONS FOR FURTHER WORK

Computer simulation offers -an economical and effective way to examine alternatives in the design and operation of methane recovery installations at landfills. By providing a means for predicting oxygen draw that might detrimentally affect methane production, the approach described in this paper should result in considerable financial savings in field operations.

\subsection{DEVELOPMENT OF INTERACTIVE GRAPHICS CAPABILITIES}

In the Puente Hills site study, as more realistic geometries were incorporated into the computer program, the generation of input data cards occupied an increasingly large proportion of the total project $t$ ime. It was felt that, for computer-assisted design and operation to have a significant impact on landfill methane recovery, the computer programs would have to be made available in a more user-oriented format.

Therefore, . an interactive graphics alternative was proposed to allow the user considerable flexibility in providing input to the program. In addition, it would format program output in a much more useful way than possible under previous batch modes of operation.

Preliminary work was undertaken on a Tektronix 4014 computer interactive graphics terminal to investigate the feasibility of this approach. A typical result is shown in Fig. 7.1, which illustrates where the methane concentration exceeds $5 \%$ around a hypothetical landfill. However, the 4014 has serious limitations. First, the device has essentially no local intelligence and thus depends entirely upon the host machine for its computational power. Because much of the conditioning of input and output data can be done with a small amount of intelligence, the use of host machine time for such simple tasks is highly inefficient.

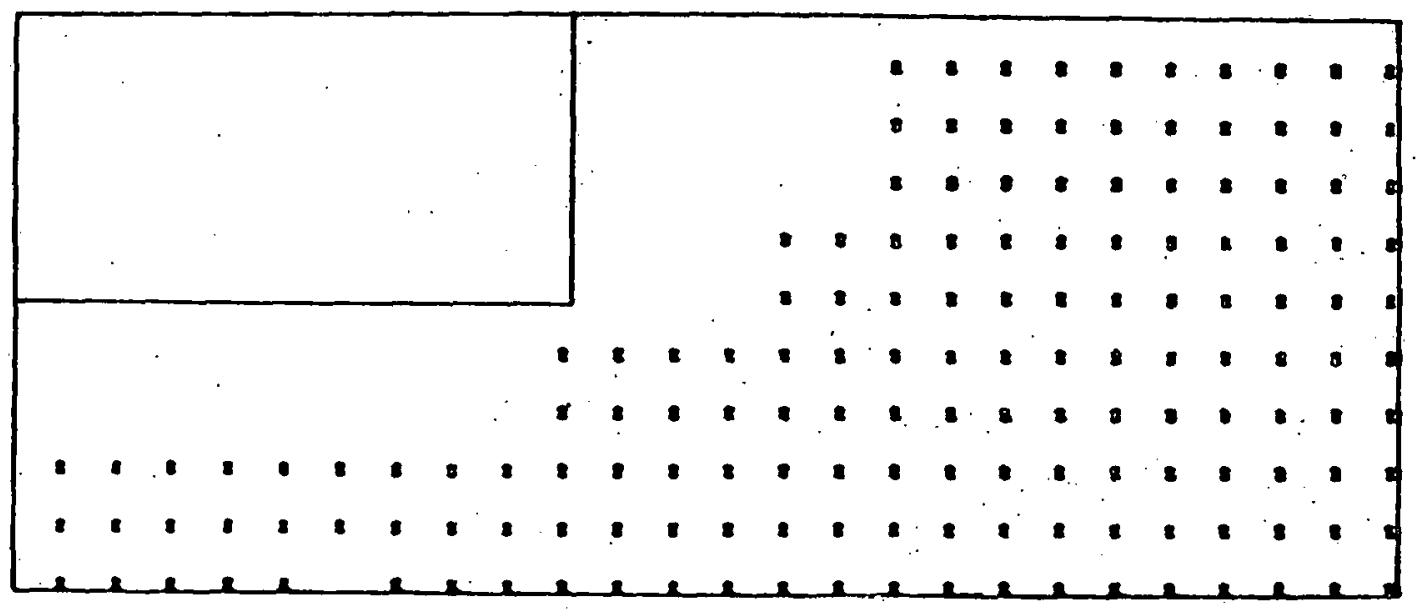

Fig. 7.1 Sample Output from Computer Graphics Terminal (showing area where methane concentration exceeds $5 \%$ ) 
The second limitation of the 4014 for the present: study is its lack of dynamic graphics capability. Such a capability is important because it would permit proposed design configurations to be modified quite easily. For example, the designer: may: want: to use a specific configuration for methane recovery wells; the number and locations of the wells could be optimized by the computer. Dynamic graphics capability facilitates moving and adding weils: quickly and avoids the necessity of inputting large amounts of data for each we11. Based: on the success of the preliminary studies with the 4014, a proposal was submitted for the purchase of a Tektronix 4054 dynamic graphics terminal with expanded local intelligence.

\subsection{DEVELOPMENT: OF HYBRID NUMERICAL METHODS TO TREAT EXTRACTION WELLS.}

Additional recommendations for further work include expansion of the computer programs to more realistically simulate important details of the field configurations for methane recovery systems.. Because of the: complexity of the well configurations in commercial recovery systems, the computer programs must be modified to achieve: more effective resolution in specifying the geometry at the well point. This, in turn, requires that the basic numerical methods employed in the programs be modified to introduce hybrid solution elements in the vicinity of the wells. Although the hybrid approach is conceptually borrowed from finite element techniques, it. retains the structural simplicity of the finite difference formulation. 


\section{REFERENCES}

\section{Literature Cited on Gas Transport}

Alzaydi, A.A., Flow of Gases through Porous Media, Ph.D. dissertation, Ohio State University, University Microfilms, No: 76-3367, Ann Arbor, Mich. (1975).

Alzaydi, A.A., C.A. Moore, and I.S. Rai, Combined Pressure and Diffusional Transition Region Flow of Gases in Porous Media, American Institute of Chemical Engineering J. 24(1). (Jan. 1978).

Bird, R.B., W.E. Stewart, and E. Lightfoot, Transport Phenomena, John Wiley and Sons, Inc., p. 780, New York (1960).

Brakat, H.Z., and J.A. C1ark, On the Solution of the Diffusion Equation by Numerical Methods, J. of Heat Transfer, Trans. ASME, Series C, 88:421-427 (1966).

Brian, P.L.T., A Finite Difference Method of Higher Order Accuracy for the Solution of. Three-Dimensional Transient Heat Conduction Problems, American Institute of Chemical Engineering J., 7:367-37:0 (1961).

Carnahan, B., H.A. Luther, and J.0. Wilkes, Applied Mumerical Methods, John Wiley and Sons, Inc., New York (1969).

Douglas, J., and J.E. Gunn, A General Formulation of Alternating-Direction Methods, Part. I: Parabolic and Hyperbolic Problems, Numeriche Mathematik, $6: 428-453(1964)$.

Douglas, J., and B.F. Jones, On Predictor-Corrector Methods for Nonlinear Parabolic Differential Equations, Society for Industrial and Applied Mathematics J., 11:195-204 (1963).

Evans, R.B., G.M. Watson, and E.A. Mason, I. Gaseous Diffusion in Porous Media, II. Effect of Pressure Gradients, J. of Chemical Physics, 36(7): 1894-1902 (1962).

Geankoplis, C.J., Mass Transport Phenomena, Holt, Rhinehart and Winston, Inc., New York, pp. 151-158 (1972).

Knudsen, M. , The Laws of Molecular and Viscous Flow of Gases through Tubes, Annals of Physics, 28:75 (1909).

Mackay, D.; and R.S. Matsugu, Evaporation Rates of Liquid Hydrocarbon Spills on Land and Water, Canadian J. of Chemical Engineering, 51:434-439 (1973).

Moore, C.A., Landfill Gas Generation, Migration and Control, Critical Reviews in Environmental Control, 9(2) (May 1979).

Rai, I.S., Mathematical Modeling and Mumerical Analysis of Flow of Gases around Sanitary Landfills, Ohio State University, University Microfilms, No. 76-10030, Ann Arbor, Mich. (1975). 
Rothfeld, I.B., Gaseous Counterdiffusion in Catalyst Pellets, American Institute of Chemical Engineering J., $\mathscr{P ( 1 ) : 1 9 - 2 4 ~ ( 1 9 6 3 ) . ~}$

Scott, D.S., and F.A.L. Dullien, Diffusion of Ideal Gases in Capillaries and Porous Solids, American Institute of Chemical Engineering J., 8(1):113-117 (1962).

Wilke, C.R., A: Viscosity Equation for Gas Mixtures, J.. of Chemical Physics, $18(4): 517-519(19.50)$.

\section{Literature Cited on Methane. Generation.}

Anon., Sanitary, Landfill Studies, Bulletin No. 147-5, Dept. of Water Resources, The Resources Agency, Sacramento, Calif. (1969).

Bryant, M.P., et al., Nutrient Requirements of. Methanogenic Bacteria, F.G. Pohland, ed., Advanced Chemistry. Series No. 105, American. Chemical Society, pp. 23-40, Washingt.on, D.C. (1971).

Buchanon, R.E., and N.E. Gibbons, Bergey's Marual of Determinative Bacteriology, 8th. Ed., The Williams \& Wilkens Co., Baltimore: (1974).

DeWalle, F.B., and E.s.K. Chian, Gas Production from Solid Waste in Landfills;: J. of Environmental Engineering Division, Proc. American Society of Civi.1 Engineers, 104:41.5-43.2. (19.78).

Eliassen, R., Decomposition of Landfiliz, American J. of Public Health, 32:1029-1037 (1942).

Farquhar, G.J., and R.A. Rovers, Gas Productionduring Refuse Decomposition, Water, Air \& Soil Pollution, 2:483-495 (1.973).

Ferry, J.G., and R.S. Wolfe, Nutritional and Biochemical Characterization of Methanospimillum hungatii, Applied and Environmental Microbiology, 34:371-376 (1977).

Fungaroli, A.A., and R.L. Steiner, Laboratory study of the Behavior of a Sanitary Landfilz, J. of Water Pollution Control Federation, 43:252-26.7 (:1971):

Golueke, C.G., and P.H. McGauhey, Comprehensive. Studies of Solid Wastes Management, SERL Report. No. 67-7, Dept. of Civil Engineering, University of California, Berkeley (1967). .

Gray, C.T., and H. Gest, Biological Formation of Molecular Hydrogen, Science, 148:186-192 (1965).

Hoban, D.J., and L. van den Berg, Effect of Iron on Conversion of Acetic: Acid to Methane during Methanogenic Fermentations, J. of Applied Bacteriology, 47:153-159 (1979).

Kirsch, E.J., and R.M. Sykes, Anaerobic Digestion in Biological Waste Treatment; Progrese in Industrial Microbiology, 9:155-237 (1971). 
Lawrence, A.M., and P.L. McCarty, Kinetics of Methane Fermentation in Anaerobic Waste Treatment, Technical Report No. 75, Dept. of Civil Engineering, St anford University, Stanford, Calif. (1967).

Leckie, J.0., J.G. Pacey, and C. Halvadakis, Landfill Management with Moisture Control, J. of Environmental Engineering Division, Proc. American Society of Civil Engineers, 105:337-355 (1979).

Mah, R.A., M.R. Smith, and L. Baresi, Studies on an Acetate-Fermenting. Strain of Methanosarcina, Applied and Environmental Microbiology, $35: 1174-1184(1978)$.

Mah, R.A., et al., Biogenesis of Methane, Annual Review of Microbiology, $31: 309-341$ (1977).

Miorin, A.F., et al., Wastewater Treatment Plant Design, Manual of Practice No. 8, Water Pollution Control Federation, Washington, D.C. (1977).

Patel, G:B.; A.W. Khan, and L.A. Roth, Optimum Levels of Sulphate and Iron for the Cultivation of Pure Cultures of Methanogens in Synthetic Media, J. of Applied Bacteriology, 45:347-356 (1978).

Pfeffer, J.T., Terperature Effects on Anaerobic Fermentation of Domestic Refuse, Biotechnology and Bioengineering, 16:771-787 (1974).

Pirt, S.J., Principles of Microbe and Cell:Cultivation John Wiley \& Sons, Inc., New York (1975).

Rovers, F.A., and G.J. Farquhar, Infiltration and Landfill Behavior, J. of Environmental Engineering Division, Proc. American Society of Civil Engineers, $99: 67.1-690(1973)$.

Sanders, F.A., and D.E. Bloodgood, The Effect of Nitrogen-to-Carbon Ratio on Anaerobic Decomposition, J. of Water Pollution Control Federation, 37:1741-1752 (1965).

Shea, T.G., et al., Kinetios of Hydrogen Assimilation in Methane Fermentation, SERL Rept. No. 68-7, Dept. of Civil Engineering, University of California, Berkeley (1968).

Sievers, D.M., and D.E. Brune, Carbon/Nitrogen Ratio and Anaerobic Digestion of Swine Waste, Trans. American Society of Agricultural Engineers, 21:537-549 (1968).

Taylor, G.T., and S.J. Pirt, Mutrition and Factors Limiting the Growth of a Methanogenic Bacterium (Methanobacterium thermoautotrophicum), Archives of Microbiology, 113:17-22 (1977).

Van den Berg, L., Effect of Temporature on Growth and Activity of a Methanogenic Culture Utilizing Acetate, Canadian J. of Microbiology, 23:898-902 (1977).

Zeikus, J.G., The Biology of Methanogenic Bacteria, Bacteriological Reviews, $41: 514-541$ (1977). 
69

APPENDIX A

CODE IV LISTING 
THIS PAGE

\section{WAS INTENTIONALLY LEFT BLANK}




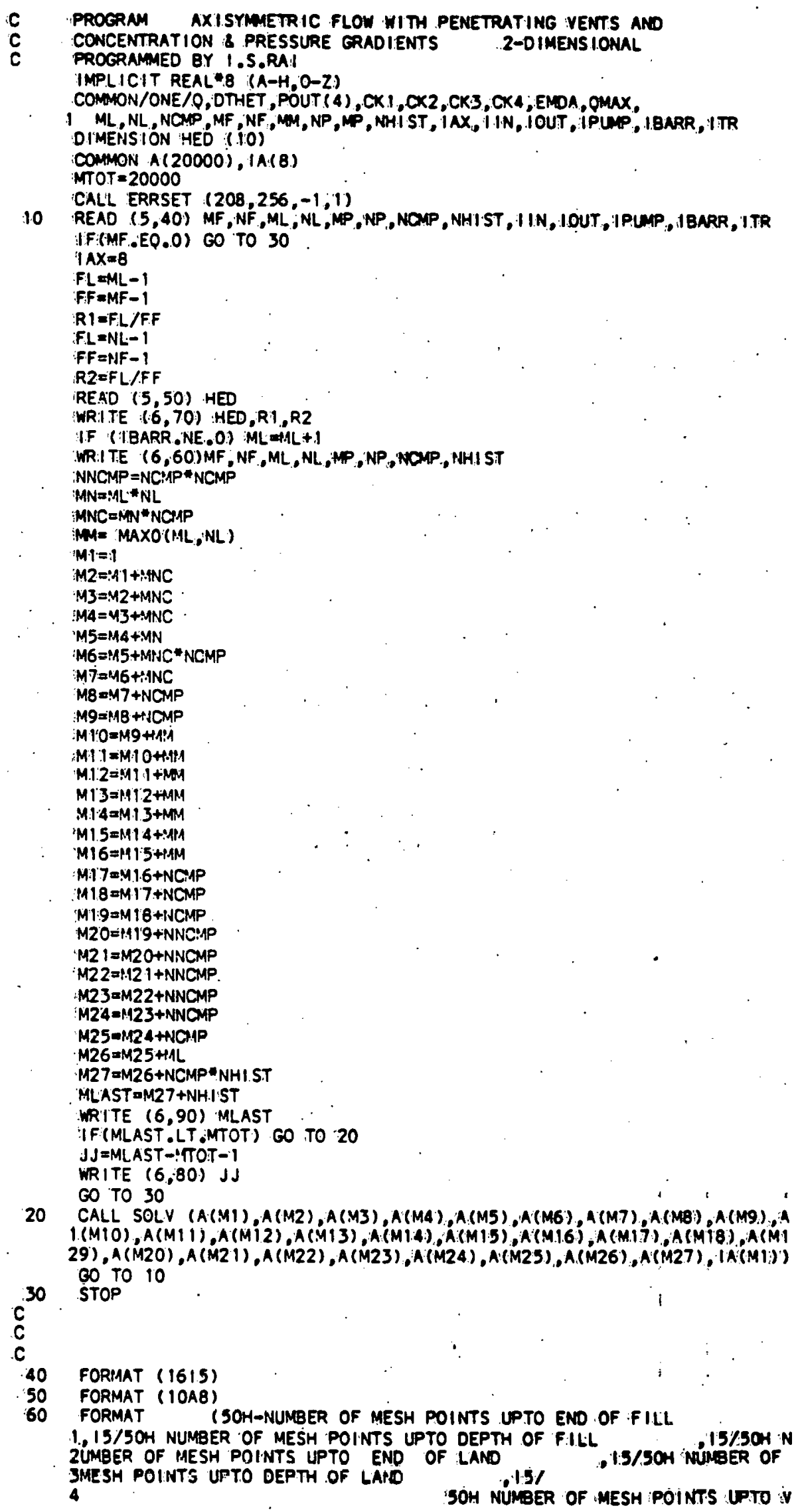




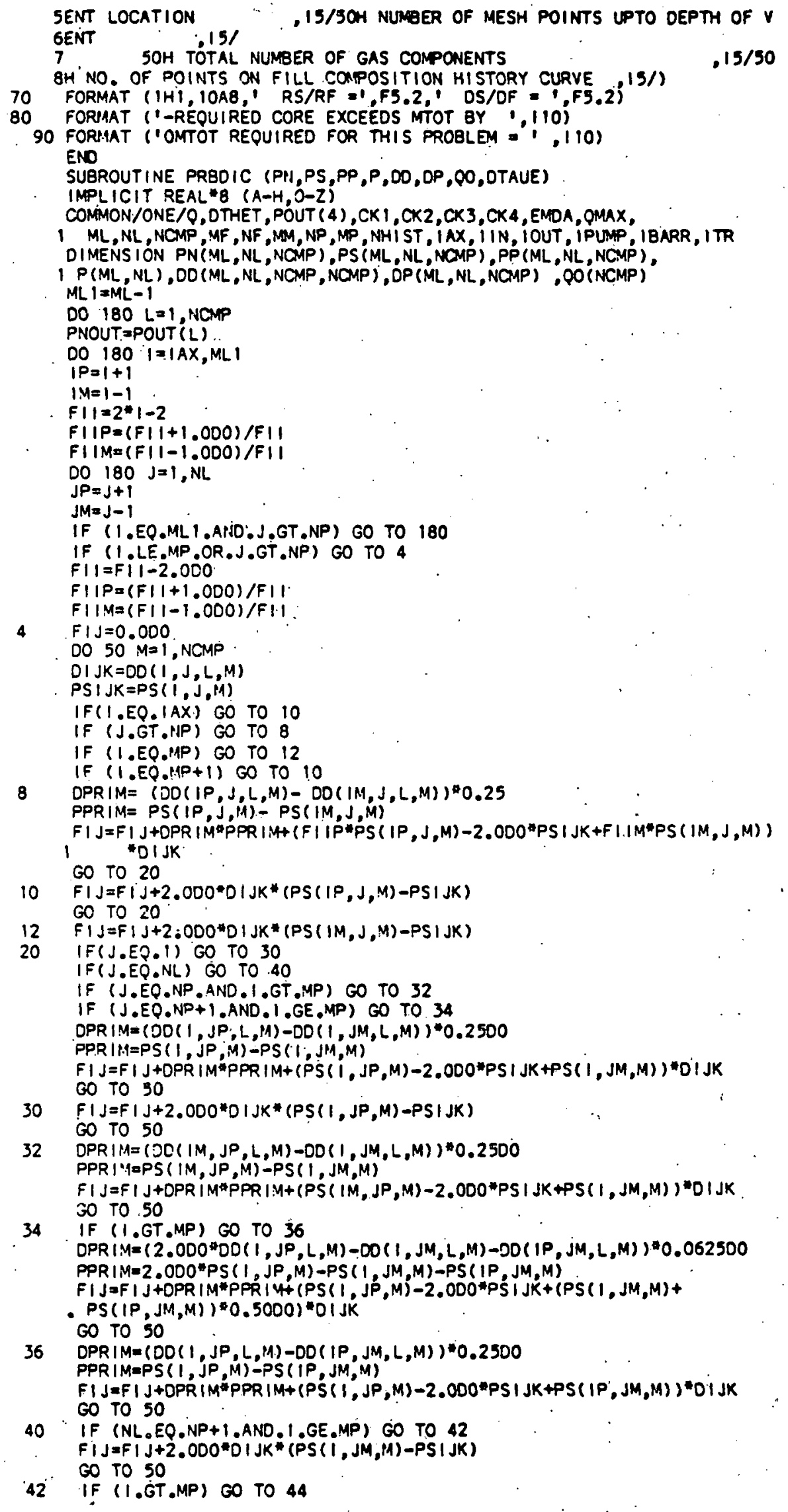


$F|J=F| J+D \mid J K\left(P S(I, J M, M)+P S(\mid P, J M, M)-2,000^{*} P S \mid J K\right)$

GO TO 50

$44 \quad F I J=F I J+D I J K=2.000$

- (PS $(\mid P, J M, M)-P S \mid J K)$

50 CONTINUE

$P S \mid J K=P S(1, J, L)$

$D P \mid J K=D P(1, J, L)$

$P I J K=P(1, j)$

IF (I.EO.|AX) GO TO 90

IF (J.GT.NP) GO TO 88

IF (1.EO.MP) GO TO 92

IF (I.EQ.MP+1) GO TO 90

$88 D P R \mid M=(D P(\mid P, J, L)-D P(\mid M, J, L)) * 0.2500$

$P P R I M=P(I P, J) \rightarrow P(I M, J)$

$F|J=F| J+D P R|M * P P R| M+(P(\mid P, J) * F|| P-2.000 * P|J K+\dot{P}(\mid M, J) * F| \mid M)$

- DPIJK

GO TO 100

90 FIJEF|J+2.000"DPIJK (P ( IP,J)-P|JK)

GO TO 100

$92: F|J=F| J+2.000^{*} D P \mid J K *(P(I M, J)-P \mid J K)$

100 IF(J.EQ:1) GO TO 110

IF (J.EO.NL) GO TO 120

IF (J.EQ.NP.AND.1.GT.MP) GO TO 112

IF (J.EQ.NP+1,AND.1.GE,MP) GO TO 114

$O P R \mid M=(D P(1, J P, L)-D P(1, J M, L))=0,2500$

$P P R I M=P(1, J P)-P(1, J M)$

$F|J=F| J+D P R|M * P P R| M+(P(1, J P)-2.000 * P \mid J K+P(1, J M)) * D P \mid J K$

GO TO 130

$110 F|J \approx F| J+2.000^{\circ} D P|J K *(P(1, J P)-P \mid J K)+C K|$ (PNOUT-PS IJK)

IF (1.NE.MP) GO TO 130

$F|J=F| J+$. (PNOUT-PSI.JK) *(CK2-CKI)

CO TO 130

120 IF (NL.EO.NP+1.AND.1.GE.MP) GO TO 122

$F|J=F| J+2.0 D 0^{*} D P \mid J K *(P(1, J M)-P \mid J K)$

GO TO 130

122 IF (1.GT.MP) GO TO 124

$F|J=F| J+D P\{J K *(P(1, J M)+P(\mid P, J M)-2.000 * P \mid J K)$

GO TO 130

$124 F\left|J=F i J+2.000^{*} D P\right| J K *(P(\mid P, J M)-P \mid J K)$

GO TO 130

$112 D P R I M=(D P(I M, J P, L)-D P(1, J M, L)) * 0.2500$

$P P R \mid M=P(\mid M, J P)-P(1, J M)$

$F|J=F| J+O P R \mid M$ APR IM+DP $\mid J K(P(I M, J P)-2.000 * P \mid J K+P(1, J M))$

GO TO 130

114 IF (I.GT.MP) GO TO 116

$D P R \mid M=\left(2.000^{*} D P(1, J P, L)-D P(1, J M, L)-D P(I P, J M, L)\right) * 0.0625 D 0$

$P P R \mid M=2.000^{\circ} P(1, J P)-P(1, J M)-P(\mid P, J M)$

$F|J=F| J+D P R\left|: A^{*} P P R\right|(M+D P \mid J K *((P(1, J M)+P(I P, J M))=0.500-2.000 * P \mid J K$

- $+P(1, j \mathrm{P}))$

GO TO $\{30$.

$116 D P R \mid M=(. D P(1, J P, L)-D P(I P, J M, L))=0.2500$

$P P R \mid M=P(1, J P)-P(\mid P, J M)$

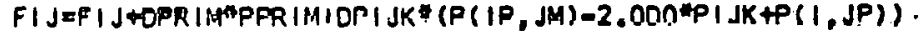

$130^{\circ}$ CONTINUE

IF (J.EO.1.OR, I.NE.MP.OR,J.GT.NP) GO TO 162

IF (IPUMP.EQ.2) $B O$ TO 140

IF (L.NE.NCMP) GO TO 162

$F|j=F| J+0$

GO TO 162

$140 \mathrm{~F}|J=F| J-S^{N} P S \mid J K$

162 CONTINUE

$F I J=F I J+Q O(L)$

(I.GT.MF.OR.J.GT.NF) CO TO 165

$165 F|J=F| J=E M O A+P S(1, J, L)$

$\operatorname{PP}(I, J, L)=F \mid J$

170 CONTINÚE

180 CONTINUE

DO $210 \quad I=I A X, M L 1$

DO $210 \mathrm{~J}=1, \mathrm{NL}$

$P \mid J K=0.0$

DO $190 \mathrm{~N}=1, \mathrm{NCMP}$

$P S \mid J K=P P(1, J, N)$

$P S(1, J, N)=P S I J K$

$P N(I, J, N)=P S I J K$

190 PIJREPIJK $+P S I J K$

$200 P(I, J) \quad \triangle P . J K$ 
210 CONTINUE

DO $355 I=|A X, M L|$

If (1.EQ.MP) GO TO 355

$P\{J K=1.000 / P(1,1)$

$P(1,1)=1.000^{\circ}$

DO 354 L=1, NCMP

PS I JK $=P S(1,1, L)$ :PI JK

PP $(1,1, L)$ PS IJK

$P N(1, j, N)=P S I J K$

354 PS $(1,1, L)=P S I J K$

355. CONTINÚE

IF( QMAX .NE. 0.) GO TO 357

IF(ITR,EQ.0)GO TO 357

DO $356 \mathrm{~J}=1, \mathrm{NP}$

$P \backslash J K=1.000 / P(N P ; J)$

$P(M P, J)=1,000$

DO $356 \mathrm{~L}=1$, NCMP

PSI JK $\Rightarrow P S(M P ; J, L) * P \mid J K$

$P P(M P, J, L)=P S I J K$

$P N(1, J, N)=P S I J K$

(MP, J, L) =PSI JK

CONTINUE

RETURN

END'

SUBROUT INE CORBCT (PN,PS,PP,P,DP,OD,A,B,C,F,CPRIM;BETA,GNMA, , O,

- DTAUE)

IMPLICIT REAL $B(A-H, O-Z)$

COMMON/ONE/Q, OTHET, POUT (4),CK1, CK2, CK3, CK4, EMDA, OMAX

I ML,NL, NOAP, IF, NF, MM, NP, MP, NHI ST, I IX, I IN, IOUT, IPUMP, I I ARR, I TR

OIMENSION PN(ML, NL, NCMP), PS (ML, NL, NCMP), PP (ML, NL, NCMP),

$1 P(M L, N L), D D(M L, N L, N C M P, N C M P), D P(M L, N L, N O M P), P O(N C M P)$,

2 A(PM) $, 3(M M), C(M M), F(M M), B E T A(M M), G A M M A(M M), C P R I M(M M)$

IAL $1=: A L-1$

DO $210 \quad L=1$, NOMP

MAX $=M L 1$

PNOUT $=$ POUT (L)

DO $210 \mathrm{~J}=1, \mathrm{NL}$

$J P=J+1$

$J M=J-1$

$M|N=| A X$

IF (J.GT.NP) : MAX $=M L-2$

DO $180 \quad l=\mid A X$, MAX

$F \|=2 * 1-2$

IF (1.LE.MP.OR.J.GT.NP) GO TO 4

4.

$F\|=F\| 1=2.0$

$F \mid J=0.000$

$F|| P=(F \mid 1+1.000) / F \mid 1$

$F|| M=(F||-1,000) / F \mid 1$

$\mid P=1+1$

$1, M=1-1$

DO $50 \mathrm{M}=1, \mathrm{NCAP}$

IF (L.EQ.M) GO TO 50

OI $J K=D D(1, J, L, M)$

$P S \mid J K=P S(1, J, M)$

IF (I.EQ. IAX) GO TO 10

IF (J.GT.NP) GO TO 8

IF (I.EQ.MP) 60 TO 12

IF (I.EO.MP+1) GO TO 10

.8

DPRIM= $(D D(I P, J, L, M)-D O(I M, J, L, M))=0.25$

$P P R I M=P S(I P, J, M)-P S(I M, J, M)$

$F|J=F| J+O P R I M * P P R \mid M+\left(F|| P * P S(I P, J, M)-2.000^{*} P S|J K+F| \mid M * P S(I M, J, M)\right)$

1 DIJK

GO TO 20

$10 \quad F|J=F| J+2.000 * D \mid J K *(P S(I P, J, M)-P S \mid J K)$

GO TO 20

$12 \quad F|J=F| J+2.000 * O \mid J K *(P S(\mid M, J, M)-P S \mid J K)$

20

IF(J.EQ. I) 60 TO 30

IF(J.EQ.NL) GO TO 40

IF (J.EQ.NP.AND. I.GT.MP) GO TO 32

IF (J.EQ.NP+1.ANC.I.GE.MP) GO TO 34

$D P R I M=(D D(1, J P, L, M)-D D(1, J M, L, M))=0.2500$

PPRIM=PS $(1, J P, M)-P S(1, J M, M)$

$F|J=F| J+O P R|M+P P R| M+(P S(I, J P, M)-2,000 * P S \mid J K+P S(1, J M, M)) * 0 \mid J K$

GO TO 50

$30 \quad F\left[J=F\left|J+2.000^{*} D\right| J K *(P S(I, J P, M)-P S \mid J K)\right.$ 
Co. TO 50

32 DPRIM $M=(D D(I M, J P, L, M)-D D(T, J M, L, M)) *$,

PPR:IM=PS $(I M, J P, M)-P S(I, J M, M)$

$F . I J=F \mid J+O P R I M{ }^{\circ} P P R I M+\left(P S(I M, J P, M)-2,000^{\circ P S} I J K+P S(I, J M ; M)\right) " D I J K$ GO TO 50

34 IF (I.GT MP) GO TO 36

$D P R I M=(2.000 \% D D(1, J P, L, M)-D D(1, J M, L, M)-D D(I P, J M, L, M))=0.062500$

PPR IM=2.0D0"PS (I, JP, M)-PS (I.JM, M)-PS (IP.JM,M)

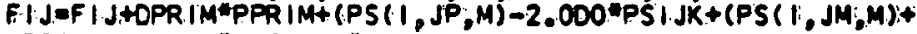

- PS(IP, JM, M: $)=0.5000) * 0.1 \mathrm{JK}$

GO. TO 50:

36 DPRIM= $(D D(1, J P, L, M)-O D(I P, J M, L, M))=0.2500$

PPR IM=PS $(1, J P, M)-P S(1 . P . J M, M)$

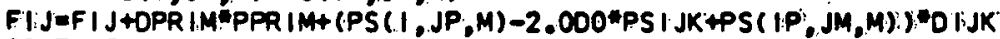
co TO: 50

40. I.F (NL.EQ.NP+I,AND,I,GE,MP) GO TO 42

$F .1 J=F \mid j+2.0000^{\circ}(J K=(P S(i, J M, M)-P S I J K)$

GO TO 50

42 IF' (I.GT.AP) CO. TO 44

$F|J=F I J .0| J K *\left(P S(I, J M, M)+P S(I P, J M, M)-2,000^{*} P S . I J K\right)$

CO TO $50^{\circ}$

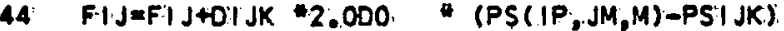

50: CONTINUE

$D P(J K=D P(1, J, L)$

$P I J K=P(-1, j)$

PSIJJK=PS $(1, J, L)$

PNI JK=PN $(: I, J, L)$

$D D I: J K=D D(1, J, L, L)$

IF:(:I.EQ: $\mid A X)$ GO TO 90

IIF (J.GT.NP) GO TO 88

IF (1.EO.YPP) GO TO 92

1.F: (1.EO.MP+1), GO. TO 90

$88 \quad D P R I M=(D P(I P, J, L)-D P(I M, J, L))=0.2500$

$D D R I M=(-D D(I P, J, L, L)-D D(I M, J, L, L))=0.2500$

PPRIM=P(IP, J) $\rightarrow P(I M, J)$ :

PSPRIM=PS $(I P, J, L)-P S(I M, J, L)$

PNPRIM=PN (IP,J,LST-PN (IM;.J,L)

$F I J=F|J+D P R| M-P P R|M+D P| J K=(F|| P * P(I P, J)-2 ; 000 * P I J K+F+\mid M *$

-. $P(I M, J))+(D O H J K=(F \mid M N P N(I M, J, L)$

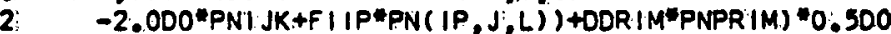

$A(1)=D D R I M-D D I J K * F I I M$

C(I) $=$ a-DDR:IM-DDI JK *FIIP

GO TO 100

90: $\quad F|J=F| J+2.0 D 0 * D P I J K *(P(I P, J)-P \mid J K)+O D I J K *(P N(\mid P, J, L)-P N I J K)$

$C(1)=-2.000 * 0 D 1 \mathrm{JK}$

$A(1)=0.000$

GO: TO 100

$92 F \cdot I J=F \mid J+2.000 * D P I J K *\left(P\left(I M_{0} . J\right)+P \mid J K\right)+0 D .1 J K *\left(P N\left(I M_{0}, J, L\right)-P N I J K\right)$

$C(1)=0.000$

$A(1)=-2.000 \div 00.1 \mathrm{JK}$

100: $B(1)=E M D A+2.0 * 0 D F J K$

IF(J.EQ.1) 60 TO 110

IF( J.EQ.NL) GO TO 120

IF (J.EQ.NP.AND.1.QT,MP). GO: TO: 112

IF (J.EO.NP+1.ANE.I.GE.MP): GO TO 114

DPRIME $(D P(1, J P, L)=D P(1, J M, L))=0.2500$ :

DDR:IM= $(D O(I, J P, L, L)-D D(I, J M, L, L)=0.2500$

$P P R I M=P(1, J P)-P(I, J M)$

$P S P R I M=P S(1, J P, L)-P S(1, J M, L)$

PNPR IM=PN $(1, J P, L)-P N(I, J P A, L)$

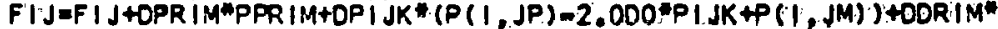

- PNPRIM+ODI JK" (PN $(1, J P, L)-2,000$ *PNI JK+PN $(I, J M ; L))$

CO TO 130

1'10 $F|J=F| J+2.000 * D P|J K *(P(1, J P)=P \mid J K)+2.000 * 0 D| J K *(P N(1, J P ; b)=$

- PNIJK.)+CKI* (PNOUT-PSI JK)

IF (1.NE.AP) GO TO 130

FIJ=FIJ+ (PNOUT-PSIJK)*(CK2-CKI)

CO TO 130

120 IF (NL.EQ.NP+1.AND.1.GE,MP) GO TO 122

$F|J=F| J+2.000^{\circ} D P \mid J K=(P(I, J M)-P \mid J K)+2.000^{*} 001 J K *(P N(I, J M / E)-P N \mid J K)$

60 To 130

122 .IF. (1.GT.4P) 60 TO 124

$F \mid J=F\left(J+D P\left(J K *\left(P(1, J M)+P(I P, J M)-2.000^{*} P(J K)\right.\right.\right.$

- $+O D I J K *\left(P N(1, J M, L)+P N(I P, J M, L)-2.000^{*} P N(J K)\right.$

GO TO 130 
124. $F|J=F| J+2.000^{\circ} D P \mid J K *(P(\mid P, J M)-P \mid J K)$ +2.000*DDI JK (PN (IP,JM, L) -PNIJK) GO TO 130

$112 D P R I M=(D P(I M, J P, L)=O P(1, J M, L))=0.2500$

$D D R I M=(D D(I M, J P, L, L)-D D(I, J M, L, L))=0.2500$

$P P R I M=P(I M, J P)-P(I, J M)$

PNPRIMAPN (IM,JP, L) PN $(I, J M, L)$

$F|J=F| J+O P R|M * P P R| M+O P \mid J K *(P(I M, J P)-2,000 * P \mid J K+P(1, J M))$

- + DDRIM*PNPRIM+DDI JK* (PN (IM,JP,L) -2.000"PNI JK+PN $(I, J M, L))$

GO TO 130

114 IF (1.GT.AP) GO TO 116

$D P R I M=\left(2.000^{*} D P(1, J P, L)-D P(1, J M, L)-D P(I P, J M, L)=0.062500\right.$

$D D R I M=\left(2.000^{*} D O(1, J P, L, L)-O D(1, J M, L, L)-D O(I P, J M, L, L)\right)=0.062500$

PNPR IM=2.000 $P N(1, J P, L)-P N(1, J M, L)-P N(I P, J M, L)$

$P P R I M=2.000 * P(1, J P)-P(1, J M)-P(I P, J M)$

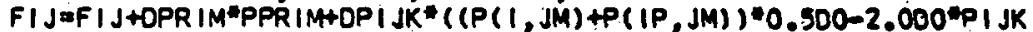

- $\quad+P(1, J P I)+D D R I M * P N P R I M+D D I J K=\left(P N(I, J P, L)-2,000\right.$ WPN $J K+0.5000^{*}$

- $(P N(I, J M, L)+P N(I P, J M, L)))$

GO TO 130

$116 \quad O P R I M=(D P(1, J P, L)=D P(I P, J M, L))=0.2500$

$D D R I M=(D D(1, J P, L, L)-D D(I P, J M, L, L)) * 0.2500$

$P P R \mid M=P(1, J P)-P(\mid P, J M)$

PNPRIMEPN (I,JP,L)-PN(IP,JM,L)

$F|J=F| J+O P R|M=P P R| M+D P \mid J K=\left(P(I P, J M)-2,000^{*} P \mid J K+P(1, J P \mid)\right.$

- $+D D R I M * P N P R I M+D D I J K *\left(P N(I, J P, L)=2.000^{*} P N \mid J K+P N(I P, J M, L)\right)$

130 . CONT INUE

IF (J.EO, I.OR,I.NE.MP.OR.J.GT.NP) GO TO 162

IF (IPUMP.EQ.2) GO TO 140

If (L.NE.NCMP) GO TO 162

$F|J=F| J+0$

GO TO 162

$140 \mathrm{FIJ}=\mathrm{F} \mid \mathrm{J}-\mathrm{O}$ \#PS IJK

162 CONTINUE

$F|J=F| J * 2.000+E: 10 A * P N \mid J K$

IF (I.GT.MF.OR.J.GT.NF) GO TO 175

$F|J=F| J+00(L) * 2.000$

$175 F(1)=F \mid$ J

180 CONTIINUE

$190 F($ MAX $)=F($ MAX $)-C$ (MAX) *POUT (L)

CALL TRIDAG (MIN,MAX,A,B,C,F,CPRIM,BETA, GAMMA, MM)

DO $200 \quad|=M| N, M A X$

$200 \operatorname{PP}(1, J, L)=C P R I M(1)$

210 CONTINUEE

DO $220 \quad I=\mid A X$, MAX

DO $220 \mathrm{~J}=1, \mathrm{NL}$

DO $220 \quad L=1, N C M P$

$P S(1, J, L)=P P(1, j, L)$

$M A X=N L$

DO 290 L 21, NCMP.

DO $290 \quad \|=|A X, M L|$

$M I N=1$

$1=11$

DO $260 \mathrm{~J}=1$, NL

IF (1.GT.!P.AND.J.GT.NP) $1=1.1-1$

$\mid P=1+1$

$I M=1-1$

$D O 1 J K=D O(1, J, L, L)$

PNI JK $=P N(1 ; J, L)$

$B j=2.000^{*} D O I^{\prime} J K$

$F I J=E ! \cdot I D A * P S(I, J, L)+B J * P N I J K$

$B(j)=E M D A+B J$

$J P=J+1$

$J M=j-1$

IF(.J.EO.1) GO TO 230

IF (J.E. NL) GO TO 240

IF (J.EQ.NP.AND.I.GT.MP), GO TO 232

IF (J.EP.NP+1.AND.1.GE.MP) GO TO 234

$D O R I M=(D O(1, J P, L, L)-O D(I, J M, L, L))=0.2500$

$A(J)=D D R I M-D D \mid J K$

$C(J)=-D D R I M-D O I J K$

$F(J)=F \mid J+A(J)+N(1, J M, L)+C(J)+P N(1 ; J P, L)$

GO TO 260

232. DDR $I: 1=(D D(\mid M, J P, L, L)-D D(I, J M, L, L))=0.25 D 0$

$A(J)=D O R|M-D D| J K$

$C(J)=-D D R \mid M-D O I J K$ 
$F(J)=F \mid J+A(J) * P N(1, J M, L)+C(J)$ *PN $(1, J P, L)$

EO TO 260

234 IF (I.GT.MP) 50 TO 236

$D O R I M=\left(2,000^{\circ} D D(1, J P, L, L)-D D(1, J M, L, L)-D D(1 P, J M, L, L)\right)=0.123 D 0$

$A(J)=D D R I M-D O I J K$

$C(J)=-D D R I M-D D 1 . J K$

$F(J)=F(J+A(J) *(P N(1, J M, L)+P N(1 P, J M, L)) * 0,500+C(J) * P N(1, J P, L)$

CO TO 260

$236 \quad D O R I M=(D D(1, J P, L, L)-D D(I P, J M, L, L)=0.2500$

$A(J)=D D R I M-O D I J K$

$C(J)=-D D R \cdot M-D D I . J K$

$F(J)=F \mid J+A(J)=P N(I P, J M, L)+C(J)=P N(1, J P, L)$

CO TO 260

$230 C(J)=-8 J$

$F(J)=F I J-B J * P N(I, J P, L)$

GO TO 260

$240 \quad A(J)=-B J$

I:F (NL.EQ.NP+1.AND.1.GE.MP) GO TO 242

$F(J)=F(J-B J \backsim P N(1, J M, L)$

60 TO 260

242 I:F (1.GT.MP) GO TO 244

$F(J)=F_{1} J-B J *(P N(I, J M, L)+P N(I P, J M, L)) * 0.5000$

GO TO 260

$244 F(J)=F I J-9 J * P N(I P, J M, L)$

260 CONTINUE

CALL. IR, DAG (MIN,MAX,A,B,C,F,CPRIM,BETA, GNMA, MMI)

DO 280 J $=$ MIN,MAX

$1=1: 1$

IF (I.GT.MP.AND. J.GTT.NP) $\quad I=11-1$

.280 :PP $(1, J, L)=C P R I M(J)$

290 CONTINUE

RETURN

END

SUBROUTINE TRIDAG (IF,L,A,B,C,O,V,BETA, GAMMA, MM)

IMPLICIT REAL $B$ B (A-H, O-Z)

DIMENSION A.(MM), B (HM), C(MM),D(MM), V(MM), BETA (MM), SAMMA (MM)

$B E T A(I F)=B(\mid F)$

GAMMA $($ IF.) $=D($ (IF) $/ B E T A A(I F)$

IF (IF.EQ.L. GO TO 30

$1 F P I=1 . F+1$

:00 10. 1.:1F.PI,L

BETA $(1)=9(1)-A(1)-C(1-1) / B E T A(1-1)$

10 GA:MMA $(1)=(O(1)-A(1)$ "GAMMA $(1-1))$ /SETA $(1)$

$\checkmark(L)=G A M M A(L)$

LAST $=L-1 F$

DO $20 \mathrm{~K}=1$, LAST

$1=L-K$

$20 \quad V(1)=\operatorname{GAMMA}(1)-C(1) * V(1+1) / \operatorname{BETA}(1)$

GO TO 40

$30 \quad V(L)=$ GAMMA $(L)$

40 RETURN

END

SUBROUT INE PREDIC (PN,PS,PD,P,DD,DP, 00, DTAUE)

IMPLIICIT REAL $* 8(A-H, O-Z)$

COMMON/ONE/0, OTHET,POUT (4), OK1, CK2, CK3, CK4, EMOA, PHAX,

$1 \mathrm{ML}, \mathrm{NL}$, NCMP, MF.,NF.MM, NP, IMP NHIST, INX, IIN IOUT, IPUMP, IBARR, IT TR

D.IHENSION PN(ML, NL, NCMP),PS (ML, NLL, NOMP), PP (ML, NL, NCMP),

$1 P(M L, N L), D D(M L, N L, N C M P, N O M P), D P(M L, N L, N C M P), D 0$ (NCMP)

$M L I=M L-1$

DO $180 \quad L=1$, NCMP

PNOUT $=$ POUT $(L)$

DO $1.80 \quad 1=1$ AX,MLI

$|P=|+1$

$1 M=1-1$

$F, 1=2 * 1-2$

$F|| P=(F||+1.000) / F||$

$F|| M=(F \mid 1-1.000) / F I)$

$00180 \mathrm{~J}=1, \mathrm{NL}$

$F$ I $J=0.000$

$0050 \mathrm{M}=1, \mathrm{NCMP}$

OI JK=DD $(1, J, L, M)$

PSI.JK=PS $(1, j, M)$

IF(I.EO, $\mid A X)$. CO TO 10

DPRIM=(DD $(i+1, J, L, M)-D O(1-i, J, L, M))=0.25$

PPRIMAPS $(1+1, J, M)-P S(1-1, J, M)$ 


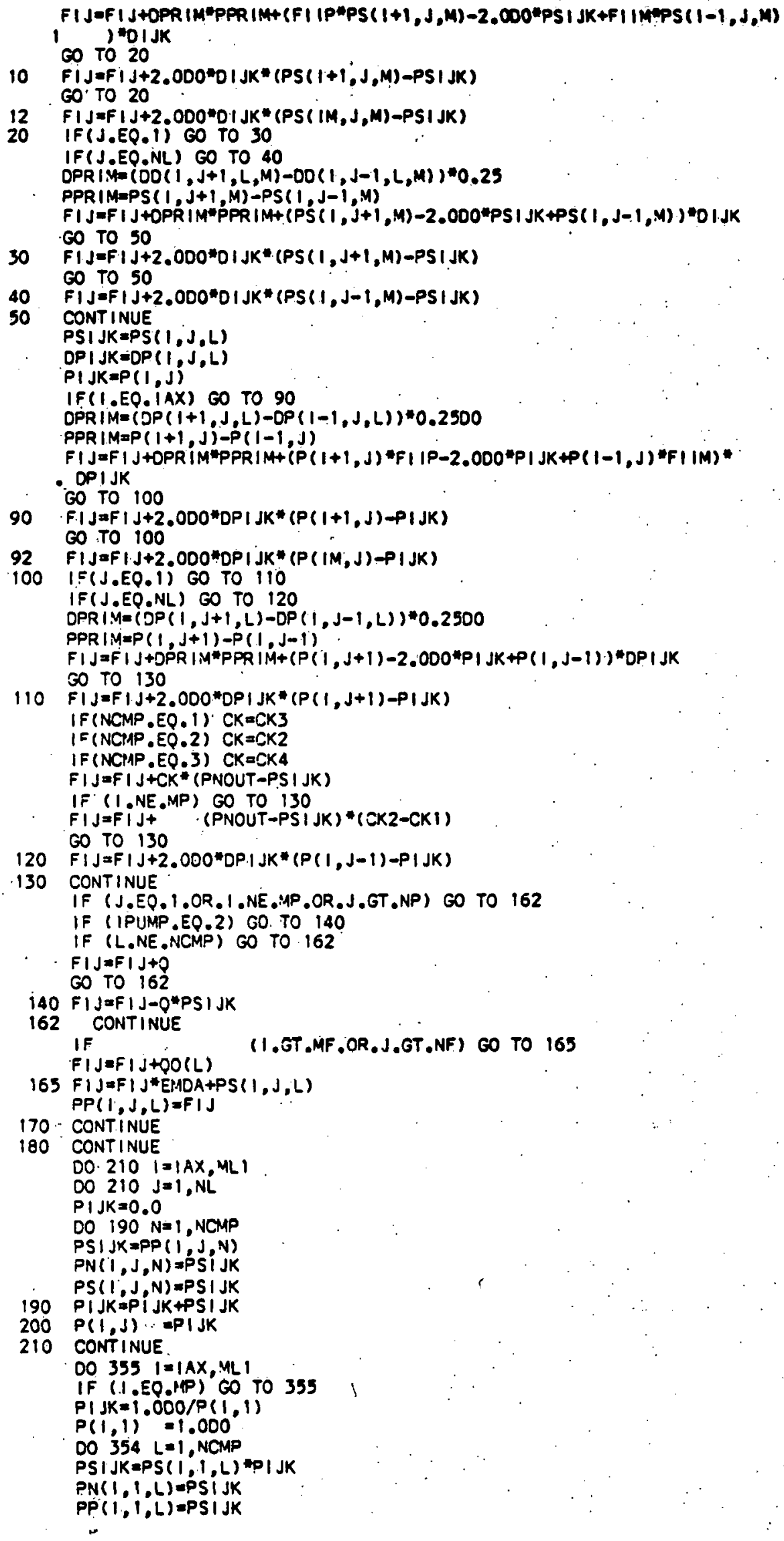


354: PS $(1,1, L)=P S I J K$

355. CONTINUE

IF(OMAX .NE.0.) GO TO 357

IF(ITR.EQ.0)GO TO 357

DO $356 \mathrm{~J}=1, N P$

$P I J K=1.000 / P(M P, J)$

$P(M P, J)=1.000$

DO 356 LEI NOMP

PSIJK =PS (INP, J,L) *PI JK

PN(MP, J,L) =PS I JK

PP (MP, J,L) $=P S \mid J K$

356 PS $\left(N P_{,} J, L\right)=P S I J K$

357. CONTINUE

RETURN

END

SUBROUTINE CORECT (PN,PS,PP,P,DP,DD,A,B,C,F,CPRIM,BETA,GAYM, QO,

- DTAUE)

IMPLICIT REAL $B(A-H ; O-Z)$

COMAON/ONE/Q, DTHET, POUT (4), CK1 , CK2, CK3, CK4, ENOA, OMAX,

$I$ ML,NL,NCMP,MF, NF, MM, NP, MP; NHIST, IAX, I IN, IOUT: IPUMP, IBNRR, ITR.

OIMENS ION PN(ML,NL,NCMP), PS (ML, NL, NOMP), PP (ML, NL, NOMP).

I P(ML, NL), DD (ML, NL, NCMP', NOMP), DP (ML, NL, NOMP) ,DO (NOMP) )

2. $A(M M), S(M M), C(M M), F(M M), B E T A R(M M)$, GAMAA (MM), CPR IM(MM).

$M L I=M L-1$

$M A X=M L: 1$

DO $210 \mathrm{~L}=1, \mathrm{NCM}$

PNOUTAPOUT (L)

DO: $210 \mathrm{~J}=1, \mathrm{NL}$

$M I N=\mid A X$

DO. $180: 1=1, A X, M L I$

$F \mid I=2 * 1-2$

$F|1 . P=(F||+1.000) / F| 1$

$F|| M=(F||-1,000) / F \|$

$F I J=0,000$

DO $50 \mathrm{M=1}$, NCMP

IF(L.EQ.M) GO TO 50 .

D I JK=DD $(1, J, L, M)$

$P S I \cdot J K=P S(1, J ; M)$

IF. (I.EQ.|AX) GO. TO 10

$D P R I M=(D D(1+1, J ; L ; M)-D D(1-1, J, L, M))=0.25$

PPRIM=PS $(1+1, J, M) \rightarrow P S(1-1, J, M)$

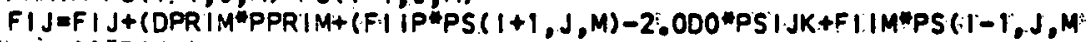

$1.1)=0(J K)$

GO TO 20

$10 F|J=F| J+2.0 * 0 \mid J K *(P S(1+1 ;, J ; M)-P S \mid J K)$

20. I.F (J.EQ.1) GO TO $30^{\circ}$

IF. ( J.EO.NL) GO TO 40

$D P R I M=(D D(I, J+1, L, M)-D D(I, J-1, L, M)) * 0.25$

PPRIMEPS $(1, j+1, M)-P S(1, j-i, M)$

$F I J=F|J+D P R| M * P P R \mid M+(P S(1, J+1, M)-2,000$ "PS $1 \cdot J K+P S(1, J=1, M)) * D \mid J K$

6O. TO 50

30: $F(J=F \mid J+2,000 " U I J K "(P S:(1, J+1, M)-P S(J K)$

60 TO 50

40 F.I.J $=F 1 \mathrm{~J}+2.000 * 01 \mathrm{JK} *(P S(1, \mathrm{~J}-1, M)-P S .1 \mathrm{JK})$

50. CONTINUE

$D P \mid J K=D P(I, J, L)$

$P(J K=P(1, J)$

$P S I J K=P S(I, J, L)$

$P N I J K=P N(1, J, L)$

DDI JK=DD $(I ; J, L, L)$

IF(I.EO.|AX) GO TO 90

$D P R I M=(D P(1+1, J, L)-D P(1-1, J, L))=0.2500^{\circ}$

$D D R I M=(D D(1+1, J, L, L)-D D(1-1, J, L, L))=$.

PSPRIMAPS $(1+1, J, L)=P S(1-1, J, L)$

PPRIM=P $(1+1, j)-P(1-1, j)$

PNPR IM=PN $(1+1, J, L)-P N(1-1, J, L)$

$F|J=F| J+O P R I M " P F R|M+D P| J K$ (FI IP* $P(.1+1, J)-2,000 * P|J K+F|, \mid M *$

- $P(1-1, J))+(D D \mid J K *(F \mid 1 Y * P N(1-1, J, L)$

$2 \quad-2,000 \backsim P N|J K+F| \mid P \otimes P N(1+1, J, i)\}+D O R I M * P N P R I M)=0.500$

$A(1)=D D R I M-D D I J K * F I I M$

$B(1)=E M D A+2.0 \% O D I J K$

$C(1)=-D O R I M-D D I J K * F I I P$

to TO 100

$F|J=F| J+2,000 * D \bar{P} \mid J K=(P(1+1, j)-P \mid J K)$

IN $(1+1, J, L)-P N I J K)$ 
$B(1)=E M D A+2.000 \% D O I J$

$C(1)=-2.000 \cdot 001 \mathrm{JK}$

IF(J.EP. I) GO TO 110

IF(J.EO.NL) GO TO 120

DPRIM= $(D P(1, J+1, L)-D P(1, J-1, L))=0.2500$

DORIM=(DD $(1, J+1, L, L)-D O(1, J-1, L, L)=0.2500$

PSPRIMAPS $(1, J+1, L)-P S(1, J-1, L)$

PPRIM=P(1,j+1)-P(1,j-1)

PNPR IM=PN $(1, J+1, L)-P N(1, J-1, L)$

$F|J=F| J H O P R I M * P P R I M+D P I J K *(P(1, J+1) \quad-2.000 * P I J K$

$1+P(1, j-1)$ )+ODRIM"PNPRIM+DDI JK $(P N(I, J+1, L)-2$

2.000"PNI JK+PN(1,J-1,L)) GO TO 130

$110 F|J=F| J+2.000^{*} D P \mid J K *(P(I, J+1)+P \mid J K)+2.000 * 001 J K *(P$

IN(1, J+1, L) $\rightarrow$ PNI JK)

IF (NCMP.EO.1) CKACK3

IF (NCMP.EQ.2) CK=CK2

IF (NCMP.EO.3) CKNOKA

$F|J=F| J+C K$ (PNOUT-PSIJK)

IF (1.NE.MP) GO TÓ 130

FIJ=FiJt (PNOUT-PSIJK) $=(C \times 2-C K 1)$

GO TO 130

$120 F(j=F(J+2.000 * 0 P i J K *(P(1, J-1)-P(J K)$

IN( $1, J-1, L)-P N \mid J K)$

130 CONTINUE

IF (J.EO, I.OR I NE.MP.OR J.GT ANP) CO TO 162

IF (IPUMP.EQ.2) GO TO 140

IF (L.NE,NCMP) GO TO 162

FIJ JFIJ+O

GO TO 162

140 FIJJFIJ-2"PSIJK

162 CONTINUE

$F|J=F| J * 2.000+3 M D A * P N \mid J K$

(I.GT.MF:OR,J.GT.NF) GO TO 173

$F|J=F| J+Q O(L) * 2.000$

$175 F(1)=F I J$

180 CONTINUE

$190 \quad F($ MAX $)=F($ MAX $)-C$ (MAX) POUT $(L)$

CALL TRIDAG (MIN, MAX, A,B,C,F,CPRIM, BETA, GAMMA, MA)

DO 200 I=MIN, MAX

$200 \operatorname{PP}(1, J, L)=C P R I M(1)$

210 CONTINUE

DO $220 \quad I=\mid A X, M L 1$

$00 \cdot 220 \cdot \mathrm{J}=1, \mathrm{NL}$

DO 220 L=1,NCAP

$220 \operatorname{PS}(1, J, L)=P P(1, J, L)$

$M A X=N L$

$M \mid N=1$

DO $290 L=1$, NCMP

DO $290 \quad|=| A X, M L 1$

MIN= I

$00260 \mathrm{~J}=1, \mathrm{NL}$

$D D I J K=D D(I, J, L, L)$

$P N I J K=P N(I, J, L)$

$F \mid J=E M D A * P S(i, J, L)$

$B J=2.000 * 0 D 1 J K$

$B(J)=E M D A+B J$

IF(J.EP.1) 60 TO 230

IF (J.EQ.NL) 60 TO 240

DDRI:A= $(00(1, J+1, L, L)-00(1, J-1, L, L))=0.2500$

$A(J)=D D R|M-D D| J K$

$C(J)=-D D R I M-D D I J K$

$F(J)=F \mid J+A(J)$ *PN $(1, J-1, L)+Q J$ *PN $1 J K+C(J)=P N(1, J+1, L)$

GO TO 260

$230 C(\mathrm{~J})=-2.000 * 001 \mathrm{JK}$

$F(J)=F\left|J-2.000^{*} D D\right| J K *(P N(1, J+1, L)-P N I J K)$

GO TO 260

$240 \quad A(J)=-2.000 \cdot 001 \cdot J K$

$F(J)=F \mid J-2,000$ DD IJK $(P N(1, J-1, L)-P N \mid J K)$

260

CONTINUE

CALL TRIOAG (MIN, MAX,A, B,C,F, CPRIM, BETA, GNAM, MM)

DO 280 Je!IIN, MAX

$280 P P(1, J, L)=C P R(: A(\downarrow)$

290 CONTINUE

RETURN 
END

SUBROUTINE SOLV (PN,PS,PP,P,DO,DP,PO, PRS, A,B,C,F, CPRIM, BETA, GNMNA

1, AM, AMU, AK, DAB, PHI ,BBB, $A A A, M M, D 0, \dot{X}, \infty 00, \pi|M| M M$,

IMPLICIT REAL"B (A-H,O-Z)

COMMON/ONE/Q, DTHET, POUT (4), CK1, CK2, CK3, CK4, EMOA, OMAX,

$1 M L, N L, N C T P, M F, N F, M M, N P, M P, N H I S T, I A X, I I N$, IOUT, IPUAP, IBARR, ITR

DIMENSION PN(ML, NL, NCMP), PS (ML, NL, NOMP), PP (ML, NL, NOMP),

$1 P(M L, N L), D D$ ( $M L, N L, N C M P, N C M P$ ) ,DP (ML,NL, NCMP), PO (NCMP);

2 PRS (NCMP), A (MM), S(MM), C (MM), CPRIM(MM),BETA (MM), GNMA (MM), AM(NCNP)

3, AMU (NCMP), AK (NCMP), DAB (NCMP, NOMP), OO (NCMP), X(ML),F (MM),

4 PHI (NCMP, NCMP), B日B (NCMP, NOMP), AAA (NCMP, NCMP), AA (NCMP, NOMP),

5

$6 R(10), F V(10)$

POO(NHIST, NOMP), TTIM(NHIST), I AA (NCMP)

DIMENSION PPUP(3), PPUM(3),D(3,3)

DATA STAR/ $/ H^{*} /$

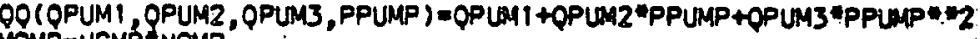

MCMP $=$ NCMP N NOMP

$M L I=M L-1$

IMIN $=M A X O(M P-6, \mid A X)$

(MAX $=M I N O(M P+6, M L)$

ISTOP $\triangle 0$

READ (5,360) Q,POUT

WRITE $(6,560) Q$

READ $(5,360)$ TORT, TEMP, DX, TMAX1,DTI

READ (5,370) IFREO, NSTEP, NPRDC

REAO $(5,360)$ CK1,CK2,CK3,CK4

READ $(5,380)$ NRAÓ I, $(R(1), F V(1), 1=1, N R A D I 1)$

WRITE $(6,470)(1,101, N O M P)$

DO $10 \quad 1=1, \mathrm{NH} I \mathrm{ST}$

READ $(5,360)$ TTIM(1), $(Q 00(1, J), J=1, N C M P)$

WRITE $(6,480) \operatorname{TTIM}(i),(P 0 O(i, j), j=1, N O M P)$

DO $201: 1$, NOMP

20

READ $(5,360)$ PO(1), PRS(1),AM(1), AMU(1)

DO $301: 1$, NCMP

30 READ $(5,360)$ (DAB $(1, j), J \pm 1, N C M P)$

READ $(5,380)$ NPUMP, (QPUM(1), PPUM(1), $1=1$, NPUAP)

QMAX $=$ PPUM (i)

IF (NPUMP.EO.1) GO TO 32

CALL PUMP (PPUH,QPUM, D, NPUPAP)

QPUM $1=$ PPUM (1)

OPUP $2=$ OPUA $(2)$

OPUM3 $=$ PPUM( 3 )

GO TO 34

32 QPUM1 $=$ PPUM(1)

WRITE $(6,560)$ QPUMI

$34 P I=2.0$ DARS IN $(1.000)$

$E=0.00$

RFV $=0.000$

RSPFV $=0.000$

$P|B F=P| \div 0.2500$

DO $40 \quad I=1$, NRADII

REQ $=R(1)$

FVE $=F V(1)$

RFV $=R F V+R E Q * F V E$

RSOFVARSOFV+FVE*REQ 2

$40 \quad E=E+F V E$

$F M P=(N P-1) *(M P-1)$

C

WRITE $(6,390)$ E, TORT, TENP,OX, TMAX1,DTI, O, NSTEP, IFREO, NPRDC

WRITE $(6,400)$ CK1,CK2

WRITE $(6,460) \quad(1$, POUT $(1), 1=1$, NCMP)

WRITE $(6,410)(1, R(1), F V(1), 1=1$, NRADII)

WRITE $(6,420)$

WRITE $(6,430)(1, P O(1), P R S(1), A M(1), A M U(1), 1=1, N O M P)$

WRITE $(6,440)$

QPO=OMAX

OOLD=2.0*0DO

$Q F=D X * 2$

$Q F F=471.934 /(E * F M P B D X)$

DO $45 \quad 1=1, \mathrm{NHIST}$

DO $45 \mathrm{~J}=1, \mathrm{NCMP}$

$45900(1, J)=000(1, J) * O F$

CK $\left\{=2,000^{\circ} 0 x+C K i\right.$.

CK2-2.000"DX ${ }^{\circ} \mathrm{CK2}$

CK3 $=2.000 * 0 \times{ }^{*}$ CK 3 
CKA $=2.000^{*} 0 x^{*} \mathrm{CKA}$

DO $50 \quad 1=1$, NOMP

AK(1) $=9,700-05$ DSORT (TEMP/AM(1))

AMU (1) $=$ ANUU(1) $* 1.0016$

50

WRITE $(6,450)$. (OAB $(1, J), J=1, N O M P)$

PRESF $=0.000$

PRESS $=0.000$

$0060 \cdot 1=1$, NCMP

PRESS $=$ PRESSTPRS (1)

PRESF =PRESF +PO(1)

$0060 \mathrm{~J}=1$, NCMP

60

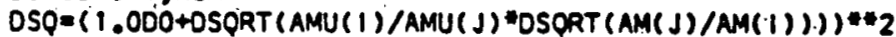

C

PHI $(J, J)=$ OSORT $(0.12500$ AM(J)/(AM(J)+AM(J))) DOSO

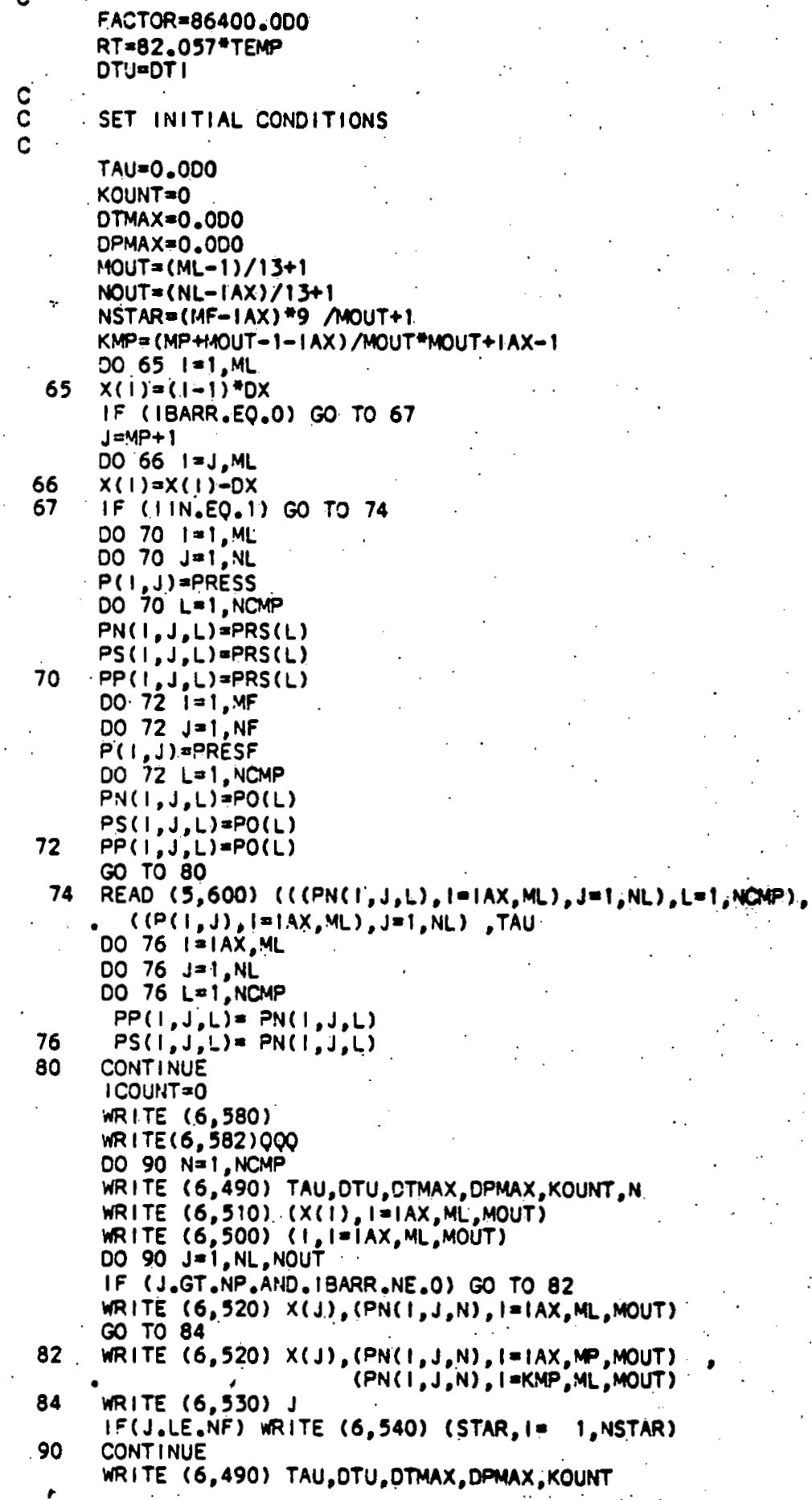




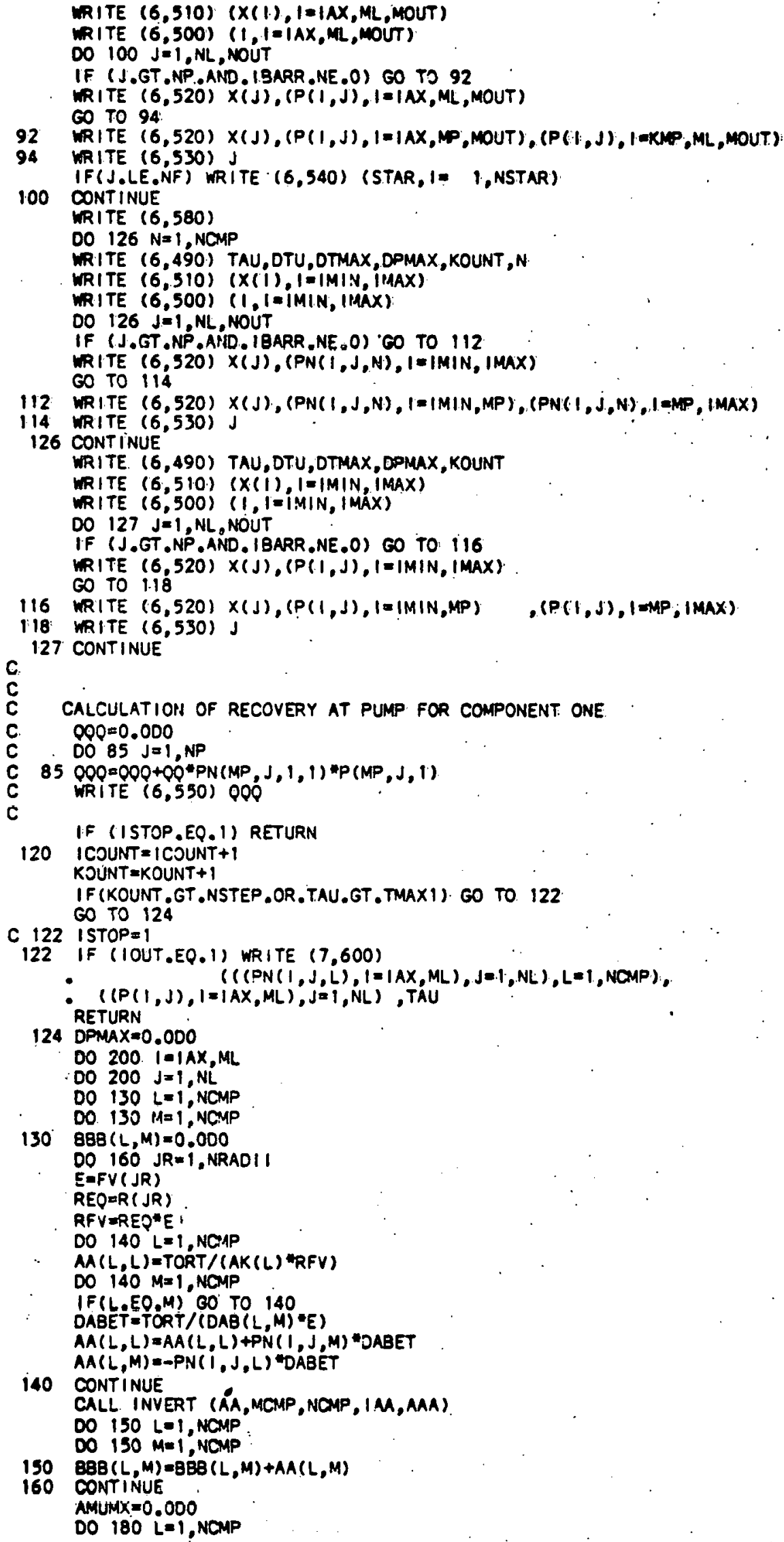




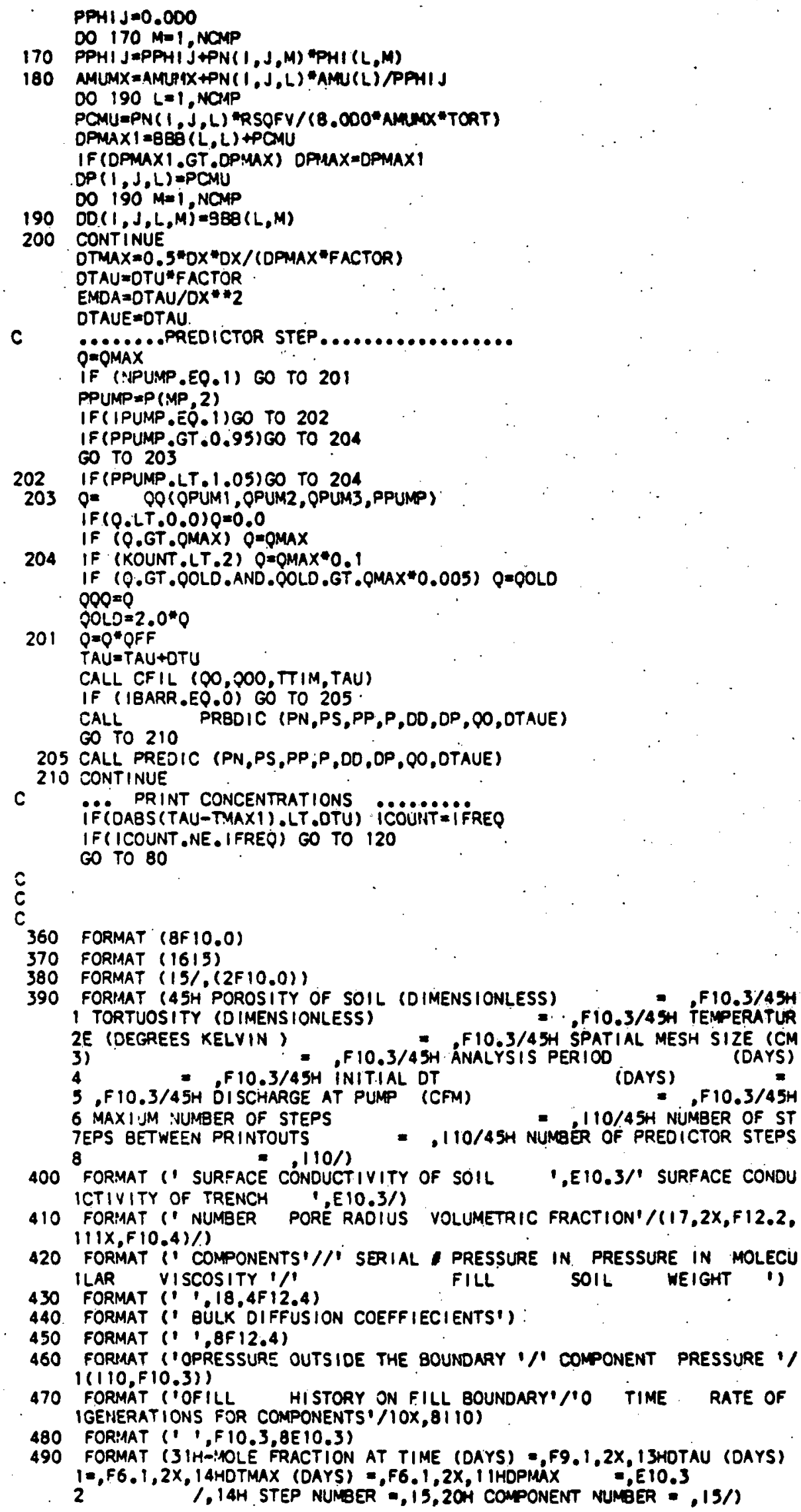




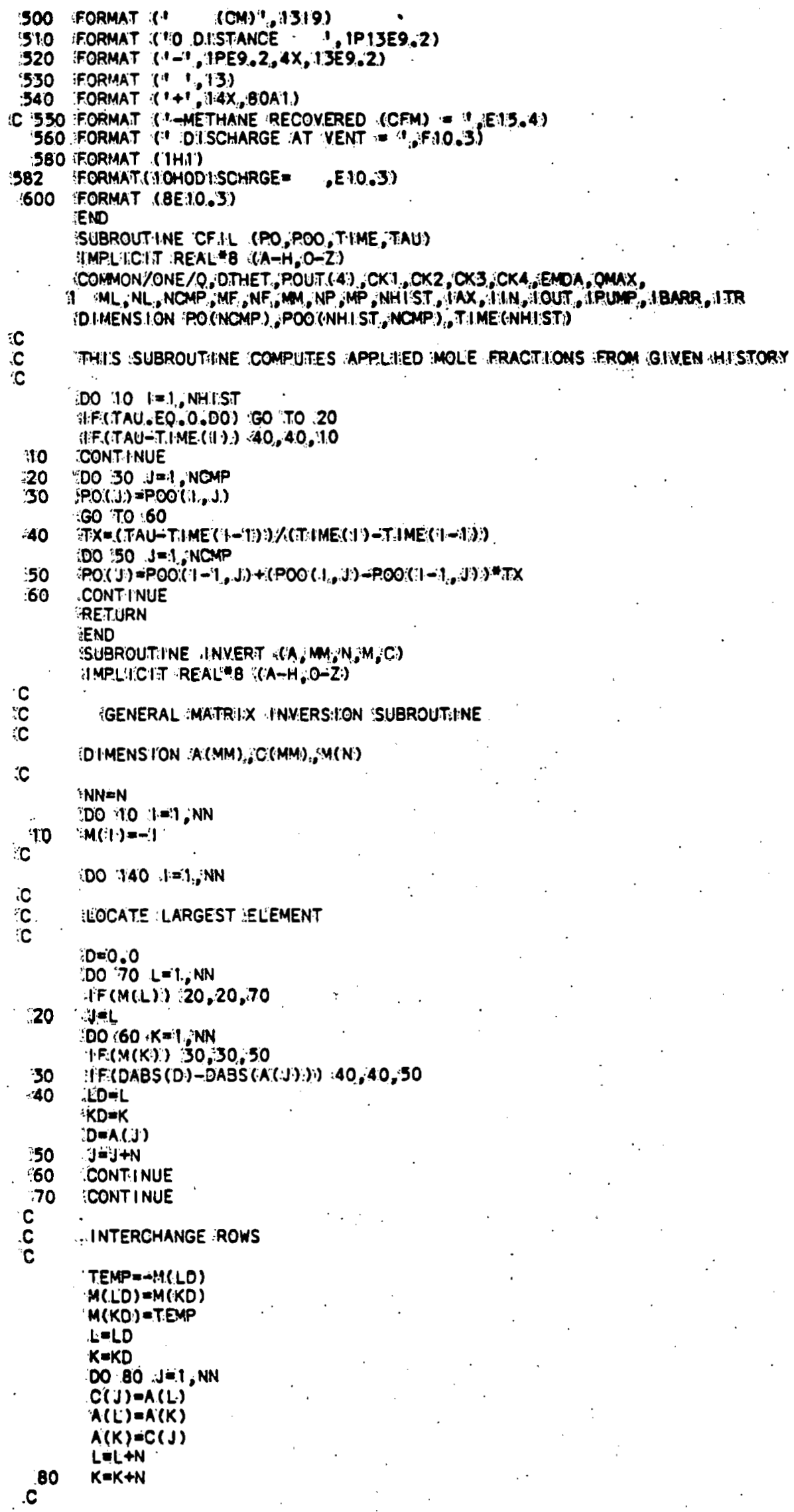




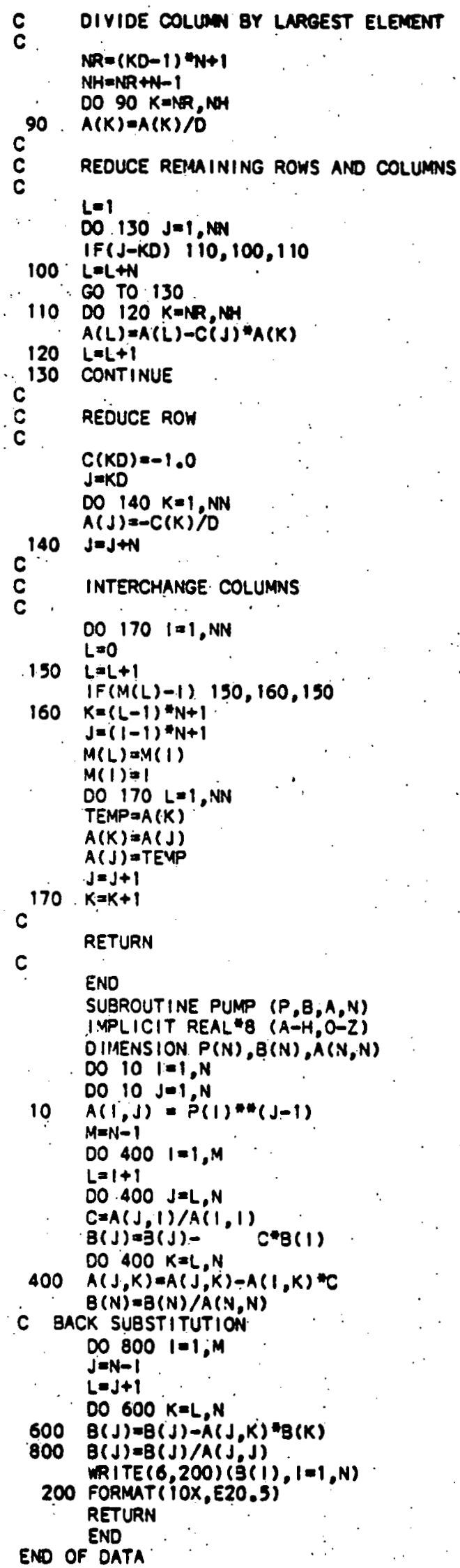


APPENDIX B CODE V LISTING 
THIS PAGE

\section{WAS INTENTIONALLY \\ LEFT BLANK}


C PROGRAM AXISMMETRIC FLOW WITH PENETRATING VENTS AIDO

C CONCENTRATION \& PRESSURE GRMDIENTS

C PROGRAMMEO BY I.S.RAI

IMPLICIT REAL $8(A-H, O-Z)$

COMMON/ONE/Q(8), DTHET, FOUT (4), EMOA,

1

2 ,NPIPS, IAX, IAXX, IIN, IOUT, ITER, MPOR

DIMENSION HED (10)

COMMON A(35000), IA(B)

MTOT $=35000$

10 READ $(5,40)$ MF, NF, ML, NL, KL, NPIIPS, NOM, NHIIST, IIN, TOUT, MPOR

READ $(5,45)$ NPC, (NP(1),MP(1), Q (1), $1=1, N P C)$

IF (MF.EO.0.) GO TO 30

I $A X=2$

$1 A \times X=6$

If (IAXX.LT,|AX) IAXX=IAX

DTHET $=3.141592653 \% 2.0 /$ NPIPSOKL $\left.^{\circ}\right)$

$F L=M L-1$

$F F=M F-1$

$R . I=F L / F F$

$F L=N L-1$

$F F=N F-1$

R2=FL/FF

REAO $(5,50)$ HED

WRITE $(6,70)$ HED, R I,R2

WITE $(6,60)$ MF, NF, ML, NL,KL, NPIPS, NOP, NHIST, NPC

NRITE $(6,65)$ (1,NP(1),NP(1),Q(1), $1=1, N P C)$

NNCMP = NOMP "NCMP

$M N=M L * N L " K L$

MNC $=$ MN NOMP

$M M=M A X O(M L, N L, K L):$

$M I=1$

$M 2=\div 1$ 1+MNC

$M 3=M 2+M N C$

$M 4=43+19 N C$

$M 5=M 4+Y N$

$M 6=M 5+M N C * N C M P$

$A 17=M 6+M N C$

$M A=M 7+N C P P$

M9arA8+NCMP.

M.16 $\operatorname{MM9+MNC}$

$M 17=M 16+N C M P$

$M 18=M 17+N C M P$

M:1 $9=+418+N C M P$

$P A 19 A=M 19+N C$ MP

$M 20=M 19 A+N N C M P$

$M 21=M 20+N N I C M P$

$M 22=M 21+N N C M P$

$M 23=M 22+N N C A P$

$124=M 23+N N C M P$

M25 =M24+NCIR

$M 26=M 25+M L$

M27 =M26+NCMP *NHIST

$M 28=M 27+N H .1$ ST

$M 29=M 28+M N C$

$M 30=1429+11 C M P$

MLAST $=M 30+A I N$

WRITE $(6,90)$ IALAST

IF(MLAST.LT.MTOT) 60 TO 20

J.J IMLAST-MTOT - 1

WRITE . $(6,80) \mathrm{JJ}$

GO TO 30

20 .CALL SOLV (ACMI),A(M2),A(MB),A(M6), A(MS), A(M6), A(M7), A(M8),A(M9), A

I (M16) $A(M 17), A(M 18), A(M 19), A(M 19 A), A(M 20), A(M 21), A(M 22), A(M 23), A(M$

224), $A(M 25), A(M 26), A(M 27), A(M 28), A(M 29), A(M 30), 1 A(M 1))$

6o. To 10

30 STOP

c.

C

40 FORMAT $(1615)$

FORMAT $(15 /,(215,55,0))$

FORMAT (1OAB)

60 FORMAT (SOH-NUABER OF MESH POINTS UPTO ENO OF FILL $1,15 / 30$ H NUMBER OF MESH POINTS WTO DEPTH OF FILL 
2UMBER OF MESH POINTS UPTO END OF LAND 15/5OH MLMBER OF SNESH POINTS UPTO DEPTH OF LAND $4 T S$ ALONG THETA DIRECTION
SCIRCUMFERENCE 15/5OH TOTAL MUMBER OF PIPES
15/50H TOTAL NUMBER OF GAS COMPONENTS 15/5OH TOTAL MUMBER OF OF MESH POIN

6 15/50H NO. OF POINTS ON FILL COMPOSITION HISTORY CURVE $7.15 / 50 \%$ NO. OF PIPE SETS $.15 / 1$

ORAT (' NUMBER NPIPE MPIPE Q'/(17,2X,15,3X,15,1X,F5.2)/)

FORMAT (IHI, 1OAB,' RS/RF =1,F5,2, DS/OF = 1,F5,2)

FORIAT ("-REQUIRÉD CORE EXCEÉDS MTOT BY ', 110 )

90 FORMAT ('OMTOT REQUIRED FOR THIS PROBLEM $=1,(10)$

ENO

SUBROUTINE SOLV IPN,PS,PP,P,DO,DP,PO, PRS,DELP

$1, A M, A M U, A K, C X, D A B, P H I, B B B, A M A, M M, \not 0, X, \infty O 0, T I M, G N, G N E R, I F I L P T, I M$

2)

IMPLICIT REAL"B $(A-H, O-Z)$

COMMON/ONE/Q (8), DTHET, POUT (4), EMDA

$M L, N L, K L, N O P, M F, N F, M M, N P(8), M P(8), N H I S T, N P C$

2 ,NPIPS, IAX, I AXX, IIN, IOUT, ITER, MPOR

DIMENS ION - PN(IUL, NL, KL, NOPP), PS (ML,NL, KL, NONP), PP (ML, NL, KL, NOMP)

$1 P(M L, N L, K L), D D(M L, N L, K L, N O F, N O M P), D P(M L, N L, K L, N C M P)$, PO(NCMP),

2 PRS (NCMP), DELP (ML,NL,KL, NOMP). M(NONP)

3, AMU (NCMP), AK (NCMP),CK (NCMP), DÁB (NCMP, NOMP), DO (NOMP), X (ML),

4 PHI (NCMP, NOMP), BBB (NCMP, NOMP), AAA (NCMP, NOMP), AA (NCMP, NOMP)

5000 (NHIST, NCMP), TTIM(NHIST), GHR(ML, NL, KL, NCMP), GNER (NCMP), IF ILPT (M 6L,NL,KL), IAA (NCMP),

$7 R(10), F V(10), T I M(12), F M P(8), Q P(8), Q F F(8)$

DATA STAR/IH",

MOMP $=$ NCMP NCMP

$M L \mid=M L-1$

IYIN=MAXO (IMPOR-6, $\mid A X)$

IMAX $=M I N O(M P O R+6, M L)$

ISTOP=O

READ $(5,360)$ POUT

READ $(5,360)$ TORT, TEMP, OX, TMAX1, TMAX2, OTI

READ $(5,370)$, IFREO, NSTEP, NPRDC

READ (5,380) NRADII, $(R(1), F V(1), 1=1$, NRAD II)

WRITE $(6,470)(1,1=1, N C M P)$

DO $10 \quad 1=1, N H I S T$

REAO $(5,360) \operatorname{TIM}(1),(\infty O O(1, j), j=1, N C M P)$

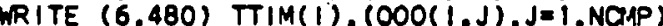

DO $201=1$, NCMP

$20 \operatorname{REAO}(5,360)$ PO(1), PRS (1),AM(1), AMU( 1$), \operatorname{CK}(1), \operatorname{GNER}(1)$

DO $30 \quad 1=1, N C A P$

30 READ $(5,360)$ (DAB $(1, j), j=1, \operatorname{NOMP})$

$P \mid=2.0$ DARS IN $(1,000)$

$E \approx 0.00$

RFY $=0.000$

RSQFV $=0.000$

PIBF $=P \mid=0.2500$

DTHET $=P \mid /(N P I P S *(K L-1))$

DO $40 \quad 1=1$, NRADII

REQ $=R(1)$

FVE $=F Y(1)$

RFV $=R F Y+R E Q$ * $F V E$

RSOFV=RSOFV+FVE*REO**2

40

$E=E+F V E$

DO $41 \cdot M=1, N P C$

FMP $(M)=N P(M) *(M P(M)-1)$

C

CONTINUE

WRITE (6,390) E, TORT, TEMP, OX, TMAX 1, DTI, NSTEP, I FREQ, NPRDC, MPOR

WRITE $(6,460) \quad(1$, POUT (1), $1=1$, NOMP)

WRITE $(6,410)(1, R(1), F V(1), i=1, N R A D I 1)$

WRITE $(6,420)$

WR!TE $(6,430)(1, P O(1), \operatorname{PRS}(1), A M(1), A M U(1), C K(1), 1=1, N O M P)$

WRITE $(6,440)$

DO $42 M=1, N P C$

$Q P(M)=P(M) / N P(M)$

OFF $(M)=471.934 /$ (E

42

$\rho(M)=P(M) * P F F(M)$

$O F=0 x * 2$

DO $45 \quad 1=1$, NHIST

$0045 \mathrm{~J}=1, \mathrm{NOMP}$

$45000(1, J)=000(1, J) * 0 F$

DO $47 \mathrm{M}=1$, NOMP 


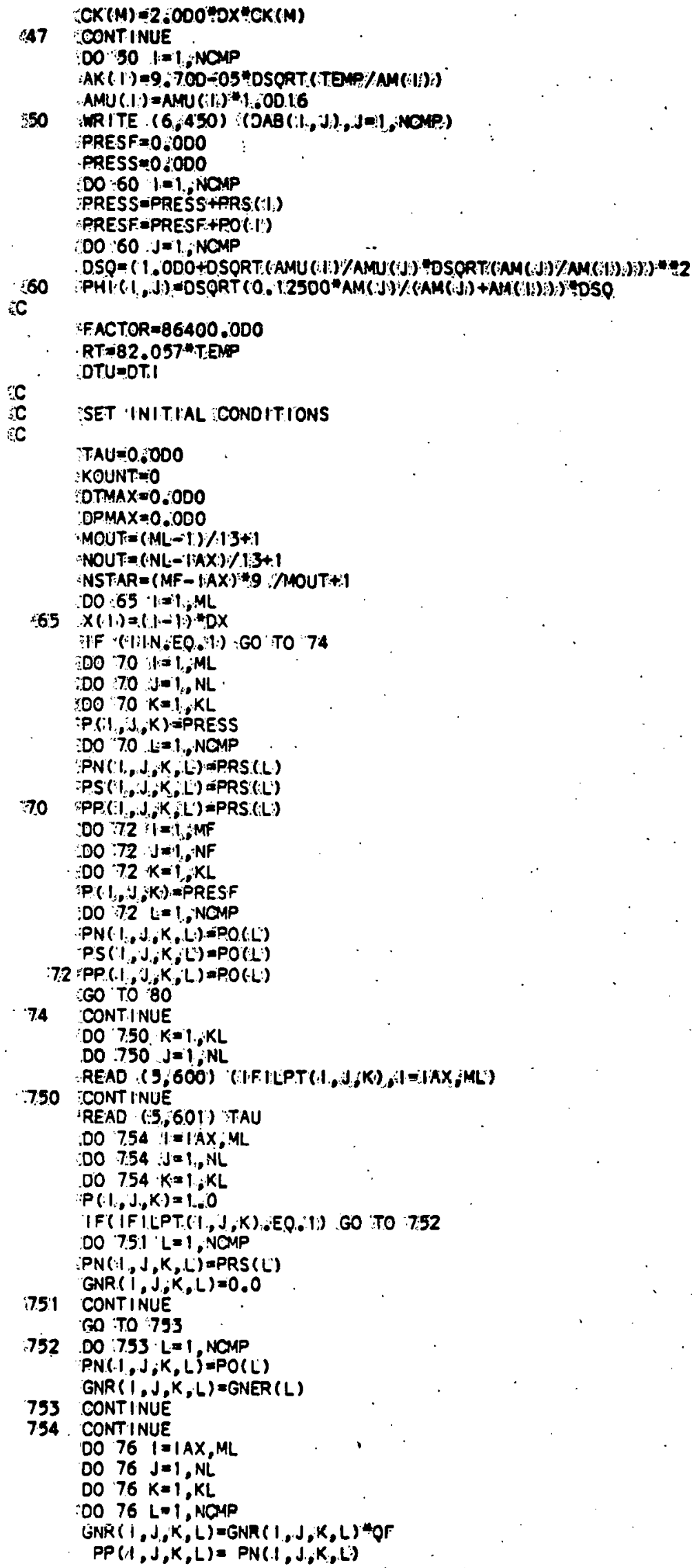

754. CONTINUE DO $76 \quad$ I IAX,ML

DO $76 \mathrm{~J}=1, \mathrm{NL}$

$0076 \mathrm{~K}=1, \mathrm{KL}$

DO 76 L- I, NOMP GNR $(1, J, K, L)=G N R(1, J, K, L)$ OOF

$P P(1, J, K, L)=P N(1, J, K, L)$ 


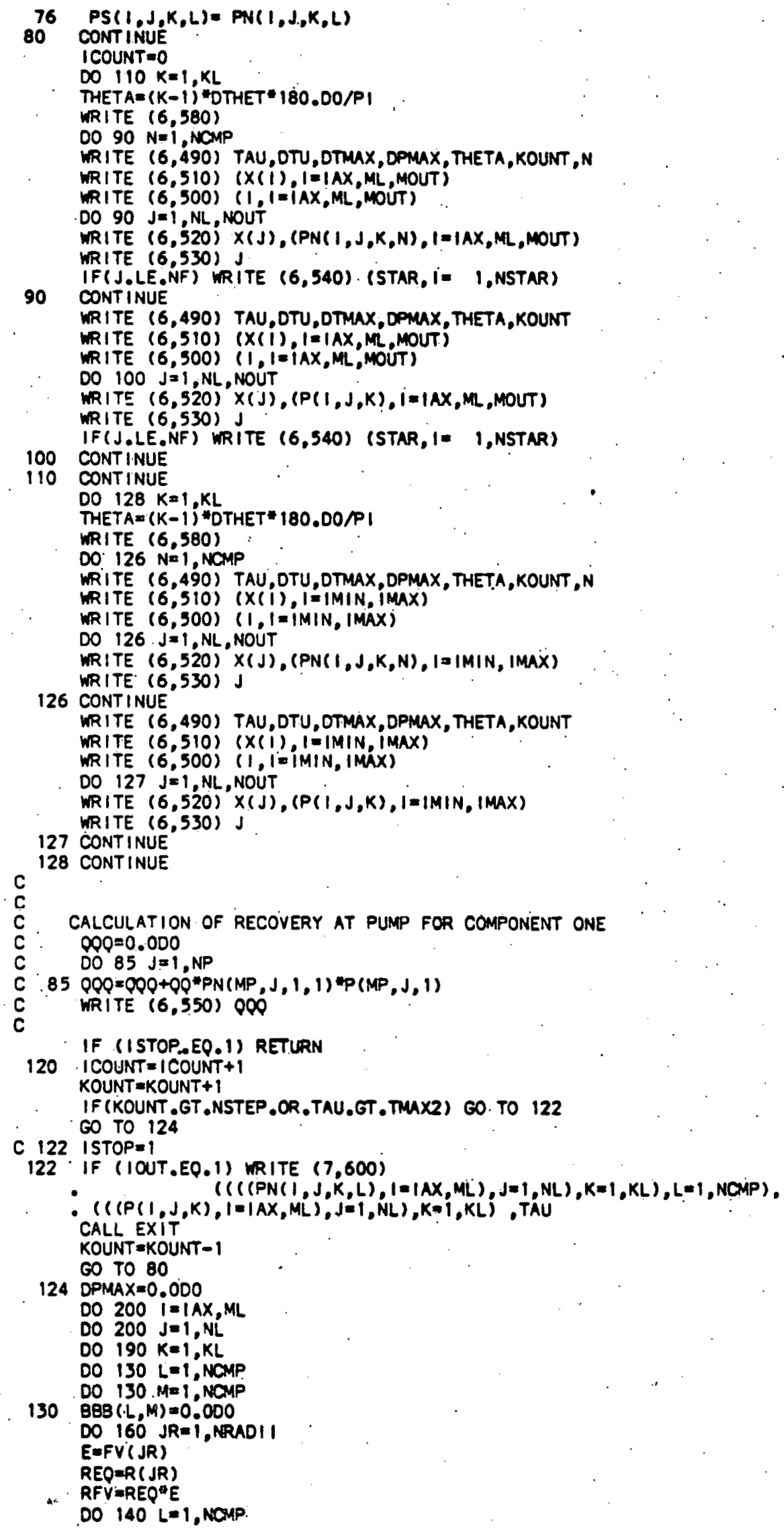




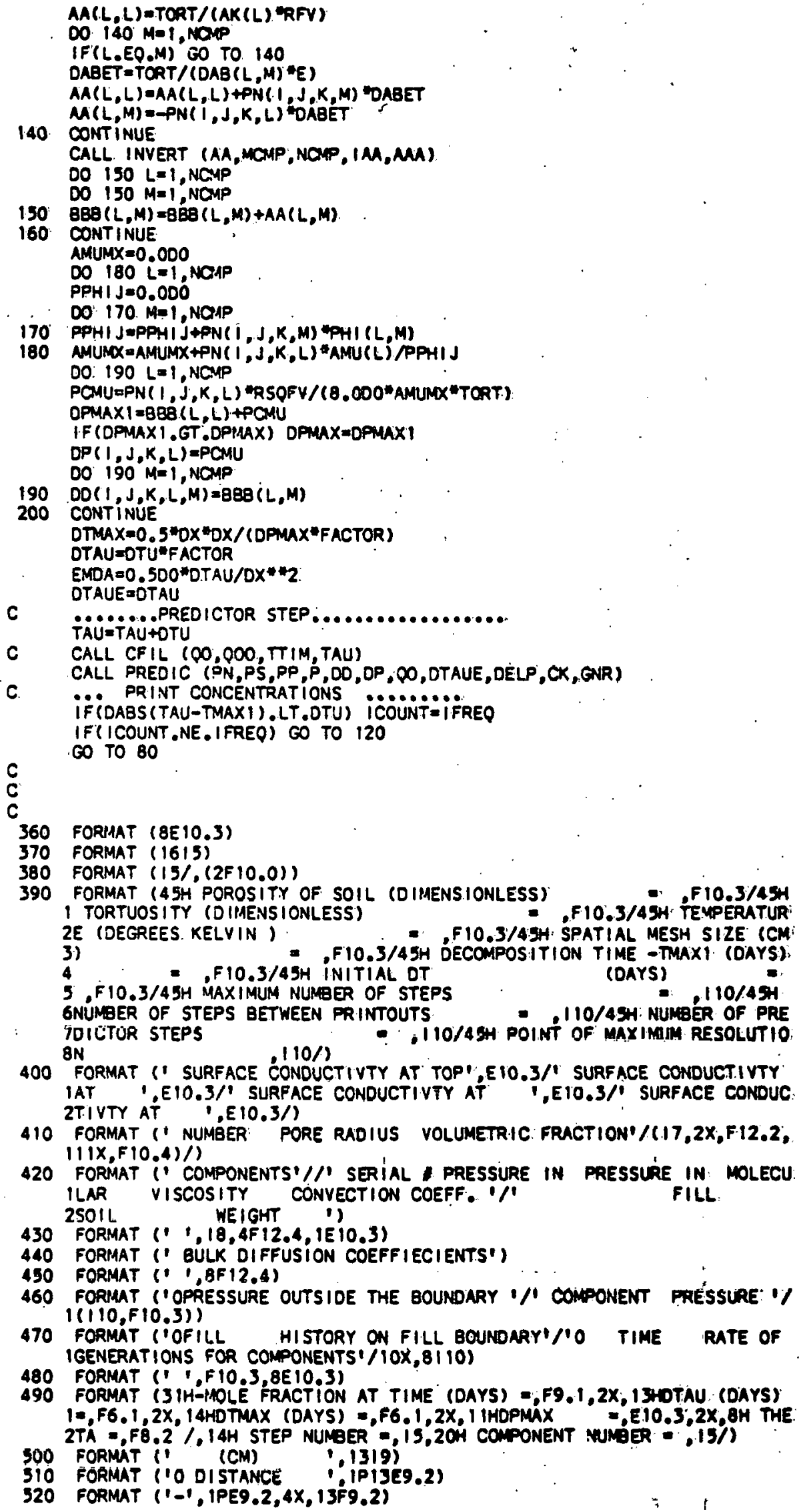

410 FORMAT (' NUMBER: PORE RADIUS VOLUMETRIC FRACTION $/(17,2 \times, F 12.2$, $\|(1 \times, F(0.4) /)$

420 FORMAT $\because$ COMPONENTS $/ /$ SERIAL PRESSURE IN PRESSURE IN MOLECU. ILAR VISCOSITY CONVECTION COEFF. ' $/ 1$ FILL. 2SOIL WEIGHT 'I

430 FORMAT (' $1,18,4 F 12,4,1 E 10.3)$

440 FORMAT (" BULK DIFFUSION COEFFIECIENTS')

450 FORMAT (' ',BF 12.4)

460 FORIAT ('OPRESSURE OUTSIDE THE BOUNDARY $1 /$ COMPONENT PRESSSURE: $\%$ $1(110, F 10.3))$

470 FORMAT ('OFILL HISTORY ON FILL BOUNDARYIIO TIME RATE OF IGENERATIONS FOR COMPONENTS' $(10 \times, 8110)$

480 FORMAT (I ', F 10,3,8E10.3)

490 FORMAT (3IH-PMLLE FRACTION AT TIME (DAYS) =,F9,1,2X,13DTAU (DAYS) $1=, F 6.1,2 X, 14 H D T M A X$ (DAYS) $=, F 6,1,2 X, 1$ HHDPMX $=, E 10,3,2 X$, OH THE: $2 T A=, 78.2 \%, 14 H$ STEP NUMER $=, 15,20 \mathrm{H}$ COMPONENT NUMBER $15 \%$

300 FORMAT (1 (CM) 1,1319$)$

Sio FÖMAT ('O DISTANCE I:IPIJE9.2)

320 FORMAT $(1-1$, IPE9,2,4X, 13F9,2) 


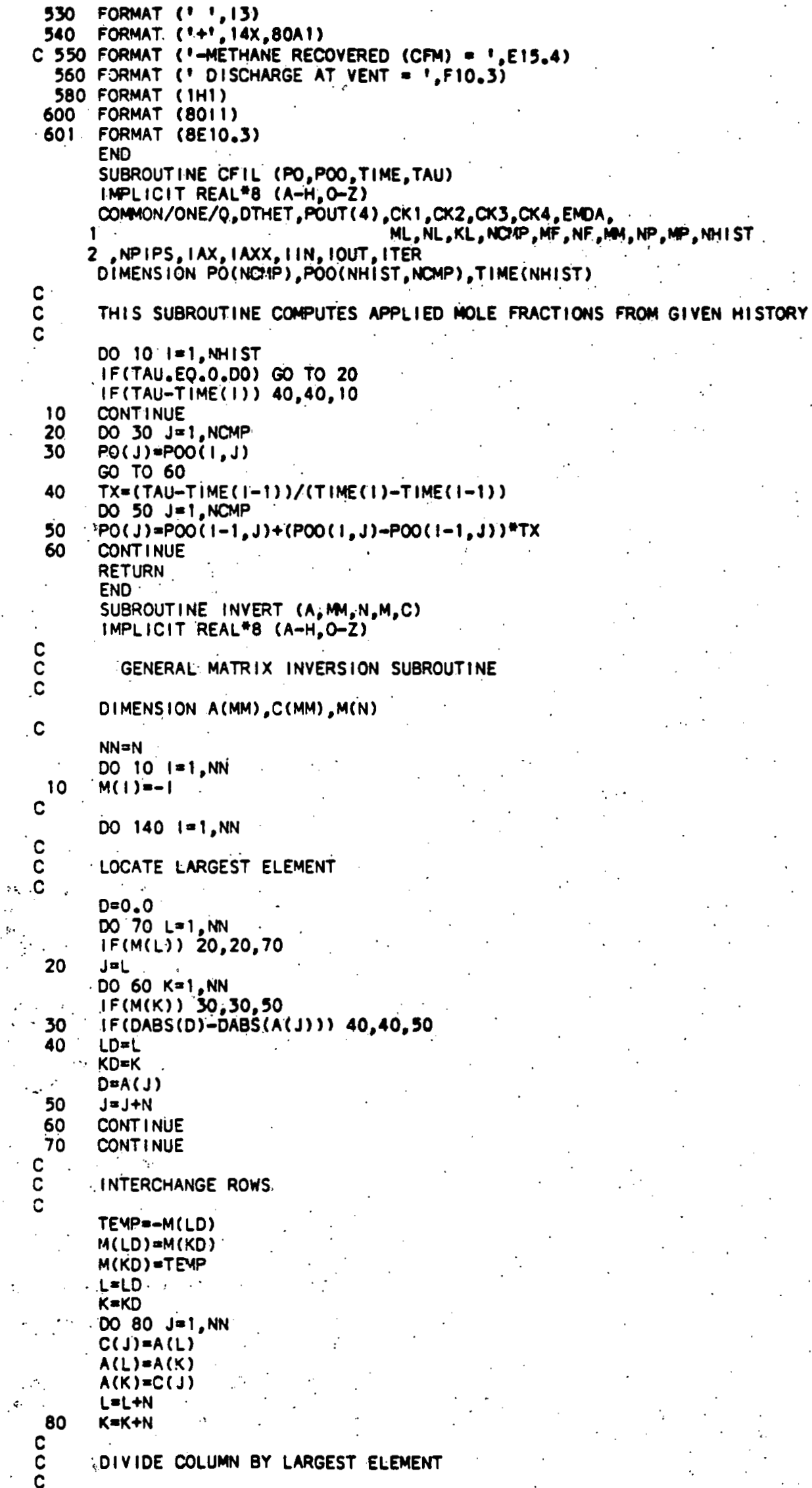




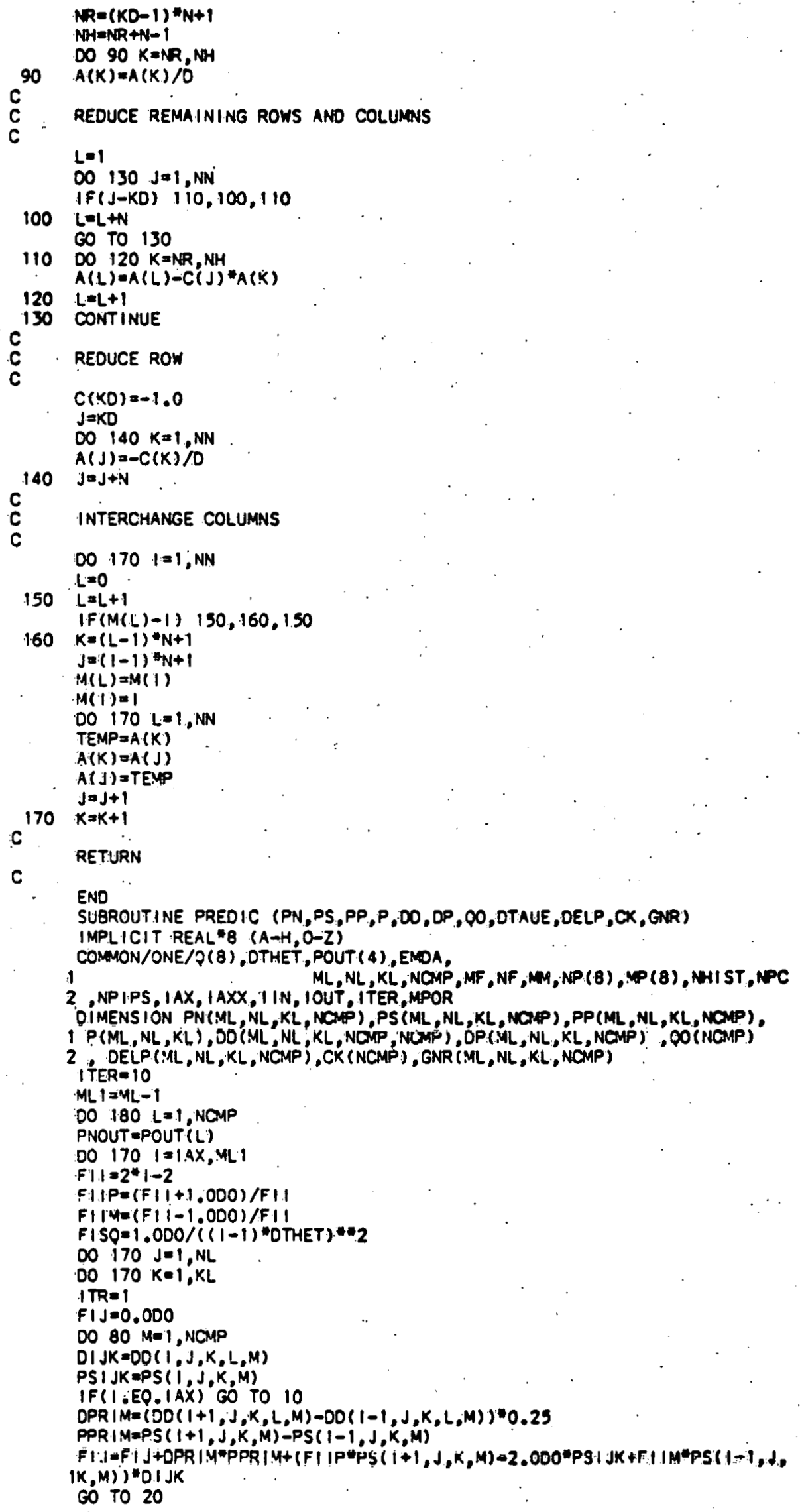




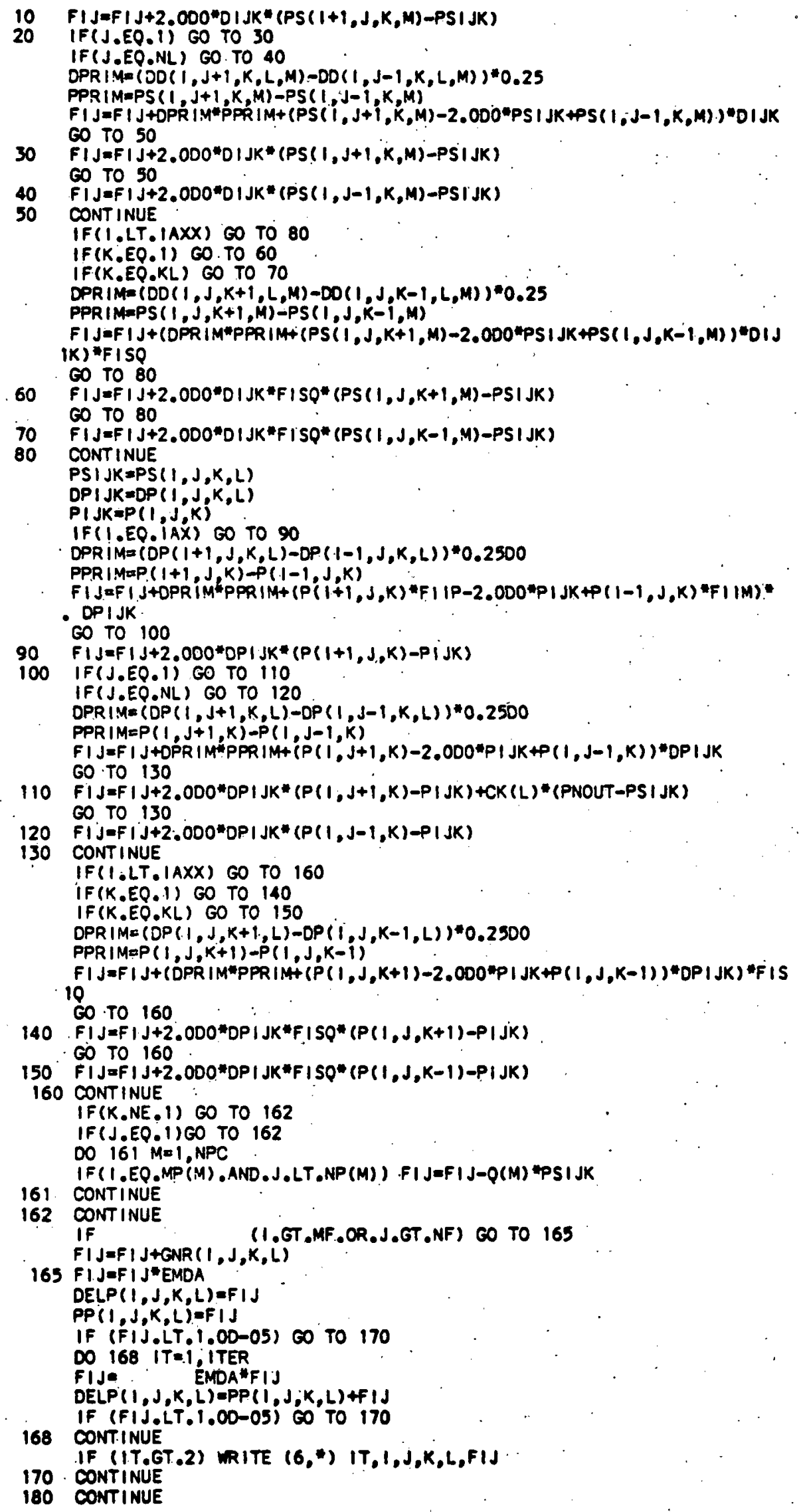


97

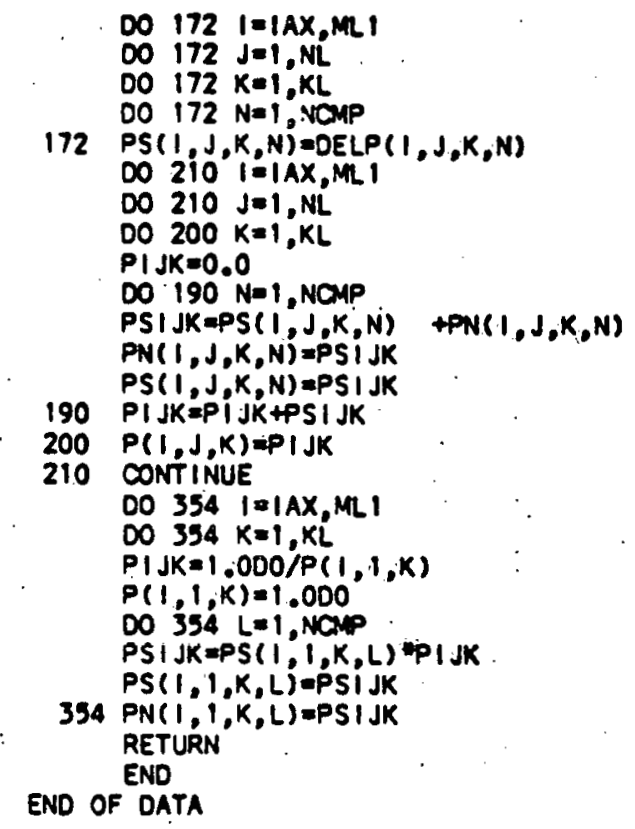

172 


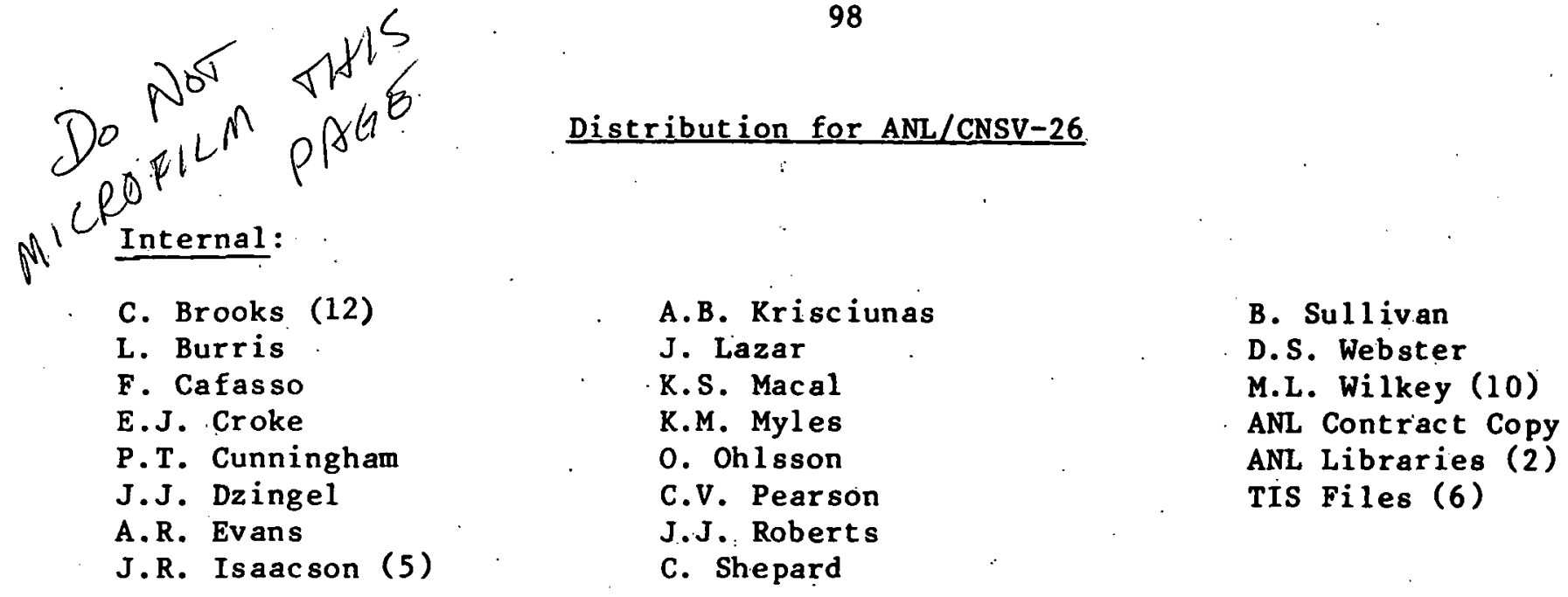

\section{External:}

U.S. Department of Energy Technical Information Center, for distribution per UC-95e (27)

Manager, U.S. Department of Energy Chicago Operations Office (DOE-CH)

Chief, Office of Patent Counsel, DOE-CH

President, Argonne Universities Association

Energy and Environmental Systems Division Review Committee:

E.E. Angino, University of Kansas

H.J. Barnett, Washington University

$E: N$. Castle, Resources for the Future, Inc., Washington, D.C.

R.L. Clodius, National Association of State Universities and Land Grant Colleges, Washington, D.C.

B.A. Egan, Environmental Research and Technology, Inc., Lexington, Mass.

N.C. Mullins, Indiana University

W.N. Poundstone, Consolidation Coal Co., Pittsburgh

J.J. Stukel, University of Illinois

J.J. Wortman, North Carolina State University

D. Armstrong, Emcon Associates, San Jose, Calif.

M.J. Blanchet, Pacific Gas and Electric Co., San Francisco, Calif.

E.R. Bogardus, New York State Energy Office, Albany, N.Y.

M. Bracy; Los Angeles Dept. of Water \& Power

D. Campbe11, Harwe11 Laboratory, Didcot, Oxfordshire, England

A.C. Cheyney, London Brick Landfill Ltd., Stewartby, Bedfordshire, England

J.L. Considine, Adams County Planning Dept., Brighton, Colo.

R. Cooke, U.S. Department of the Interior, National Park Service,

Washington, D.C.

D.W. Dailey, California State Solid Waste Management Board, Citrus Heights

D.N. DeYoung, Dresser Industries, Inc., Emeryville, Calif.

R. Eberhart, Emcon, Columbia, Md.

J. Edberg, Los Angeles County Sanitation District, Whittier, Calif.

J. Ehrsmann, Gesellschaft Fuer Beseitung von Sonderabfaellen, Frankenthal, Germany

R,P. Fay, Waukesha Engine Servicecenter, Inc., Long Beach, Calif.

C. Fojo, Los Angeles County Sanitation District, Whittier, Calif.

J.H. Gibbons, Office of Technology Assessment, U.S. Congress

A.J. Giuliani, The Brookl yn Union Gas Co., Brooklyn, N.Y.

R.K. Ham, University of Wisconsin, Madison, Wis.

K.K. Hekimian, Technical Management Services, Inc., Huntington Beach, Calif. 
J.R. Johnson, BKK Corp., Wilmington, Calif.

K.D. Jones, Solid Waste Management Board, Sacramento, Calif.

D.E. Kash, University of Oklahoma

S.L. Katten, Technical Management Services, Inc., Los Angeles, Calif.

C. Kunz, New York State Department of Health, Albany, N.Y.

W.J. Lockman, Lockman \& Associates, Monterey Park, Calif.

R.T. Mandeville, Gas Recovery Systems, Pasadena, Calif.

V.A. Mast, Ohio State University, Columbus, Ohio

L. Mims, Illinois Institute of Natural Resources, Chicago

C.A. Moore, Ohio State University, Columbus, Ohio

T.E. Myers, U.S. Army Engineers, Vicksburg, Miss.

D.C. Neilsen, Wehran Energy Corp. Mahwah, N.J.

M.E. Nosanov, Engineering Science, Inc., Arcadia, Calif.

D. 01 inyk, Underwood Mclellan Ltd., Winnipeg, Manitoba, Canada

J. Pacey, Emcon Associates, San Jose, Calif.

A. Parker, Harwell Laboratory, Didcot, Oxfordshire, England

J.C. Peck, Los Angeles Dept. of Public Works

L.G. Phillips, Johns Hopkins University, Laurel, Md.

G. Rettenberger, University of Stuttgart, Germany

F. Rice, Getty Synthetic Fuels, Signal Hills, Calif.

R.R. Rule, Southwestern Portland Cement, Los Angeles

S.R. Seid, Los Angeles Dept. of Water \& Power

J.V. Seruto, Watson Energy Systems, Inc., Carson, Calif.

F.T. Sheets, III, Azusa Land Reclamation Co., Azusa, Calif.

R.P. Stearns, SCS Engineers, Long Beach, Calif.

R.T. Waibel, Institute of Gas Technology, Chicago

J.J. Walsh, SCS Engineers, Covington, Ky.

G. Yoshioka, Johns Hopkins University, Laurel, Md.

R.E. Zimmerman, ESCOR, Inc., Northfield, Ill. 


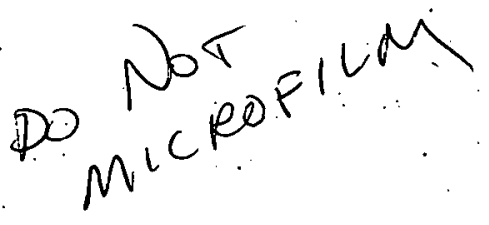

